\title{
A STUDY OF DECLINE CURVE ANALYSIS IN THE ELM COULEE FIELD
}

\author{
A Thesis \\ by \\ SETH CAMPBELL HARRIS \\ Submitted to the Office of Graduate and Professional Studies of \\ Texas A\&M University \\ in partial fulfillment of the requirements for the degree of \\ MASTER OF SCIENCE
}

$\begin{array}{ll}\text { Chair of Committee, } & \text { John Lee } \\ \text { Committee Members, } & \text { Duane McVay } \\ & \text { Walt Ayers } \\ & \text { Maria Barrufet } \\ \text { Head of Department, } & \text { Dan Hill }\end{array}$

December 2013

Major Subject: Petroleum Engineering

Copyright 2013 Seth Campbell Harris 


\begin{abstract}
In the last two years, due in part to the collapse of natural gas prices, the oil industry has turned its focus from shale gas exploration to shale oil/tight oil. Some of the important plays under development include the Bakken, Eagle Ford, and Niobrara. New decline curve methods have been developed to replace the standard Arps model for use in shale gas wells, but much less study has been done to verify the accuracy of these methods in shale oil wells. The examples that I investigated were Arps with a 5\% minimum decline rate as well as the stretched exponential model (SEPD) and the Duong method. There is a great amount of uncertainty about how to calculate reserves in shale reservoirs with long multi-fractured horizontals, since these wells have not yet been produced to abandonment. Although the Arps model can reliably describe conventional reservoir production decline, it is still uncertain which empirical decline curve method best describes a shale oil well to get a rapid assessment of expected recovery.

My focus began in the oil window of the Eagle Ford, but I ultimately chose to study the Elm Coulee field (Bakken formation) instead to see what lessons an older tight oil play could lend to newer plays such as the Eagle Ford. Contrary to existing literature, I have found evidence from diagnostic plots that many horizontal wells in the Elm Coulee that began producing in 2006 and 2007 have entered boundary-dominated flow. In order to accommodate boundary flow I have modified the Duong and SEPD methods
\end{abstract}


such that once boundary-dominated flow begins the decline is described by an Arps curve with a b-value of 0.3 .

What I found from hindcasting was that early production history, up to six months, is generally detrimental to accurate forecasting in the Elm Coulee. This was particularly true for the Arps with 5\% minimum decline or the Duong method. Early production history often contains apparent bilinear flow or no discernible trend. There are many possible reasons for this, particularly the rapid decrease in bottomhole pressure and production of fracture fluid. 


\section{NOMENCLATURE}

\begin{tabular}{|c|c|}
\hline $\mathrm{BDF}$ & Boundary-dominated flow \\
\hline PVT & Pressure-volume-temperature \\
\hline $\mathrm{N}_{\mathrm{p}}$ & Cumulative oil production \\
\hline MBT & Material balance time, $\mathrm{N}_{\mathrm{p}} / \mathrm{q}$ \\
\hline $\mathrm{q}$ & Production rate, volume/time \\
\hline $\mathrm{p}$ & Pressure, psi \\
\hline $\mathrm{t}$ & Time \\
\hline $\mathrm{D}$ & Decline rate, $t i m e^{-1}$ \\
\hline $\mathrm{q}(\mathrm{t})$ & Production rate as a function of time, volume/time \\
\hline$q_{i}$ & Initial production rate, Arps parameter, volume/time \\
\hline $\mathrm{b}$ & Arps exponent, degree of curvature, unitless \\
\hline $\mathrm{a}$ & Arps exponential decline rate, time $^{-1}$ \\
\hline$D_{i}$ & Initial decline rate, Arps parameter, time $e^{-1}$ \\
\hline$q_{o}$ & Initial production rate, SEPD parameter, volume/time \\
\hline$n$ & SEPD parameter, unitless \\
\hline$\tau$ & SEPD parameter, time \\
\hline
\end{tabular}




\section{TABLE OF CONTENTS}

Page

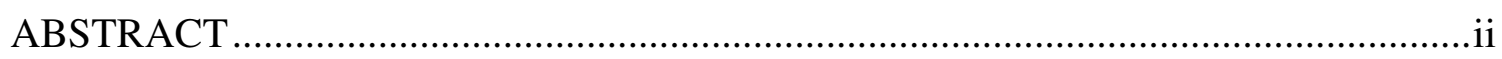

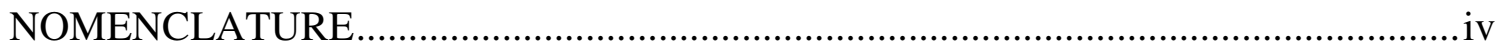

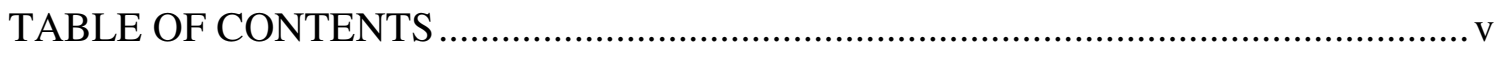

LIST OF FIGURES ........................................................................................ vii

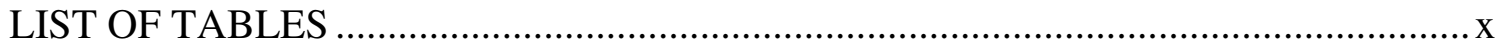

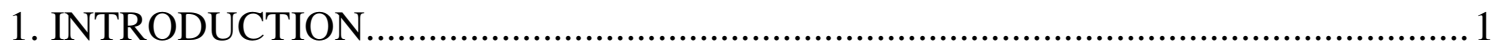

1.1 Relevance of Research ................................................................................. 1

1.2 Status of the Question ................................................................................ 1

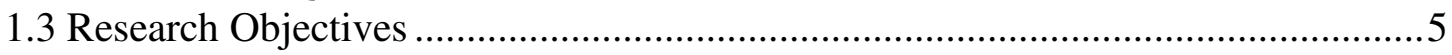

2. DECLINE CURVE ANALYSIS IN UNCONVENTIONALS................................ 7

2.1 Introduction to Linear and Boundary-Dominated Flow ........................................

2.2 Methods of Decline Curve Analysis: Arps with 5\% Minimum Decline,

Stretched Exponential (SEPD), and Duong .......................................................... 8

2.3 Theoretical Forecasting of Wells Switching from Linear to Transient Flow ......... 10

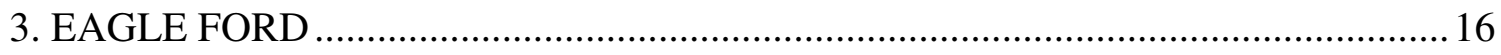

4. ELM COULEE OVERVIEW ......................................................................... 19

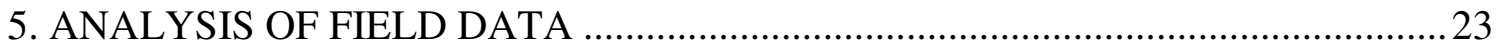

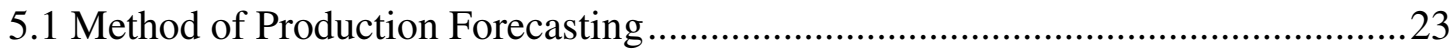

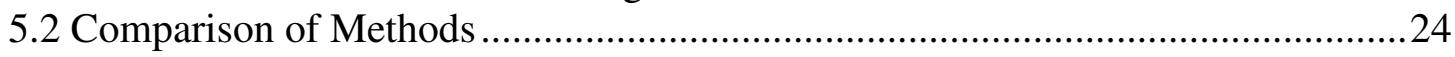

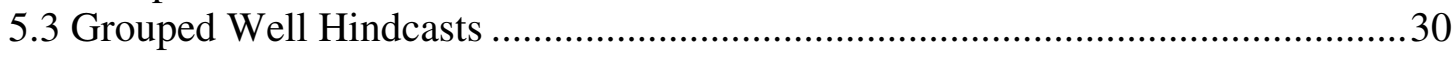

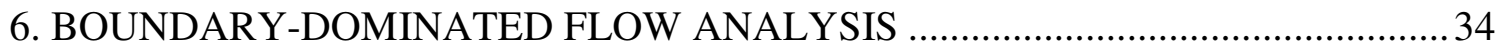

6.1 Study of Boundary-Dominated Flow Onset in Elm Coulee Field ........................42

6.2 Unexpected Deviations from Linear Flow ...................................................49

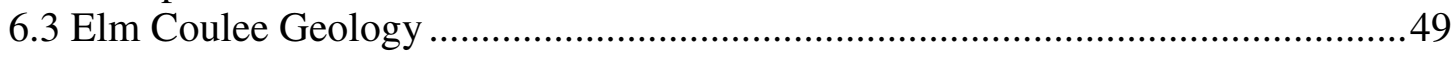

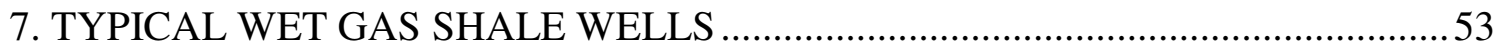




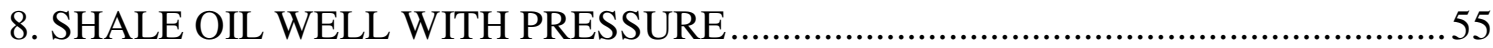

9. 30 YEAR FORECAST FOR WELLS SHOWING BDF......................................... 60

10. GROUPED WELL FORECASTS FOR WELLS SHOWING BDF ......................64

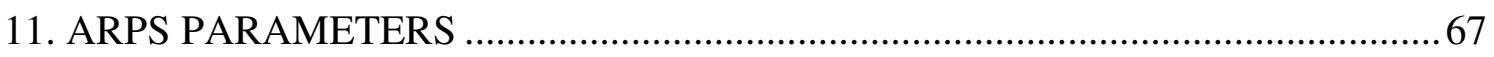

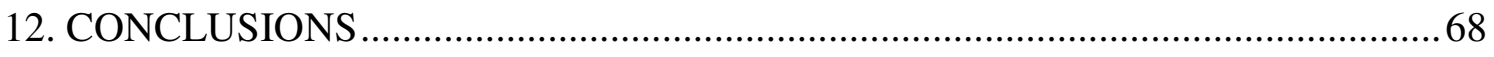

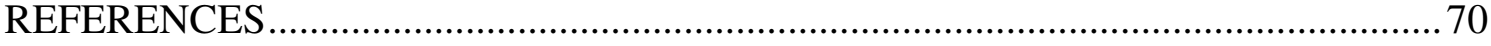




\section{LIST OF FIGURES}

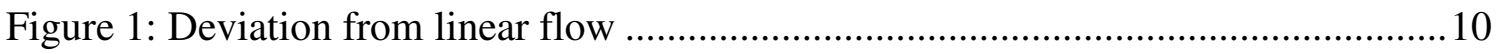

Figure 2: Production rate, actual deviation from linear flow at 7.5 years ........................12

Figure 3: Cumulative production, deviation from linear flow at 7.5 years ......................12

Figure 4: Production rate, deviation from linear flow at 2.5 years ..................................13

Figure 5: Cumulative production, deviation from linear flow at 2.5 years .......................14

Figure 6: API 42-507-32721 Forecast based on 18 month history ……...........................17

Figure 7: API 42-507-32721 Forecast based on 18 months history, ignoring first

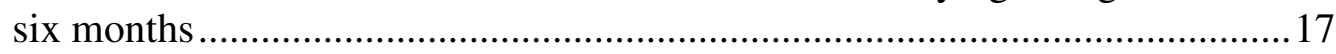

Figure 8: Elm Coulee average GOR versus time …………..........................................2

Figure 9: Elm Coulee average WOR versus time ………………………………….....21

Figure 10: Elm Coulee example well WOR..................................................................22

Figure 11: Elm Coulee example well WOR................................................................22

Figure 12: Average hindcast error, including first six months......................................26

Figure 13: Average hindcast error, ignoring first six months ........................................26

Figure 14: Standard deviation of hindcast error, including first six months....................27

Figure 15: Standard deviation of hindcast error, ignoring first six months .....................27

Figure 16: Sample Elm Coulee well, hindcast beginning after two years .......................28

Figure 17: Sample Elm Coulee well, hindcast beginning after two years, first six months omitted

Figure 18: Elm Coulee grouped well hindcast after first two years, ignoring first six months of history 
Figure 19: Elm Coulee grouped well hindcast after first two years

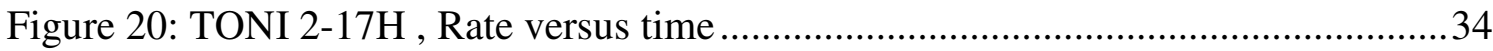

Figure 21: TONI 2-17H, Production rate versus time plot ........................................35

Figure 22: TONI 2-17H, Production rate versus material balance time diagnostic

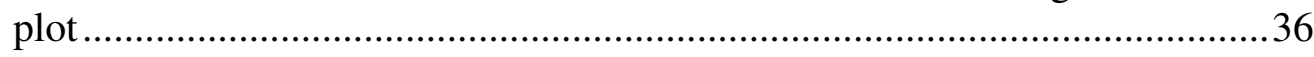

Figure 23: FOGHORN-ERVIN 20-3-HLID3 , Rate versus time.................................. 37

Figure 24: FOGHORN-ERVIN 20-3-HLID3, Production rate versus time plot ............37

Figure 25: FOGHORN-ERVIN 20-3-HLID3, Production rate versus material

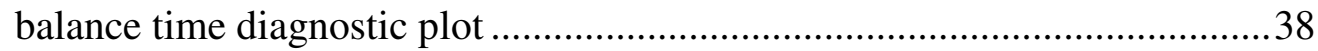

Figure 26: Elm Coulee well example hindcast after two years of history ......................39

Figure 27: Elm Coulee well example hindcast after two years, ignoring first six months of history

Figure 28: Elm Coulee well example hindcast after two years, ignoring first six months of history, BDF onset at 55 months

Figure 29: Elm Coulee well example hindcast after three years, ignoring first six months of history

Figure 30: Elm Coulee well example hindcast after three years, ignoring first six months, BDF onset at 55 months

Figure 31: Production rate versus material balance time diagnostic plot.

Figure 32: Production rate versus material balance time diagnostic plot, fitted with Arps decline model.

Figure 33: Histogram of decline rates at boundary-dominated flow onset

Figure 34: Histogram of decline rates at boundary-dominated flow onset, amended study

Figure 35: Map of Elm Coulee wells studied with high decline rate at BDF onset........51

Figure 36: Map of Elm Coulee wells studied. 
Figure 37: Wet gas well forecast with daily production data.

Figure 38: Rate and pressure versus material balance time, Shale oil well, with daily data

Figure 39: Rate versus material balance time, Shale oil well, daily data. 57

Figure 40: Pressure-normalized rate versus material balance time, shale oil well, daily data

Figure 41: Production rate forecast, shale oil well

Figure 42: Cumulative production forecast, shale oil well

Figure 43: Elm Coulee average forecasted 30 year EUR

Figure 44: Elm Coulee average forecasted 30 year EUR, first six months ignored .62

Figure 45: Elm Coulee average forecasted 30 year EUR, BDF onset at 15\% decline.

Figure 46: Elm Coulee average forecasted 30 year EUR, first six months ignored, BDF onset at $15 \%$ decline .63

Figure 47: Average 30 Year EUR Forecasts, Cumulative STB .63

Figure 48: Grouped Elm Coulee wells in BDF .64

Figure 49: Grouped well average forecast, BDF at 15\% decline rate, STB. .65

Figure 50: Rate versus material balance time diagnostic plot, sum of all Elm Coulee wells 66

Figure 51: Rate versus material balance time diagnostic plot, sum of wells entering BDF .66 


\section{LIST OF TABLES}

Page

Table 1: 30 year EUR error for different BDF onset assumptions.............................. 14

Table 2: Eagle Ford well API 42-507-32721 hindcast error ...................................... 16

Table 3: Hindcast cumulative production error until end of known history ..................25

Table 4: Hindcast cumulative production error until end of known history, first

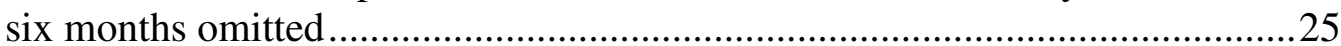

Table 5: Elm Coulee grouped well hindcast, cumulative production error to the end of history

Table 6: Elm Coulee grouped well hindcast, cumulative production error to the end of history, first six months omitted

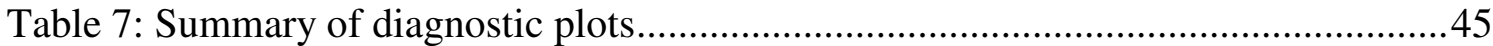

Table 8: Summary of diagnostic plots, BDF assumed at end of history if not present in data

Table 9: Elm Coulee average forecasted 30 year EUR ...........................................61

Table 10: Average b-values for hindcasts and forecasts ..........................................67 


\section{INTRODUCTION}

\subsection{Relevance of Research}

Shale oil or tight oil production has been a major focus of the oil industry for the past few years. One reason for this is the transfer of technology used for shale gas extraction into oil rich low permeability formations such as the Bakken, Niobrara, or Eagle Ford. The driving factor for this was the decline of natural gas prices concurrent with a rise in oil prices; this made many shale gas plays uneconomic.

Low permeability shale gas wells with long horizontal laterals and many stages of fractures have characteristically long periods of linear flow followed by fracture interference boundary-dominated flow (BDF). Since conventional decline curve methods are designed for forecasting boundary-dominated flow, there has been much activity in developing decline curves that model linear flow. An ideal decline curve for shale wells would be able to forecast linear flow followed by boundary-dominated flow.

\subsection{Status of the Question}

To assess the accuracy of decline curve analysis, or any forecasting technique, it is helpful to compare a hindcast to actual production history. The trouble in applying decline curve techniques for shale oil wells is the lack of production history. While my work does not account for the complex differences among various shale oil plays due to Pressure-volume-temperature (PVT) properties, geology, etc., I have attempted to use the production from horizontal wells in the Bakken formation as a study of decline curve 
analysis that may be later modified and applied to other formations such as the Eagle Ford, Niobrara, etc.

The main reason for starting this study in the Bakken formation is the longer span of production history. The Elm Coulee field, in the southwestern portion of the Bakken formation, was targeted early in the rapid development of the play that has occurred in the past few years, partly due to the field having much higher permeability than other plays termed "shale oil." The middle formation of the Elm Coulee Field has a permeability of about 0.05 millidarcies to 0.1 milidarcies, much higher than other shale oil plays such as the Eagle Ford or Niobrara (Walker et al. 2006). Drilling in this formation goes back to the 1980s, but was not extensive until the mid-2000s (Luo et al. 2010).

The oldest horizontal multi-fractured wells in "shale" oil reservoirs are in the Bakken formation in the Elm Coulee field. Kurtoglu et al. (2011), relate that no boundary-dominated flow is observed in any of the Elm Coulee wells. This compounds the problem of using Arp's decline model, as it is designed for boundary-dominated flow. Mangha et al. (2012) find that in shale gas wells, no single decline curve method is ideal for all reservoirs. Diagnostic plots are critical for assessing flow regimes in a well and determining which techniques to employ.

Forecasting production with a short period of data is problematic for any system. The Duong method appears to be a good predictor of future production in shale wells if limited data is available (Joshi and Lee 2013). However, since the Duong method assumes long term linear flow, it has a strong tendency to over predict reserves (Mangha 
et al. 2012). Since reserves vary based on economic conditions, I will substitute 30 year cumulative production forecasts as a measure of expected oil recovery. Researchers at Fekete proposed a linear flow model followed by a boundary-dominated flow model (Arps equation). The onset of boundary-dominated flow is determined by reservoir properties (Ambrose et al. 2011). This method is similar to the study done by Ilk et al. (2010), except that Fekete's model requires knowledge of reservoir properties in order to determine when boundary-dominated flow begins. My access to data on these properties was limited so this would be somewhat difficult. In addition, basing decline curves on reservoir properties may be problematic in reservoirs that are highly heterogeneous. Most of my study assumes that producing wells will switch to boundarydominated flow at approximately a $10 \%$ decline rate. This approach can be easily altered if better information is known about the well and when boundary-dominated flow should be expected.

Chu et al. studied the non-stationariness and non-linearity of shale oil reservoir production, primarily the Bakken (2012). Non-stationariness and non-linearity deal with the changing distributions of variables over time (heteroskedastic behavior) and changing relationships between variables over time. This includes changes to pressurevolume-temperature (PVT) properties due to pore throat size, pressure-dependent permeability, and multiple porous media caused by multi-stage fracturing. These nonstationary or non-linear properties indicate that forecasting or simulation will be a difficult task. Chu et al. found that in the first 1 to 5 months the decline trend can be described as stimulated reservoir volume (SRV) boundary affected flow. This seems to 
contradict the assumption that decline curves in shale wells only need to deal with two major flow periods (linear flow and fracture interference boundary-dominated flow). While the majority of the life of a well occurs during either linear flow or boundarydominated flow, a large percentage of the expected volume may be produced while affected by the SRV boundary. If decline curves are to accurately fit a linear flow trend, data from the early part of the well's production may obscure this trend.

Tran et al. (2011) divided Bakken wells into three production trends. Type I, or $51 \%$ of the wells, describes wells where the reservoir pressure drops below the bubble point pressure. Gas-oil ratio (GOR) increases rapidly for these wells, leveling off in late production. Type I well production histories indicate two distinct linear flow periods: fracture dominated and matrix supported. Type II includes wells that produce a single phase fluid below the bubble point. GOR is approximately constant for these wells. Type II wells show a single matrix supported linear flow trend. Type III wells have scattered production data.

Recovery estimation has been difficult to predict in this area. In the Bakken, linear flow is shown to last 18 years as presented by V. Hough and McClurg (2011). It remains to be seen whether modern completions will follow a similar trend.

I believe that a study of the Elm Coulee field, which is not currently a major target of exploration, may give insight into similar low permeability, oil rich plays that are currently receiving attention. As the permeability in the Elm Coulee field is higher than most formations termed to be "shale" but much lower than conventional fields we expect to see boundary-dominated flow somewhat earlier than in other "tighter" fields. 
Production decline will differ between formations due to geology and will also differ between periods of time on account of technological advances.

\subsection{Research Objectives}

The objective of my research is to determine whether decline curve models that have been used in shale gas will work for liquid rich shales. I began by applying different decline curve methods to the Eagle Ford, but the production histories proved too difficult to model. Instead I determined how well they modeled oil production in the Elm Coulee field. This must be demonstrated by hindcasting production decline at several different times from the start of production.

Other objectives:

- Estimation of the likely error in cumulative production caused by incorrect prediction of BDF onset

- Determination of the decline curve techniques that work best in shale oil formations, specifically the Elm Coulee and Eagle Ford, including an examination of the following:

- Arps hyperbolic with 5\% minimum decline

- Stretched exponential method (SEPD)

- Stretched exponential method (SEPD) with Arps hyperbolic tail for BDF

○ Duong model

- Duong model with Arps hyperbolic tail for BDF 
- An estimate of the time and annual decline rate of boundary-dominated flow onset in the Elm Coulee field

- Evaluation of the importance of pressure data correction in shale oil decline curves

- Determination of the effects of geology on boundary-dominated flow, particularly the Elm Coulee field

- Evaluation of 30 year production forecasts in the Elm Coulee field using different decline models 


\section{DECLINE CURVE ANALYSIS IN UNCONVENTIONALS}

\subsection{Introduction to Linear and Boundary-Dominated Flow}

J.J. Arps created the standard decline model for boundary-dominated flow regimes in conventional reservoirs. High permeability reservoirs enter boundarydominated flow very quickly, so an equation fitting only one flow regime is adequate for an accurate forecast.

Recent development of tight sand and shale gas reservoirs has led to the development of different decline curve techniques. The fundamental difference between forecasting conventional wells and low permeability wells is that low permeability wells have much of their production history in transient flow (often transient linear flow) rather than boundary-dominated flow (BDF). Whether or not early production in a well can be forecasted accurately during transient flow, there will be an increase in forecast error later in the life of the well due to a change to boundary-dominated flow. The significance of this error is dependent on how late in the life of the well this change occurs and how much will be produced during boundary-dominated flow before the economic limit is reached.

To demonstrate the deviation caused by the switch to boundary-dominated flow I have plotted production rate versus time for a perfect linear flow well and a well that begins with linear flow, an Arps curve with a b-value of 2, that is followed by boundarydominated flow with an Arps b-value of 0.3 (consistent with typical solution gas drive wells). 
2.2 Methods of Decline Curve Analysis: Arps with 5\% Minimum Decline, Stretched Exponential (SEPD), and Duong

\subsubsection{Arps with 5\% Minimum Decline (Terminal Decline)}

The first method I employed in forecasting is the Arps equation with a 5\% minimum decline, also called terminal decline. This gives a hyperbolic decline fit to production rates with three variables; initial production $\left(\mathrm{q}_{\mathrm{i}}\right)$, initial decline $\left(\mathrm{D}_{\mathrm{i}}\right)$, and an exponent factor (b). These factors were calculated using a least squares fit and an Excel Solver. The hyperbolic decline Arps equation is followed by an exponential decline Arps equation that begins when the annual production decline rate falls to $5 \%$.

Hyperbolic decline flow rate:

$$
q(t)=\frac{q_{i}}{\left(1+b D_{i} t\right)^{\frac{1}{b}}}
$$

Exponential decline flow rate, $5 \%$ decline:

$$
q=q_{i} * \exp [-a * t]
$$

This Arps curve with 5\% minimum decline will be the baseline method for this study as it is the simplest deviation from the traditional Arps curve. The accuracy of this method varies greatly with the value of the minimum decline rate (McMillan, 2011). The minimum decline rate will mitigate the tendency of the Arps curve forecast to overestimate recovery. A shale oil well is not expected to actually enter exponential decline since it is produced by a solution gas drive which has a characteristic hyperbolic 
decline, with a b-value of 0.3 during boundary-dominated flow. It remains to be seen whether this will hold in very low permeability reservoirs.

\subsubsection{Stretched Exponential Method (SEPD)}

The second decline curve method to be examined is the stretched exponential method or SEPD (Valko and Lee 2010). It is similar to the Arps exponential equation, but time is divided by a factor $\tau$ and raised to the $\mathrm{n}$-th power.

$$
\begin{aligned}
& \frac{d q}{d t}=-n\left(\frac{t}{\tau}\right)^{n} *\left(\frac{q}{t}\right) \\
& q=q_{o} * \exp \left[-\left(\frac{t}{\tau}\right)^{n}\right] \\
& \mathrm{Q}=\frac{q_{o^{*}} * \tau}{n} *\left\{\Gamma\left[\frac{1}{n}\right]-\Gamma\left[\frac{1}{n},\left(\frac{t}{\tau}\right)^{n}\right]\right\} \\
& \Gamma(\mathrm{x})=\int_{0}^{\infty} t^{x-1} e^{-t} d t
\end{aligned}
$$

\subsubsection{Duong Method}

The Duong method (Duong 2010) was developed to more closely match linear flow. It is calculated by finding characteristic parameters a and $\mathrm{m}$ and then determining $\mathrm{q}_{1}$ (initial production).

$$
\begin{aligned}
& q=q_{1} * t(a, m) \\
& t(a, m)=t^{-m} * \exp \left(\frac{a}{1-m} *\left(t^{1-m}-1\right)\right) \\
& E U R=\frac{q 1}{a} * \exp \left(\frac{a}{1-m} *\left(t^{1-m}-1\right)\right)
\end{aligned}
$$

$$
\begin{gathered}
\mathrm{a}=\text { intercept from a linear plot of } \log \mathrm{q} / \mathrm{G}_{\mathrm{p}} \text { versus } \log \text { time } \\
\mathrm{m}=\text { slope from a linear plot of } \log \mathrm{q} / \mathrm{G}_{\mathrm{p}} \text { versus log time } \\
9
\end{gathered}
$$




$$
q_{1}=\text { initial flow rate }
$$

The Duong equation for production rate may include an intercept, $q_{\infty}$, such that $q=q_{1} * t(a, m)+q_{\infty}$. This intercept represents the flow rate of the well as time approaches infinity. The value of $q_{\infty}$, was set to zero in my forecasts, as this parameter was found to be problematic in obtaining accurate forecasts. In addition this method is more theoretically rigorous without the constant since it is unreasonable that the well would continue producing forever.

2.3 Theoretical Forecasting of Wells Switching from Linear to Transient Flow

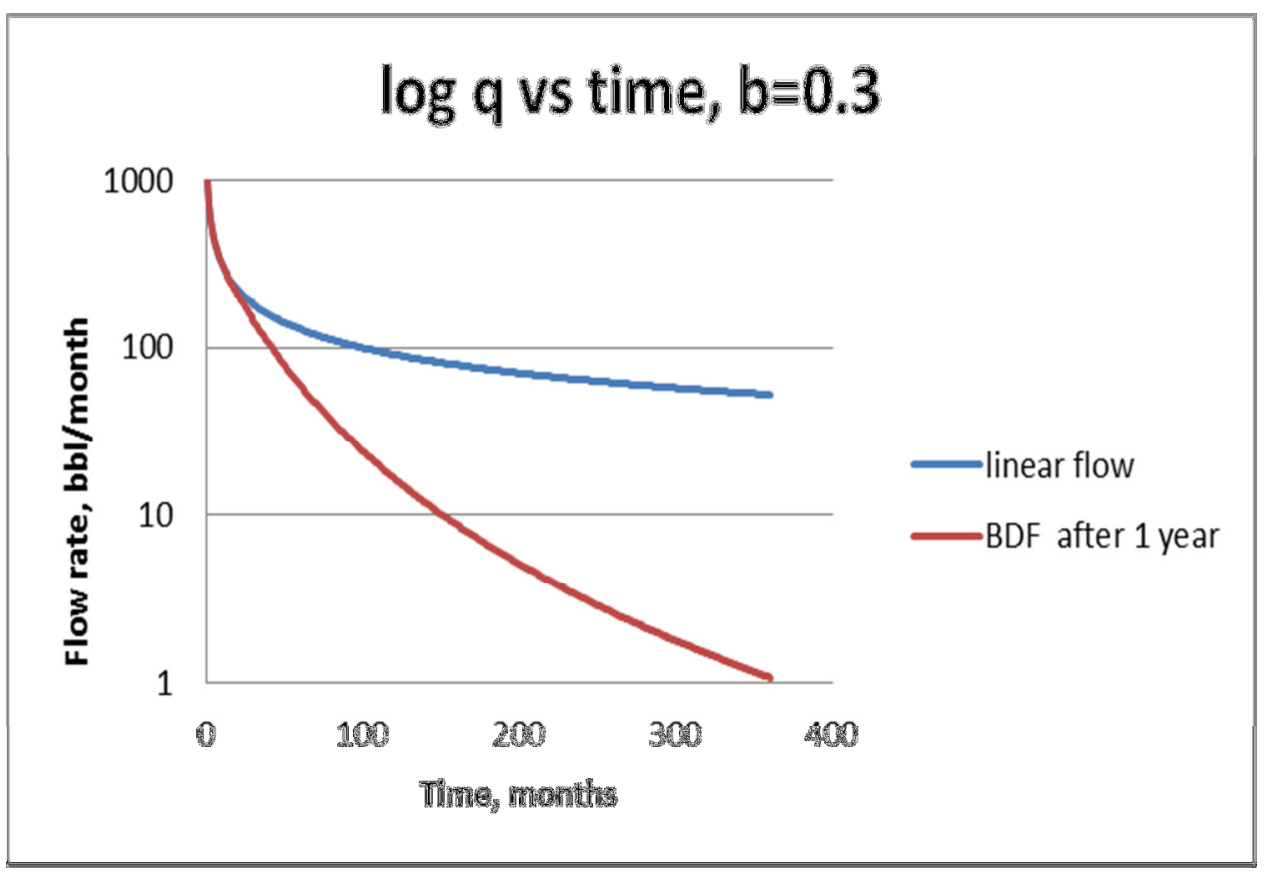

Figure 1: Deviation from linear flow 
As demonstrated in Figure 1, there is a significant decrease in production rate due to the switch from linear to boundary-dominated flow. A decline curve that fits the early production rates will overestimate the later production rates. While it is impossible to fit a trend that doesn't exist, this seems to be required to create an accurate forecast. I analyzed this issue by creating a theoretical well that begins in perfect linear flow and then switches to boundary-dominated flow. This is an idealized case since wells often have several months at the beginning of production with the appearance of bilinear flow or with no discernible trend. In this case I used a b value of 0.3 to match an oil well in solution gas drive. I attempted to "match" this well by creating similar decline curves with the switch to BDF occurring at various points in time from 5 to 20 years from the start of production. 


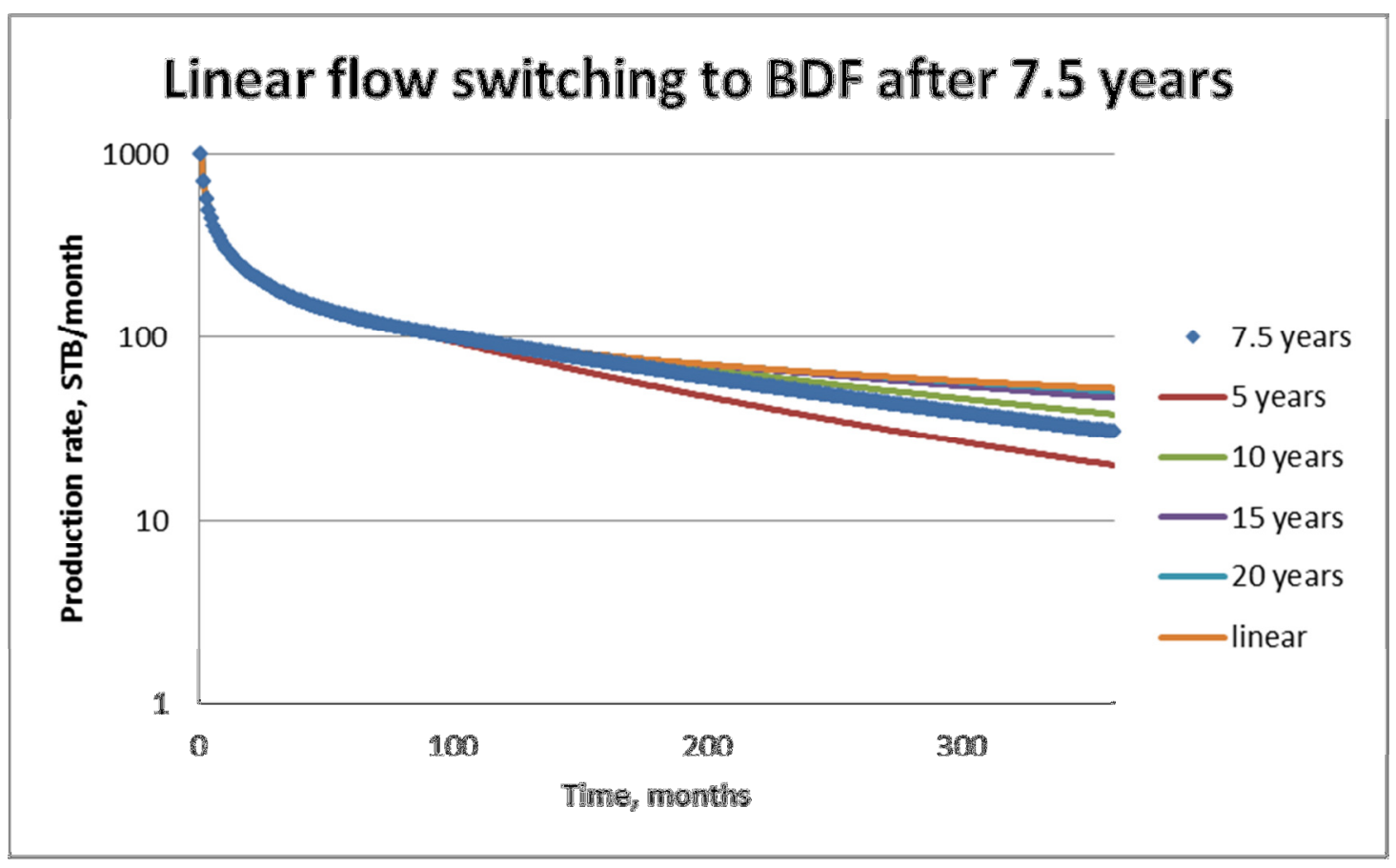

Figure 2: Production rate, actual deviation from linear flow at 7.5 years

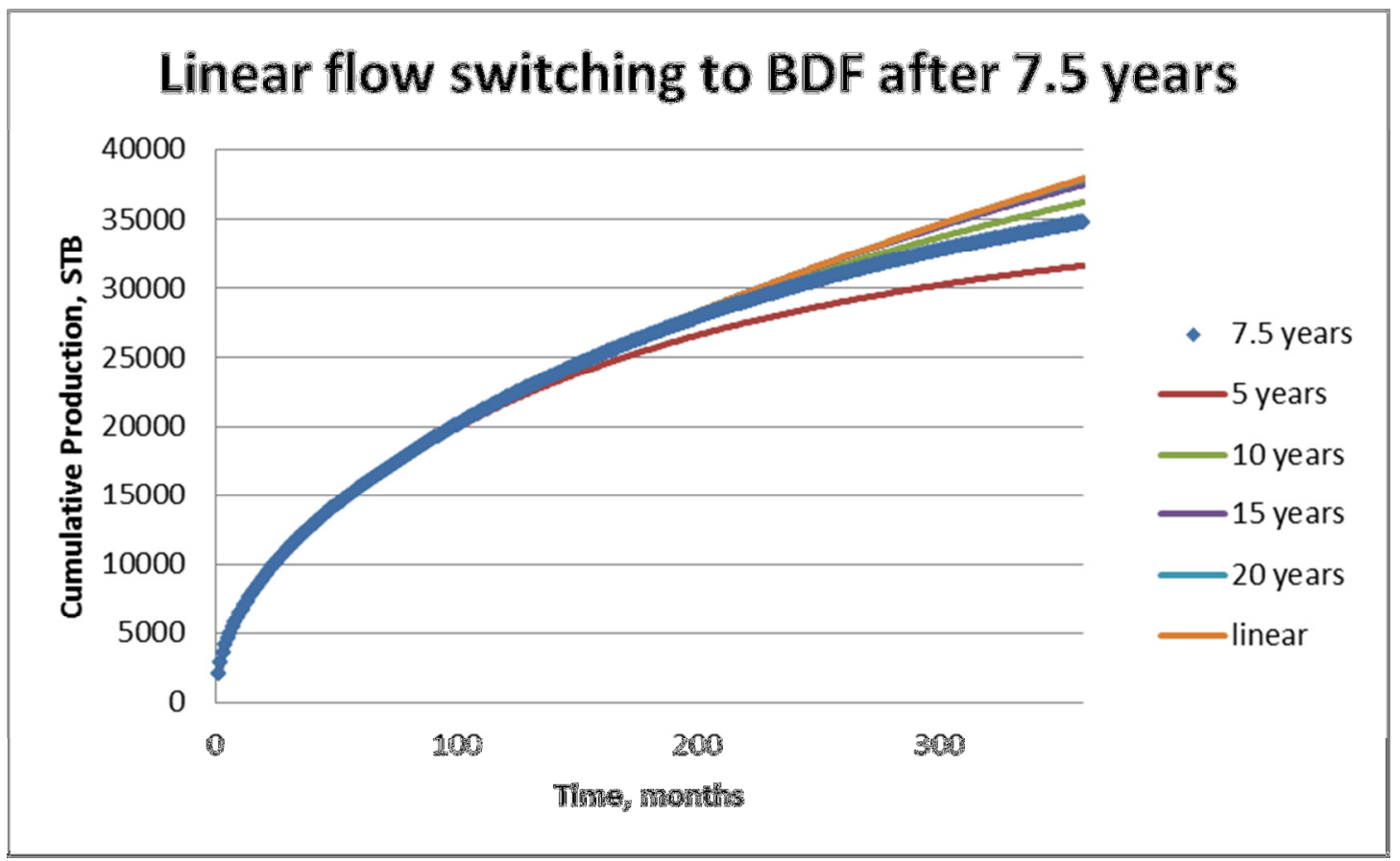

Figure 3: Cumulative production, deviation from linear flow at 7.5 years 
The example well in Figure 2/Figure 3 switched to boundary-dominated flow after 7.5 years. The nearest curve to this well switches to BDF after 10 years, with $4.47 \%$ difference in the thirty year total recovery. This compares to a $9.39 \%$ difference between the well and long term linear flow.

In contrast Figure 4/Figure 5 show production rates from a well that entered boundary-dominated flow after 2.5 years. After 30 years, the actual production is close to half of what perfect linear flow predicted. Estimating boundary-dominated flow onset at 5 years still forecasts 30 year cumulative production to be $27 \%$ too high.

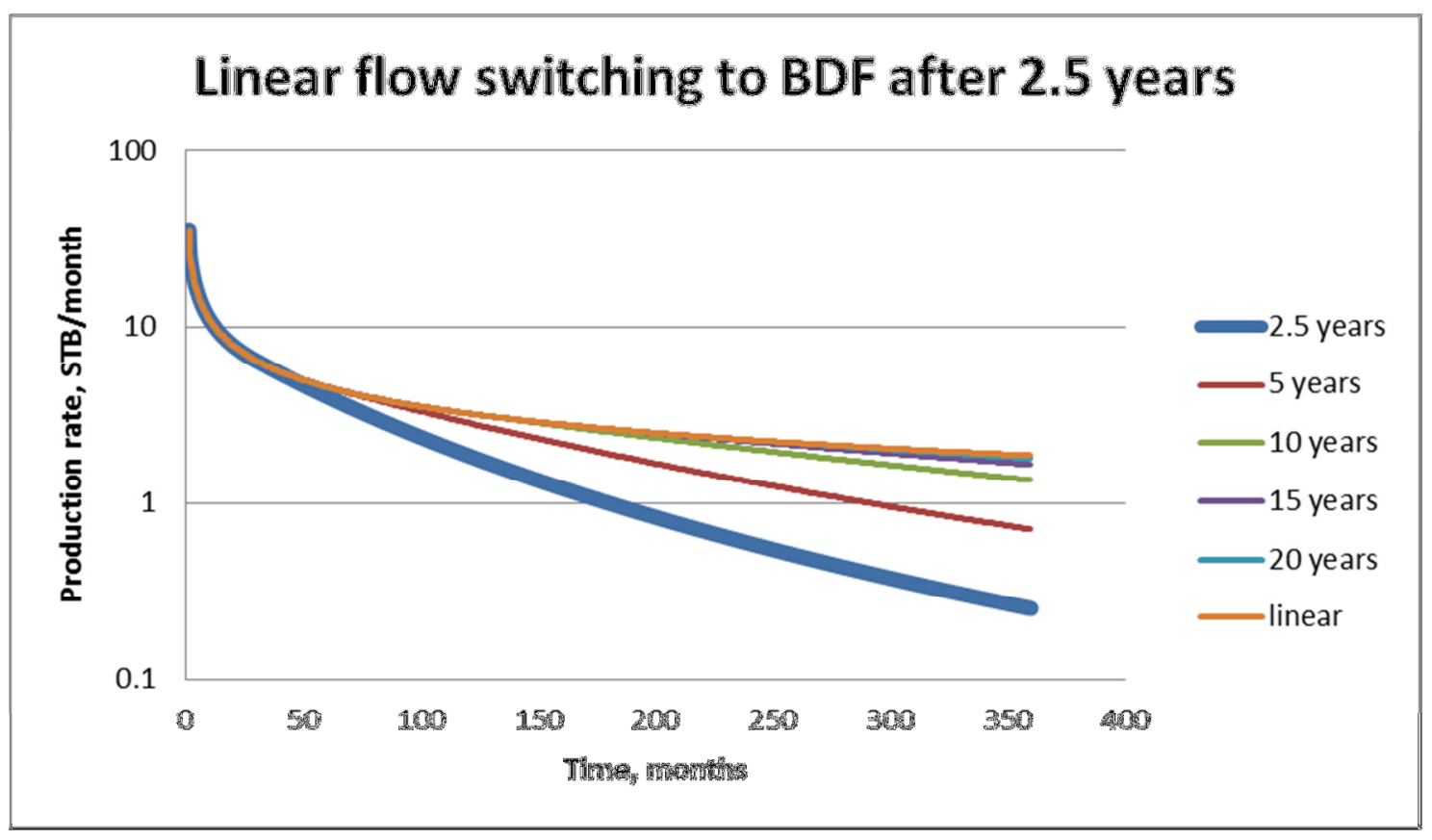

Figure 4: Production rate, deviation from linear flow at 2.5 years 


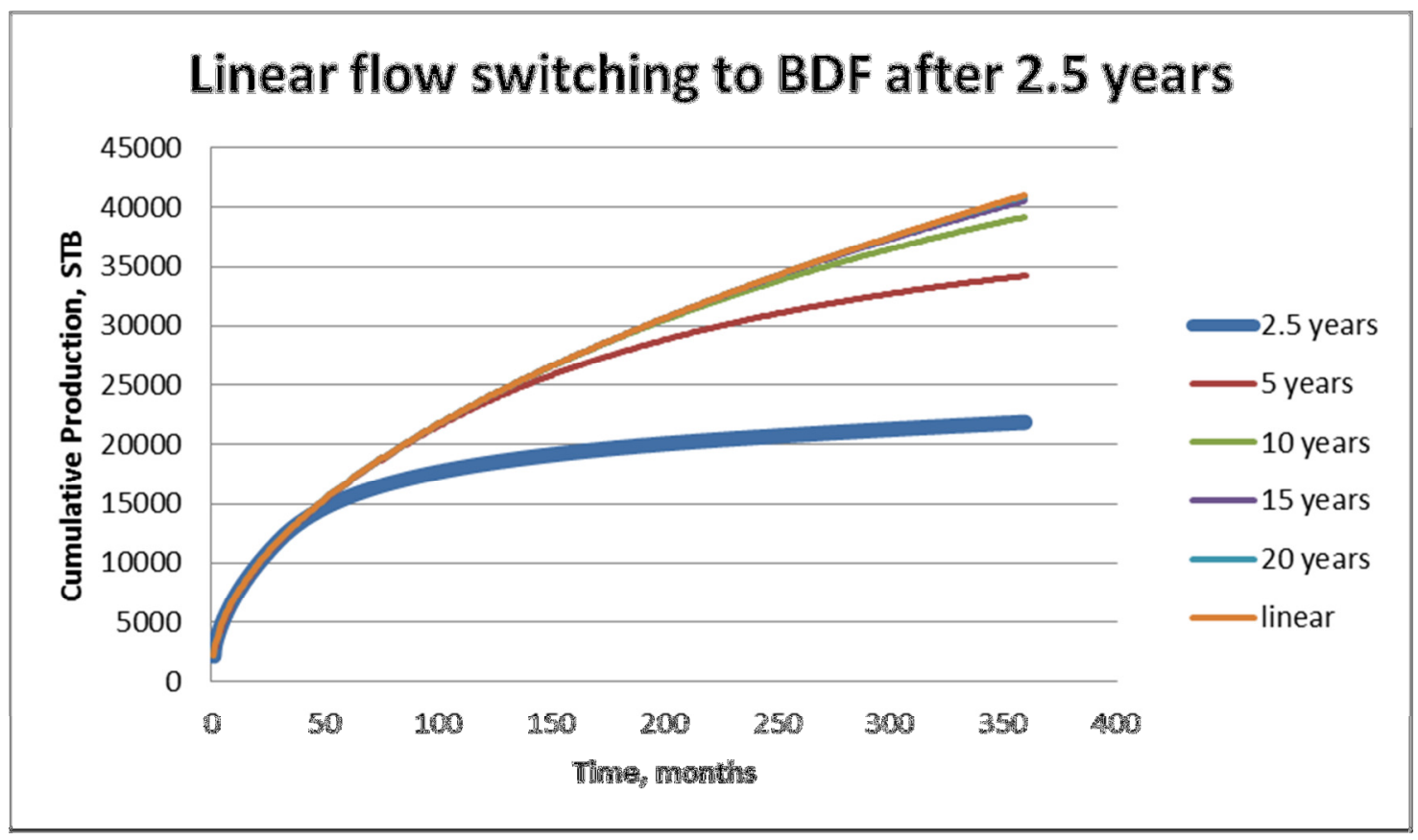

Figure 5: Cumulative production, deviation from linear flow at 2.5 years

Table 1: 30 year EUR error for different BDF onset assumptions

\begin{tabular}{|r|r|r|r|r|r|}
\hline \multicolumn{2}{|c|}{ Error in $\mathbf{3 0}$ year EUR, linear flow followed by boundary dominated flow } \\
\cline { 2 - 6 } Assumed BDF onset & \multicolumn{5}{|c|}{ Actual time of BDF onset } \\
\hline $\mathbf{2 . 5}$ years & $\mathbf{7 . 5}$ years & $\mathbf{1 2 . 5}$ years $\mathbf{1 7 . 5}$ years $\mathbf{2 2 . 5}$ years \\
\hline $\mathbf{5}$ years & $\mathbf{2 6 . 5 4 \%}$ & $-8.83 \%$ & $-14.66 \%$ & $-16.19 \%$ & $-16.59 \%$ \\
\hline $\mathbf{1 0}$ years & $\mathbf{4 4 . 9 9 \%}$ & $\mathbf{4 . 4 7 \%}$ & $-2.21 \%$ & $-3.97 \%$ & $-4.42 \%$ \\
\hline $\mathbf{1 5}$ years & $\mathbf{5 0 . 0 4 \%}$ & $\mathbf{8 . 1 0 \%}$ & $1.19 \%$ & $-0.62 \%$ & $-1.10 \%$ \\
\hline $\mathbf{2 0}$ years & $51.47 \%$ & $9.13 \%$ & $2.15 \%$ & $0.32 \%$ & $-0.15 \%$ \\
\hline linear flow & $51.83 \%$ & $9.39 \%$ & $2.40 \%$ & $0.56 \%$ & $0.09 \%$ \\
\hline
\end{tabular}

Table 1 gives the error in 30 year recovery estimates for wells that begin in linear and switch to BDF at the time specified. From this chart we understand that BDF onset error has much less of an effect on cumulative production forecasts if BDF occurs late in 
the life of the well. This is what we would expect since earlier time periods have higher flow rates and therefore an earlier error will affect the cumulative recovery more than a later error.

This is also seen for wells that switch from linear flow to boundary-dominated flow late in the life of the well. In fact, for wells that only experience boundarydominated flow at the end of their production lives there is very little deviation from what would be predicted with long term linear flow.

The switch to BDF is most significant if it occurs early. It becomes even more significant if economic production rate is taken into account. If a well falls below the economic limit rate, it will be shut in, increasing the difference in ultimate recovery with wells that experience boundary-dominated flow later and therefore stay above the economic limit rate for longer. Economic rate of course is variable and dependent upon price and costs and is not covered in this study. 


\section{EAGLE FORD}

We now consider a well from Zavala County in the oil rich zone of the Eagle Ford, API\#: 42-507-32721, which came on production in June 2009. This well with 28 months of history is one of the oldest liquids-rich wells in the play. I hindcasted this well on the first six months, both including and omitting the first six months of data, as shown in Figure 6 and Figure 7. As shown in Table 2, omitting the first six months dramatically improved the Duong method accuracy. The Arps method with 5\% minimum decline is the most accurate method for this well.

Table 2: Eagle Ford well API 42-507-32721 hindcast error

\begin{tabular}{|c|r|r|r|r|r|}
\hline Hindcast on 18 months of history & $5 \%$ minimum decline & SEPD & SEPD/Arps & Duong & Duong/Arps \\
\hline Error including first six months & $8.10 \%$ & $17.80 \%$ & $17.80 \%$ & $19.50 \%$ & $-26.50 \%$ \\
\hline Error without first six months & $5.15 \%$ & $15.17 \%$ & $15.17 \%$ & $6.66 \%$ & $6.66 \%$ \\
\hline
\end{tabular}




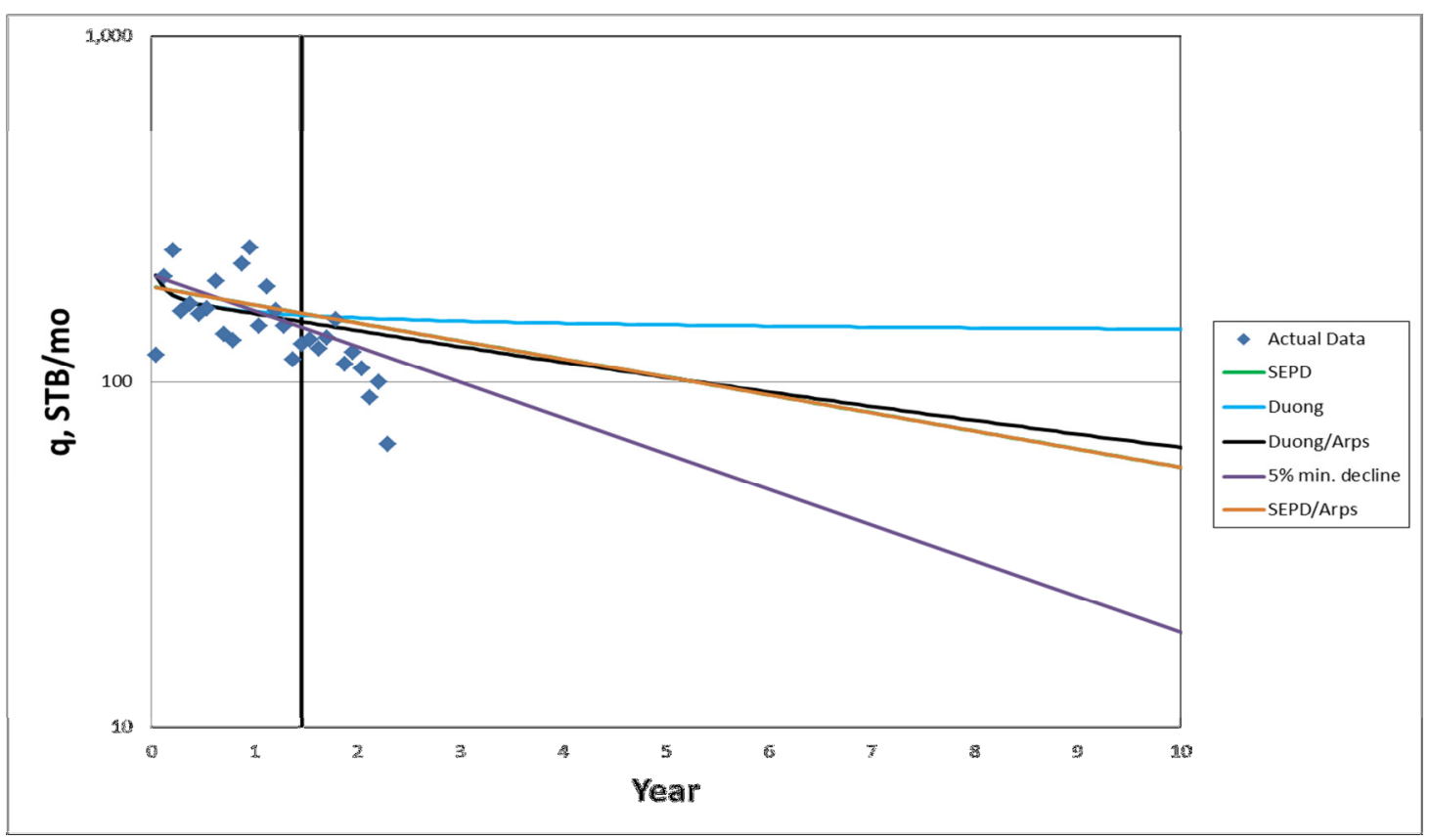

Figure 6: API 42-507-32721 Forecast based on 18 month history

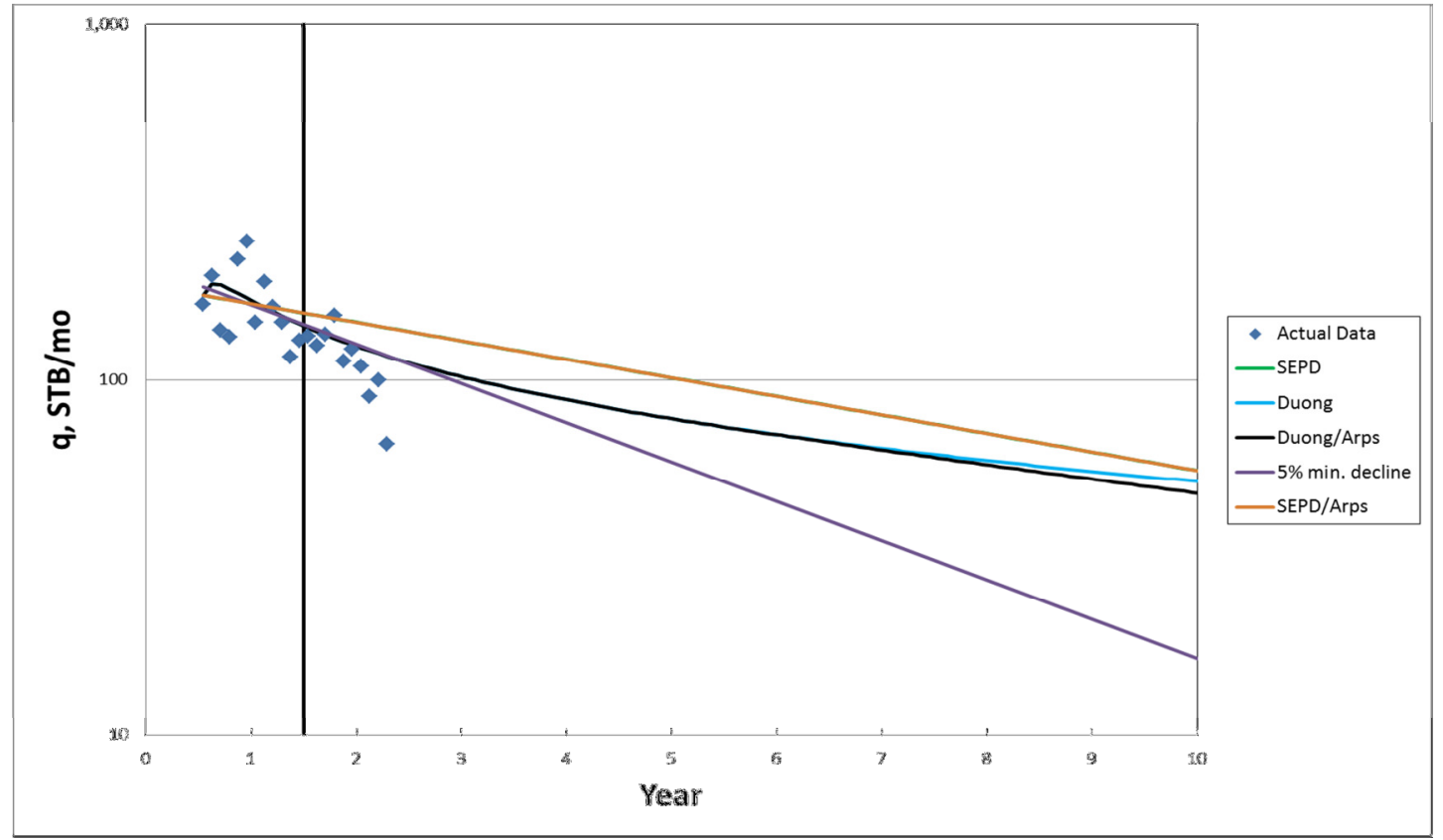

Figure 7: API 42-507-32721 Forecast based on 18 months history, ignoring first six months 
Unfortunately, many of the wells older than two years in this part of the play appear to have been recompleted or shut in for long periods of time, making it difficult to use decline curve analysis. This is problematic for gaining an understanding of the nature of these wells. It is unlikely that applying characteristics from a single well will create an accurate understanding of the play.

It would be much more effective to do an in depth study of an analog with better data, or at least another play with similar characteristics. To fill this role, I selected the Bakken formation as it is an older shale/tight oil play with horizontal wells and induced fractures. 


\section{ELM COULEE OVERVIEW}

As discussed earlier, there are only a few wells in the Eagle Ford oil window with more than three years of production history. In addition, there is a large degree of variance in production rates. The Elm Coulee formation has a much longer production history. Many horizontal wells were completed in significant numbers from this formation starting in 2006. While technology has continually improved in horizontal well stimulation, wells completed in 2006 are bound to the same concept as newer Eagle Ford wells, production occurring primarily through induced transverse fractures.

The Elm Coulee formation is only slightly overpressured, compared to the rest of the Bakken (Kurtoglu et al. 2011). The middle section of the Elm Coulee, 10-35 feet thick (Kurtoglu et al. 2011), is a dolostone rather than a true shale. The Eagle Ford has carbonate heterogeneously mixed into the shale.

Also, the permeability of the Elm Coulee field is around 0.05 to 0.1 millidarcies (Walker et al. 2006). This is many orders of magnitude larger than the permeability seen in the Eagle Ford, but still considered an unconventional reservoir. The advantage of this in evaluating decline curve models is that boundary effects should appear much faster for a given fracture spacing. This allows for analysis of periods of both linear and boundary-dominated flow in the first few years of production history. 
An average of gas-oil ratios shows steady increases that slow after two years, seen in Figure 8. This is what we would expect in a solution-gas drive reservoir. The water-oil ratio generally falls rapidly in the first few months and then stays flat, as seen in Figure 9. This can likely be attributed to continued flowback of fracturing fluid, and is problematic for history matching.

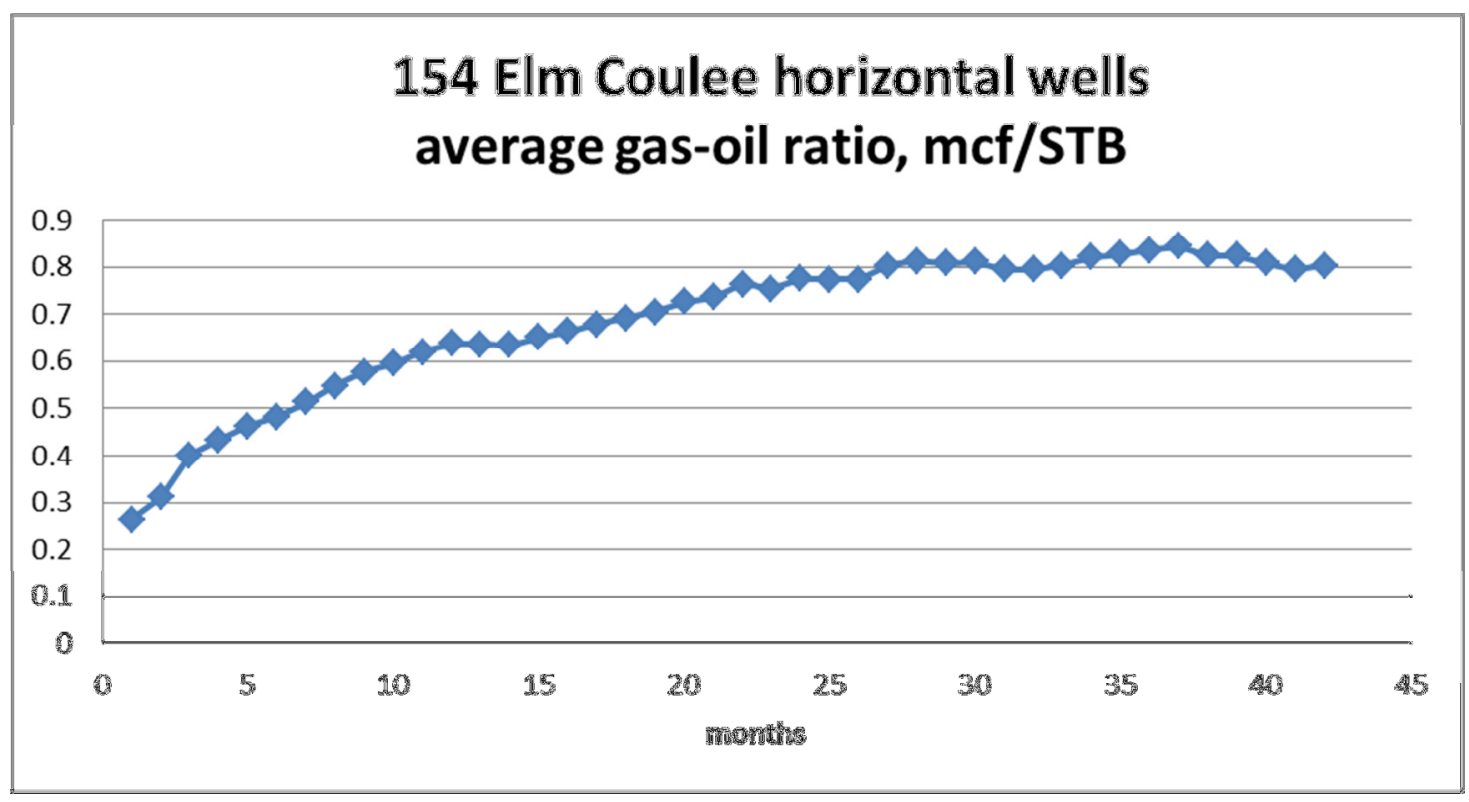

Figure 8: Elm Coulee average GOR versus time 


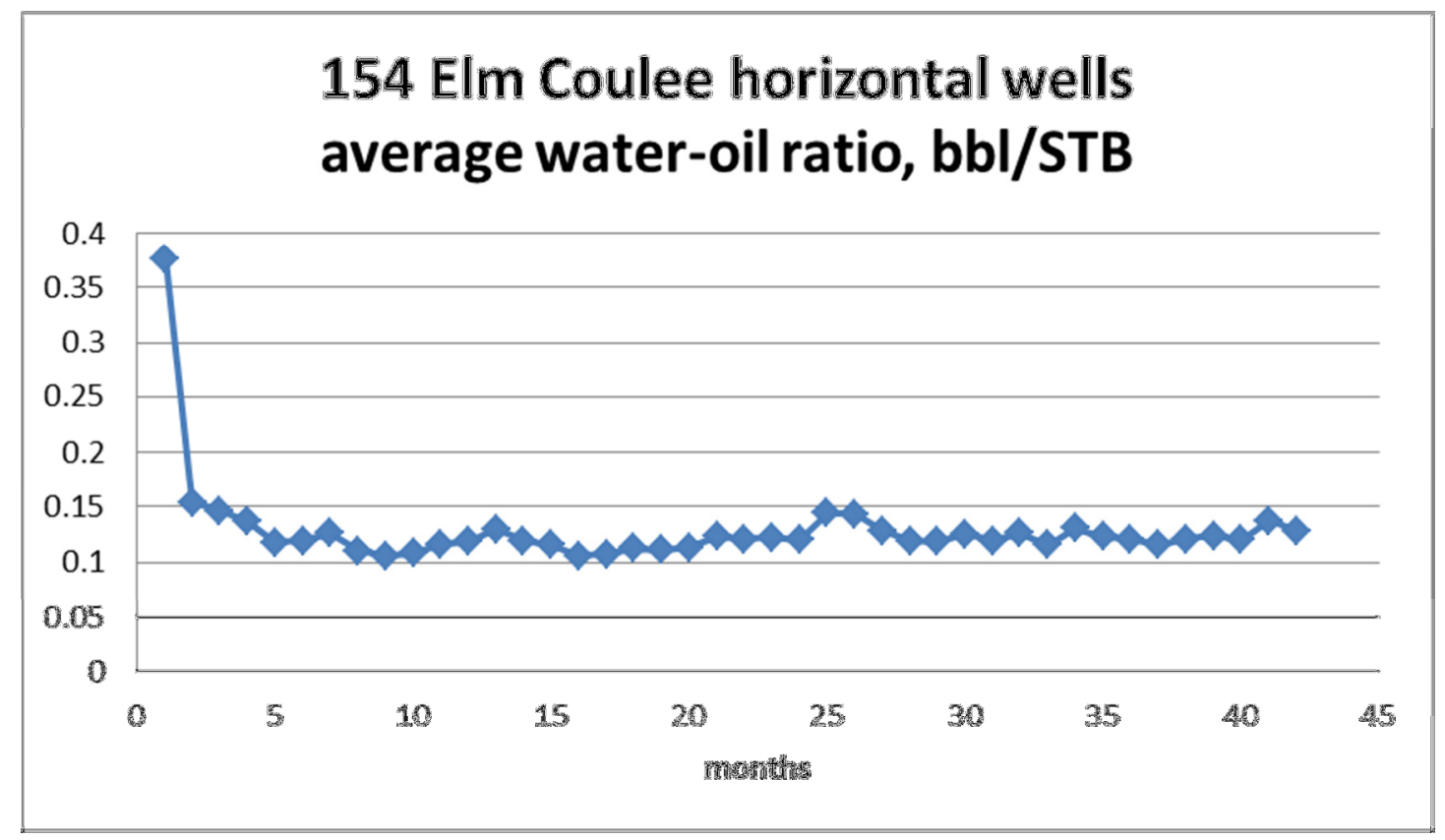

Figure 9: Elm Coulee average WOR versus time

Much of the fracture fluid flow back will occur in the first month, but in many wells high water production will last for several months, for example well BR 11-27H 43 shown in Figure 10. The oil rate in this well is decreasing as well, but most of the decrease in water production occurs in the first five months. After this point, water production is minimal. 


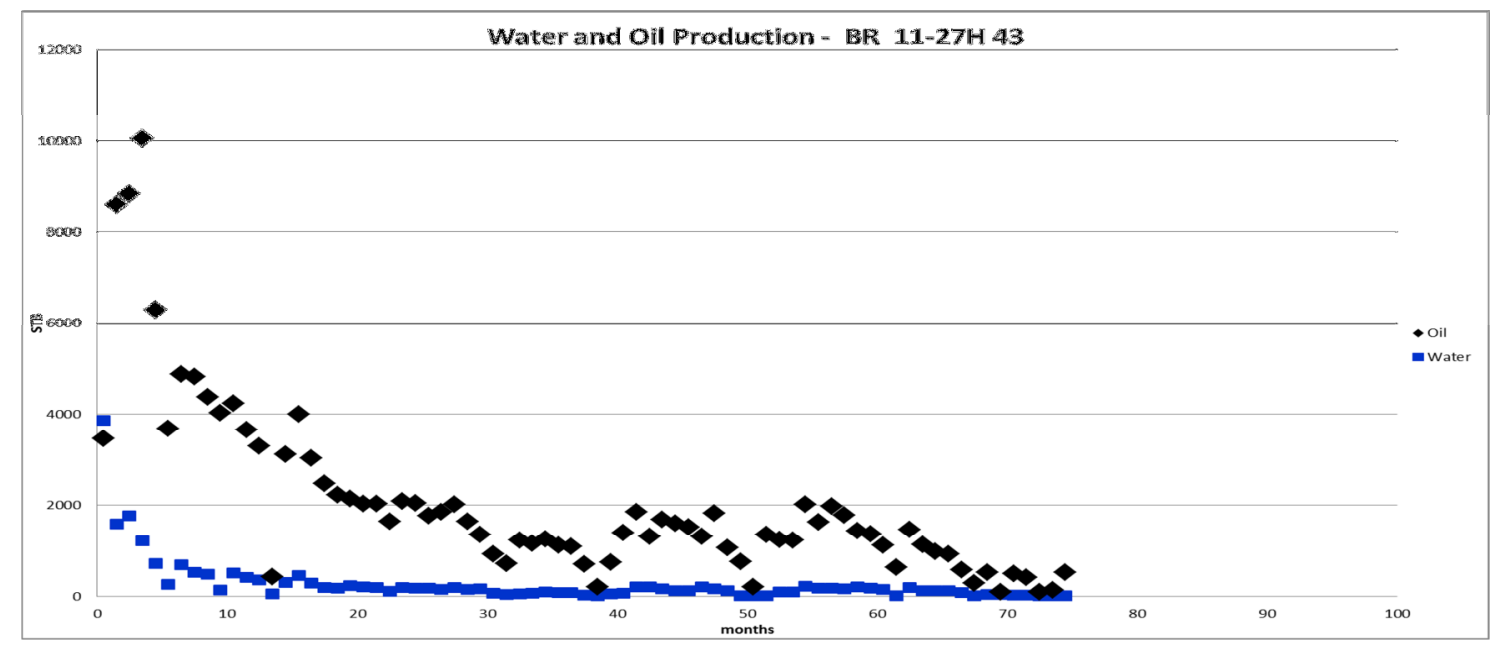

Figure 10: Elm Coulee example well WOR

This contrasts with the production of the well Mondalin 2-10H, Figure 11. Water production is low for the life of the well, except for a few spikes of production. It is obvious that in this case that fracture fluid cleanup is not a major factor in the well's production.

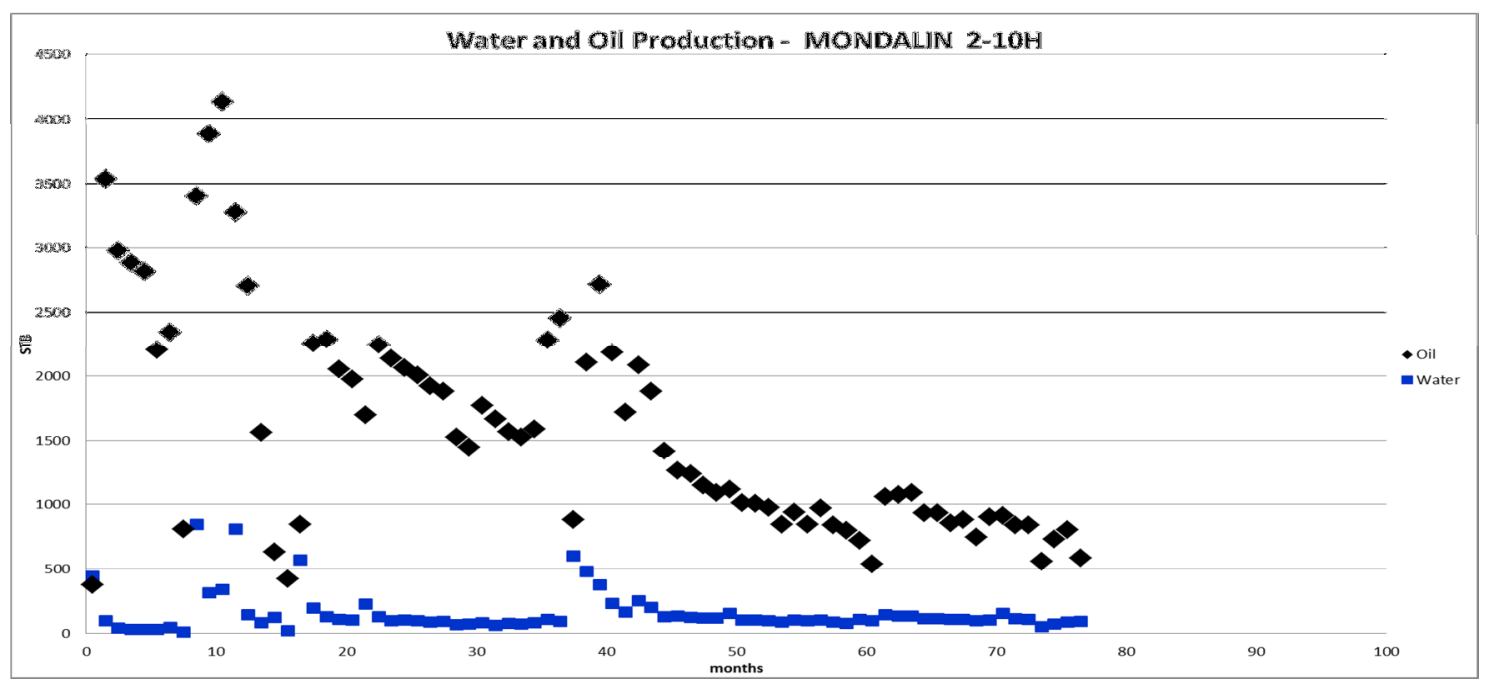

Figure 11: Elm Coulee example well WOR 


\section{ANALYSIS OF FIELD DATA}

\subsection{Method of Production Forecasting}

Early production data from shale oil formations can be erratic and may not follow a predictable flow trend. If this is the case decline curves based on predicting either linear or boundary-dominated flow should not be able to predict future production based on data that does not fit characteristic flow regimes.

I propose that the first 6 months should be omitted from decline curve analysis in shale oil formations, particularly when there are rapid changes in water-oil ratio and gasoil ratio during the early transient period.

I performed hindcasts on 154 horizontal wells in the Elm Coulee formation with production histories of 4 to 7 years. We assume that most of these wells are

hydraulically fractured. Some wells appear to have been recompleted and were omitted from the set. Wells with months in which no oil was produced, i.e. shut-in wells, were omitted from the hindcasted data set.

All of the methods mentioned earlier were applied: Arps with 5\% minimum decline, Stretched Exponential, Stretched Exponential with Arps for boundarydominated flow, Duong, and Duong with Arps for boundary-dominated flow. The SEPD model was determined (Valko and Lee 2010) as discussed above. The Duong model (Duong 2010) was applied as discussed above with $\mathrm{q}_{\text {inf }}$ set to zero. 
For the Arps model (Arps 1945) with 5\% minimum decline, a three variable solver was used to determine initial production, initial decline, and the b exponent, minimizing the least squares error for the fit history.

The Arps tails for modifying SEPD and Duong are assumed to occur at a $10 \%$ minimum decline rate. A b-value of 0.3 was also assumed, which is representative of typical solution gas depletion drive wells. The $10 \%$ decline rate may not accurately predict when boundary-dominated flow occurs, but is a reasonable value based on this study. New b-values were determined using a solver if this minimum decline rate occurred during the used history. This decline rate generally occurs after the known history in Elm Coulee wells, so further study should be done to assess the merit of this value. It would also be better to estimate the time of boundary-dominated flow onset from depth of investigation equations if permeability and drainage area values are known.

\subsection{Comparison of Methods}

From analyzing the average hindcast errors (Table 3/Figure 12 and Table 4/Figure 13), I have shown that hindcast prediction accuracy generally increases with the length of time used to forecast. There is also a general increase in precision, seen in Figure 14 and Figure 15. This is what is expected since there should be more statistical confidence in forecasts with an increasing number of data points. This may not be the case if there in increasing variance in the data (heteroskedasticity) or if the flow regime changes and throws off the prediction. 
Due to the lack of boundary-dominated flow during the known production histories, the SEPD and Duong methods are very similar to their counterparts with the Arps curve modification. Further discussion of the Arps curve addition during boundarydominated flow will be treated later.

Table 3: Hindcast cumulative production error until end of known history

\begin{tabular}{|c|c|c|c|c|}
\hline \multicolumn{5}{|c|}{ 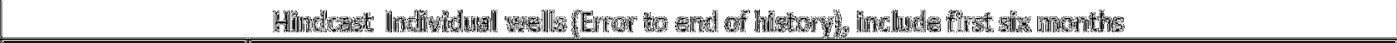 } \\
\hline 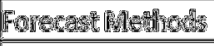 & \multicolumn{4}{|c|}{ 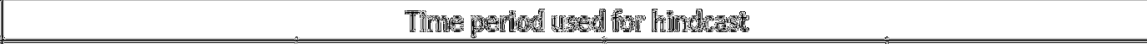 } \\
\hline & Ie monthes & 24 moiratho & 30 montits & 3E worth \\
\hline $5 \%$ min. decline & $-16.72 \%$ & $-17.25 \%$ & $-9.31 \%$ & $-10.22 \%$ \\
\hline SEPD & $-6.59 \%$ & $-10.44 \%$ & $-6.52 \%$ & $-6.67 \%$ \\
\hline SEPD/Arps & $-6.79 \%$ & $-10.63 \%$ & $-6.66 \%$ & $-7.06 \%$ \\
\hline Duong & $25.06 \%$ & $13.13 \%$ & $4.16 \%$ & $6.08 \%$ \\
\hline Duong/Arps & $24.84 \%$ & $11.32 \%$ & $4.22 \%$ & $6.23 \%$ \\
\hline
\end{tabular}

Table 4: Hindcast cumulative production error until end of known history, first six months omitted

\begin{tabular}{|c|c|c|c|c|}
\hline \multicolumn{5}{|c|}{ Hordens: In } \\
\hline \multirow[t]{2}{*}{ Foremand Mothous } & \multicolumn{4}{|c|}{ Tims period insed fin hindess: } \\
\hline & 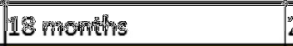 & 24 menthes & 30 monthes & 36 monthe \\
\hline $5 \%$ min. decline & $-0.18 \%$ & $1.82 \%$ & $-0.03 \%$ & $1.97 \%$ \\
\hline SEPD & $-7.04 \%$ & $-5.45 \%$ & $-4.87 \%$ & $-2.85 \%$ \\
\hline SEPD/Arps & $-7.30 \%$ & $-5,62 \%$ & $-449 \%$ & -3.298 \\
\hline पnank & 1.728 & 5258 & 3.298 & $768 \mathrm{~m}$ \\
\hline 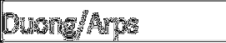 & 1.642 & 5.174 & 3.274 & $7.48,4$ \\
\hline
\end{tabular}




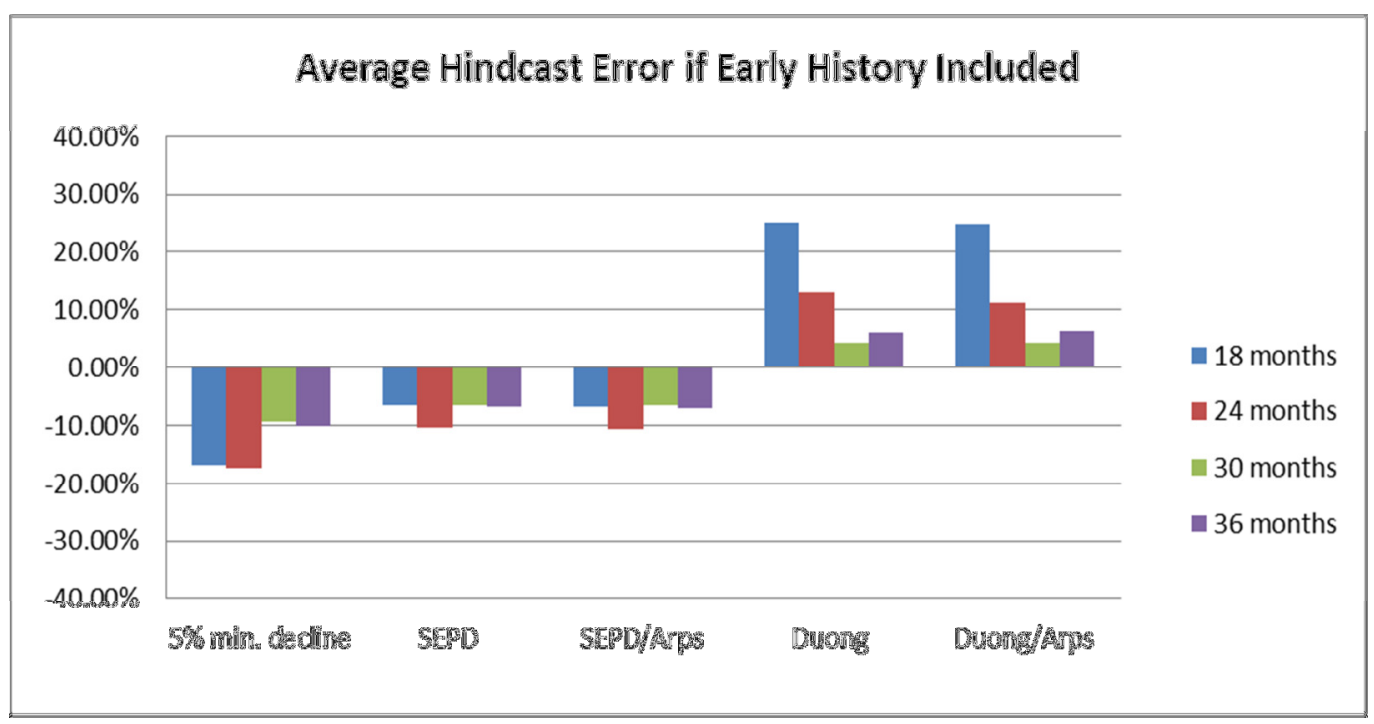

Figure 12: Average hindcast error, including first six months

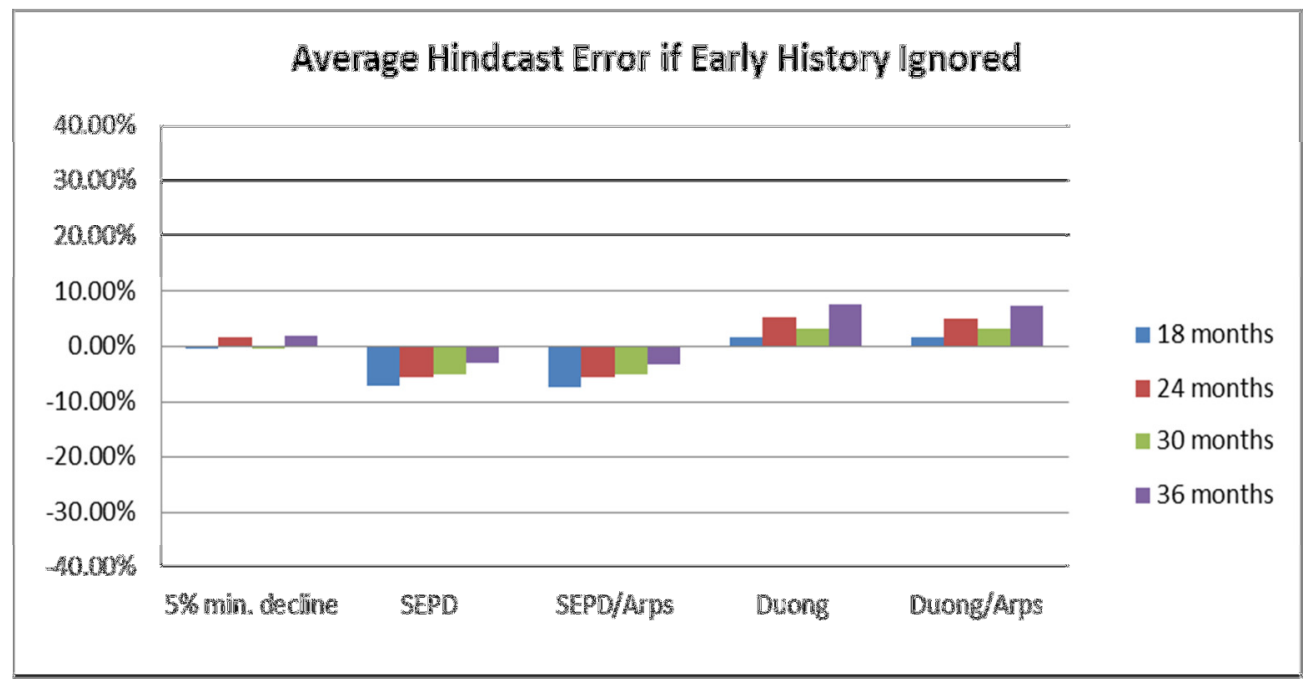

Figure 13: Average hindcast error, ignoring first six months 


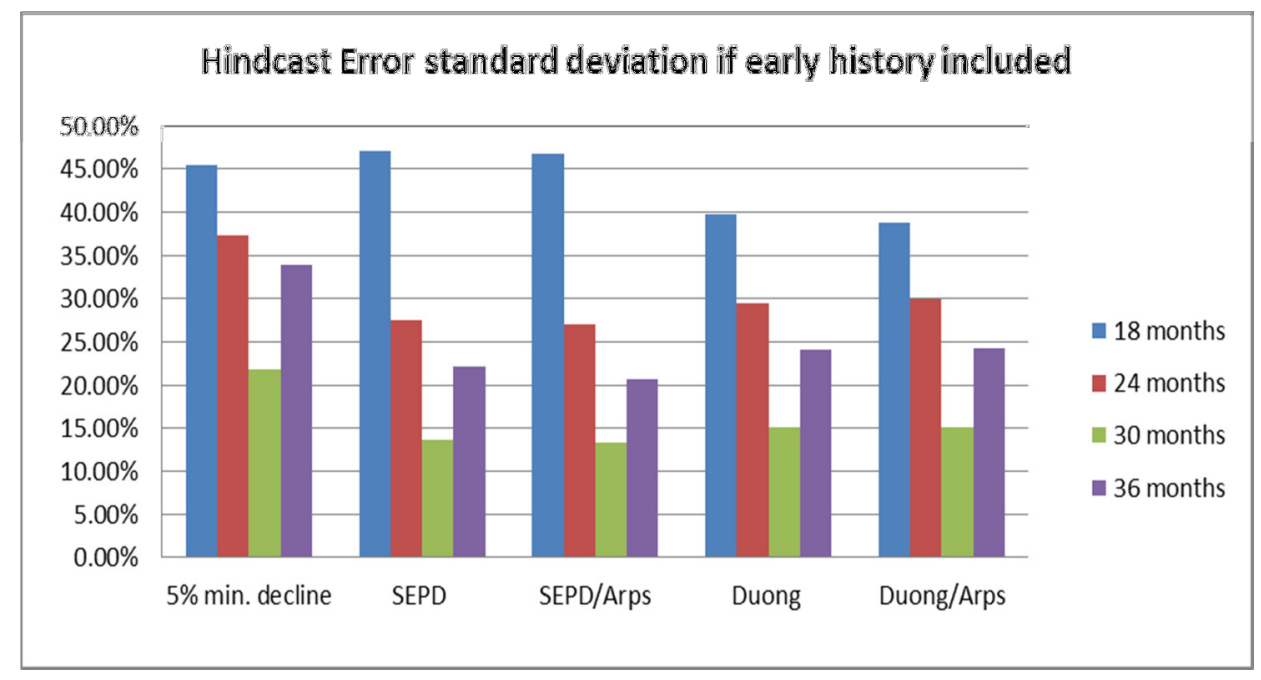

Figure 14: Standard deviation of hindcast error, including first six months

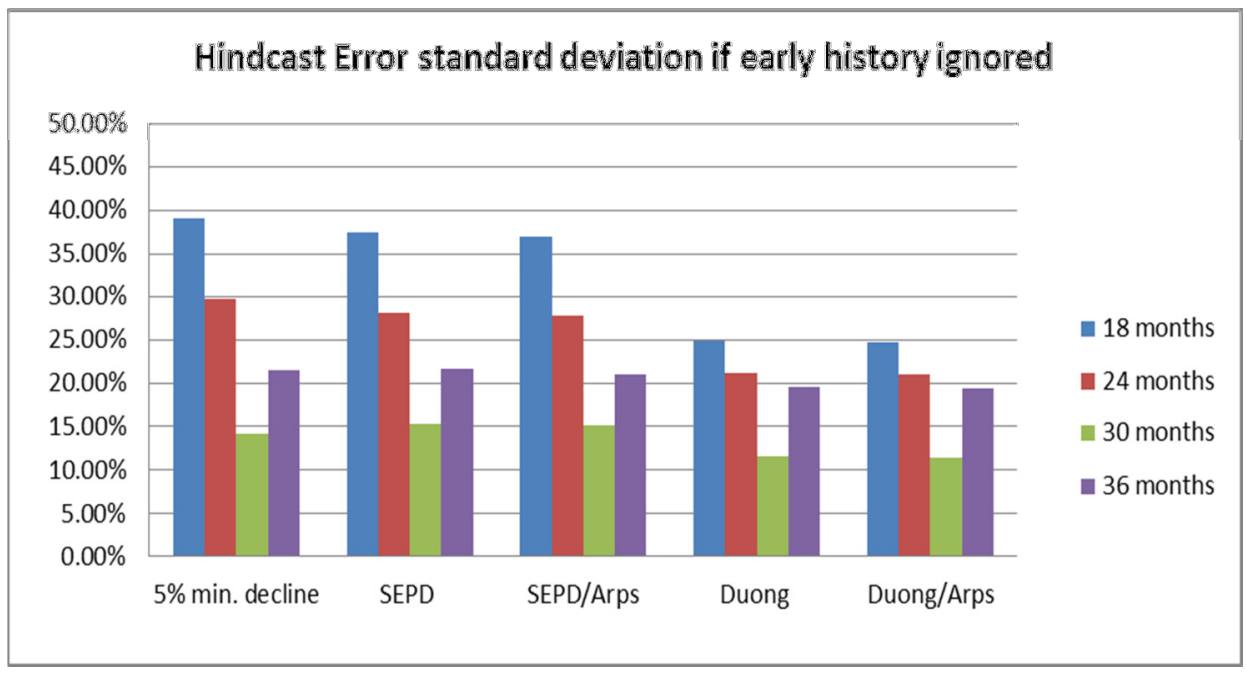

Figure 15: Standard deviation of hindcast error, ignoring first six months 


\subsubsection{Hindcasting with All Available Rate Data}

First I will discuss hindcasts with the first six months included in the fit, as in

Figure 16. The SEPD method is the most consistently accurate. However, the Duong and Duong/Arps methods are somewhat more accurate if 30 months of history is used in the fit. If only 18 months of history are used in the fit, the Duong method hindcast is $25 \%$ too high. The Arps method with 5\% terminal decline rate is the most inaccurate method except in the case of using 18 months of history for the fit. The Arps method and the stretched exponential method show a tendency to have too conservative a hindcast while the Duong method is too optimistic.

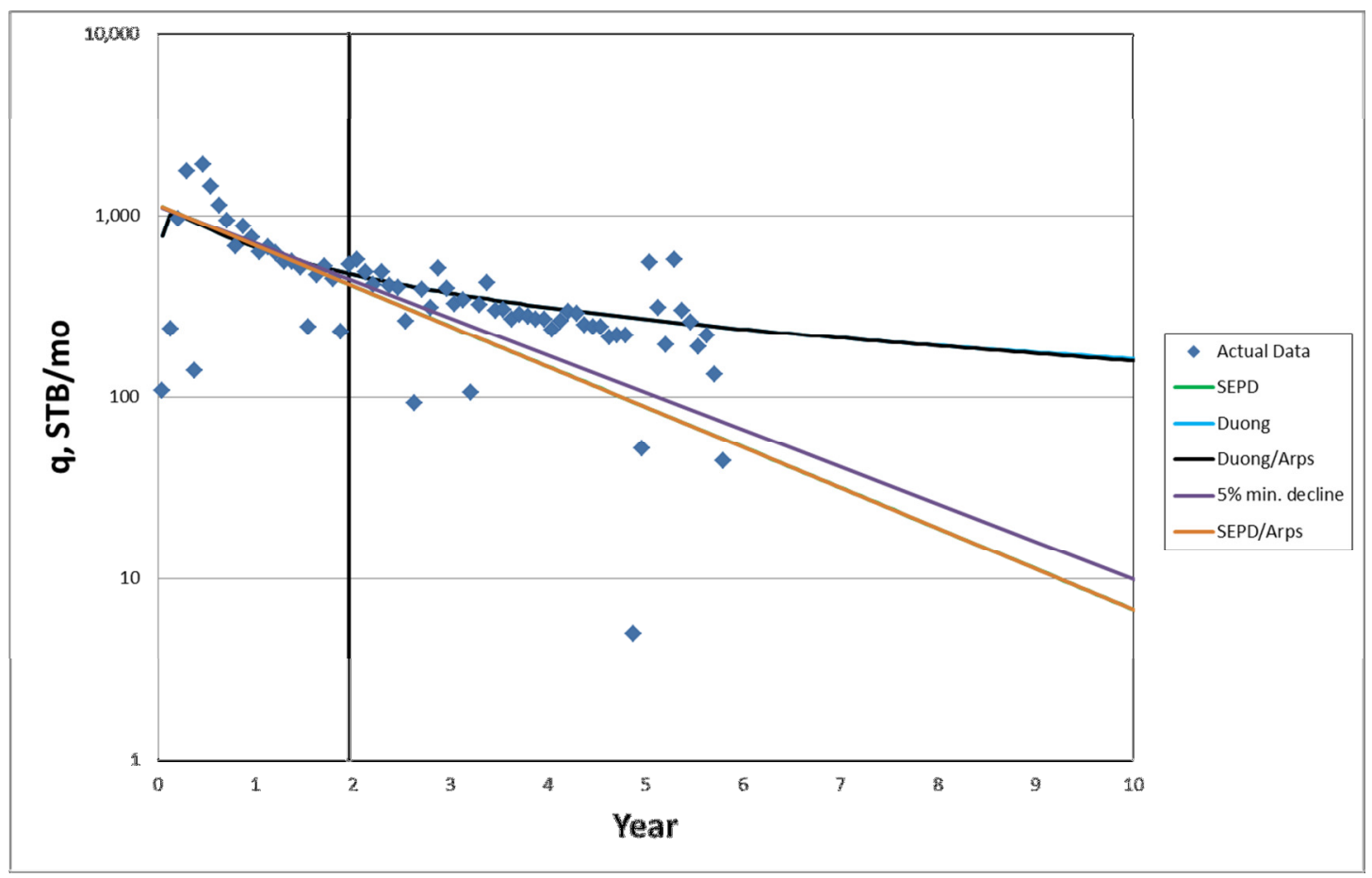

Figure 16: Sample Elm Coulee well, hindcast beginning after two years 


\subsubsection{Hindcasting without First Six Months}

Overall, I found that omitting the first six months of production history in a fit was beneficial, as in Figure 17. The most dramatic difference caused by omitting the first six months of production history may be seen in early forecasts (18 to 24 months) using the Duong method. Later forecasts using the Duong method show a much less noticeable effect when ignoring the first six months of data. With 36 months of production history available for the fit, omitting the first six months actually made the hindcast a little worse than including it.

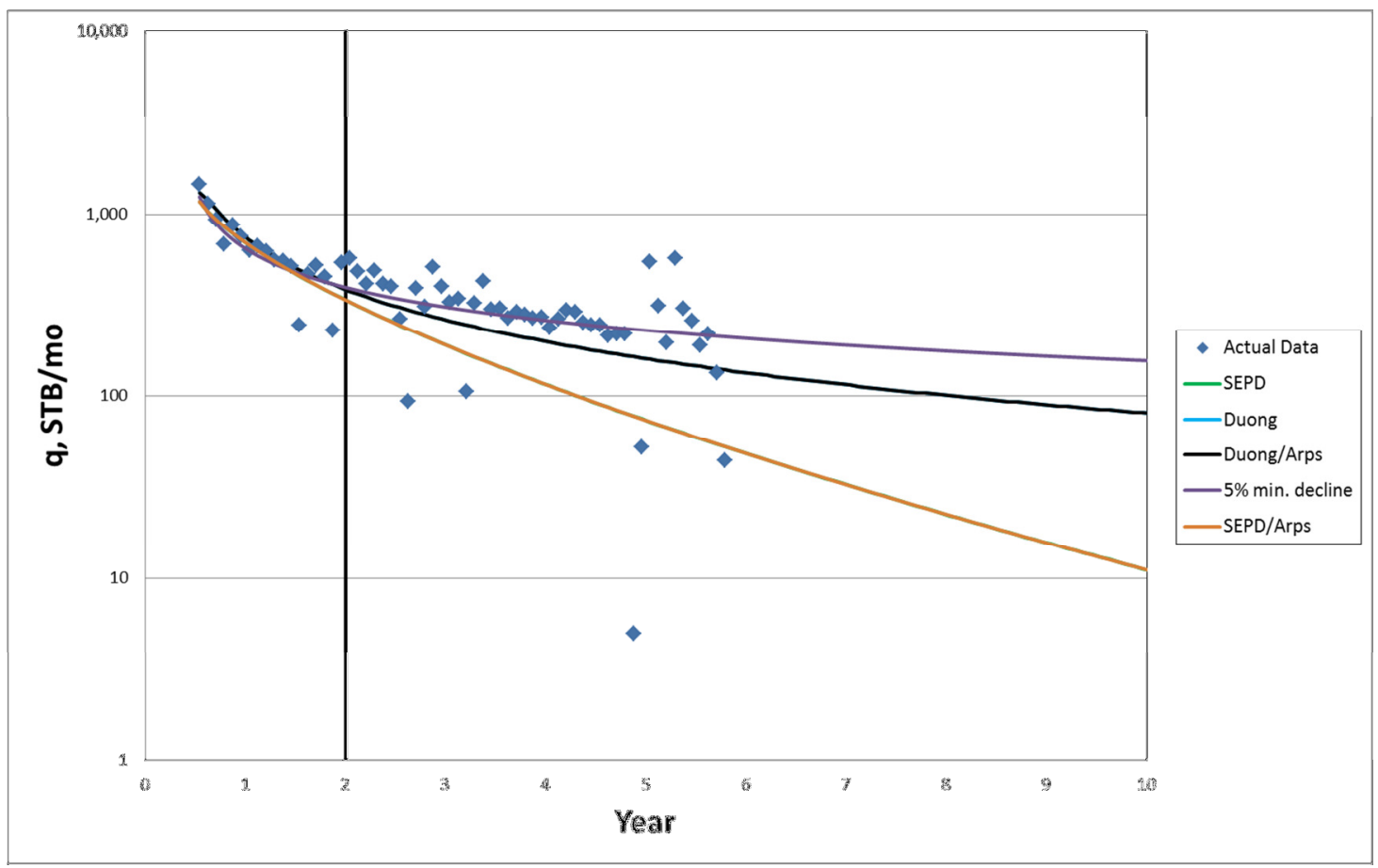

Figure 17: Sample Elm Coulee well, hindcast beginning after two years, first six months omitted 
The Arps method with 5\% minimum decline shows a dramatic increase in accuracy by omitting the first six months for all time periods studied, though not as much as the Duong method in early time. Without the first six months the SEPD and SEPD/Arps hindcasts improved in almost all cases shown, with one exception, but to a lesser extent than the other forecasting methods.

The most surprising part of this study is that the Arps method is the most accurate and most consistent method if the first six months of production history are omitted. The other methods increase in accuracy by omitting the first six months, but not nearly as much as the Arps method. This is consistent with the method proposed by Fekete (Nobakht et al. 2010). Unfortunately my study does a poor job of assessing the advantages and drawbacks of the SEPD/Arps and Duong/Arps methods. There is little difference between the original method and the modified method created to account for BDF. This occurred because decline rates generally have not yet fallen to $10 \%$ during known production history.

\subsection{Grouped Well Hindcasts}

I grouped production from all of the wells together and hindcasted on the data as if it were a single well. The grouped well hindcast errors are, with or without using the first six months of production history, are shown in Table 5 and Table 6 . I added up the 154 well production data out to 59 months, the length of the shortest well history in the set. This is an effective way of minimizing statistical and operational variation in wells that are expected to have similar production characteristics, based on completion type, 
geology, pay thickness, produced fluids, etc. If there are enough wells in the Elm Coulee field, then grouping them together should reduce statistical variation.

Since I am studying horizontal multi-fractured wells in the same formation, the wells should have similar decline trends throughout the play. Grouping the data creates a smooth curve that can be fit more reliably. There is a great amount of variation between wells, as has been seen, but there is less noticeable fluctuation between months of production.

Table 5: Elm Coulee grouped well hindcast, cumulative production error to the end of history

\begin{tabular}{|l|r|r|r|r|}
\hline \multicolumn{6}{|c|}{ Hindcast of Grouped wells (Error to end of history), include first six months } \\
\hline Forecast Methods & \multicolumn{5}{|c|}{ Time period used for hindcast } \\
\hline & 18 months & 24 months & 30 months & 36 months \\
\hline $5 \%$ min. decline & $-23.46 \%$ & $-12.30 \%$ & $-9.09 \%$ & $-5.37 \%$ \\
\hline SEPD & $-34.64 \%$ & $-6.68 \%$ & $-6.05 \%$ & $-2.57 \%$ \\
\hline SEPD/Arps & $-34.64 \%$ & $-6.68 \%$ & $-6.05 \%$ & $-2.57 \%$ \\
\hline Duong & $34.63 \%$ & $21.66 \%$ & $13.95 \%$ & $11.08 \%$ \\
\hline Duong/Arps & $34.63 \%$ & $21.66 \%$ & $13.95 \%$ & $11.08 \%$ \\
\hline
\end{tabular}

Table 6: Elm Coulee grouped well hindcast, cumulative production error to the end of history, first six months omitted

\begin{tabular}{|l|r|r|r|r|}
\hline \multicolumn{7}{|c|}{ Hindcast of Grouped wells (Error to end of history), ignore first six months } \\
\hline Forecast Methods & \multicolumn{3}{|c|}{ Time period used for hindcast } \\
\hline & 18 months & 24 months & 30 months & 36 months \\
\hline $5 \%$ min. decline & $8.90 \%$ & $9.00 \%$ & $5.51 \%$ & $6.26 \%$ \\
\hline SEPD & $5.90 \%$ & $0.87 \%$ & $-5.10 \%$ & $-1.50 \%$ \\
\hline SEPD/Arps & $5.90 \%$ & $0.87 \%$ & $-5.10 \%$ & $-1.50 \%$ \\
\hline Duong & $2.03 \%$ & $7.56 \%$ & $7.55 \%$ & $8.94 \%$ \\
\hline Duong/Arps & $2.03 \%$ & $7.56 \%$ & $7.55 \%$ & $8.94 \%$ \\
\hline
\end{tabular}


The grouped well hindcasts actually have more error than the average error for the individual well hindcasts. This may be caused by the great variation in decline trends between wells. For the group hindcast, the Arps model with 5\% minimum decline did not have the lowest error, contrary to what was found in the single well hindcast results. Assuming the first six months of history was omitted, the Duong method was the most accurate at 18 months of history and the SEPD method was the most accurate method after that time. Even with hindcasting the wells as one group, using first six months of production history in the hindcast introduced significantly more error than if it was ignored, illustrated in the differences between Figure 18 and Figure 19.

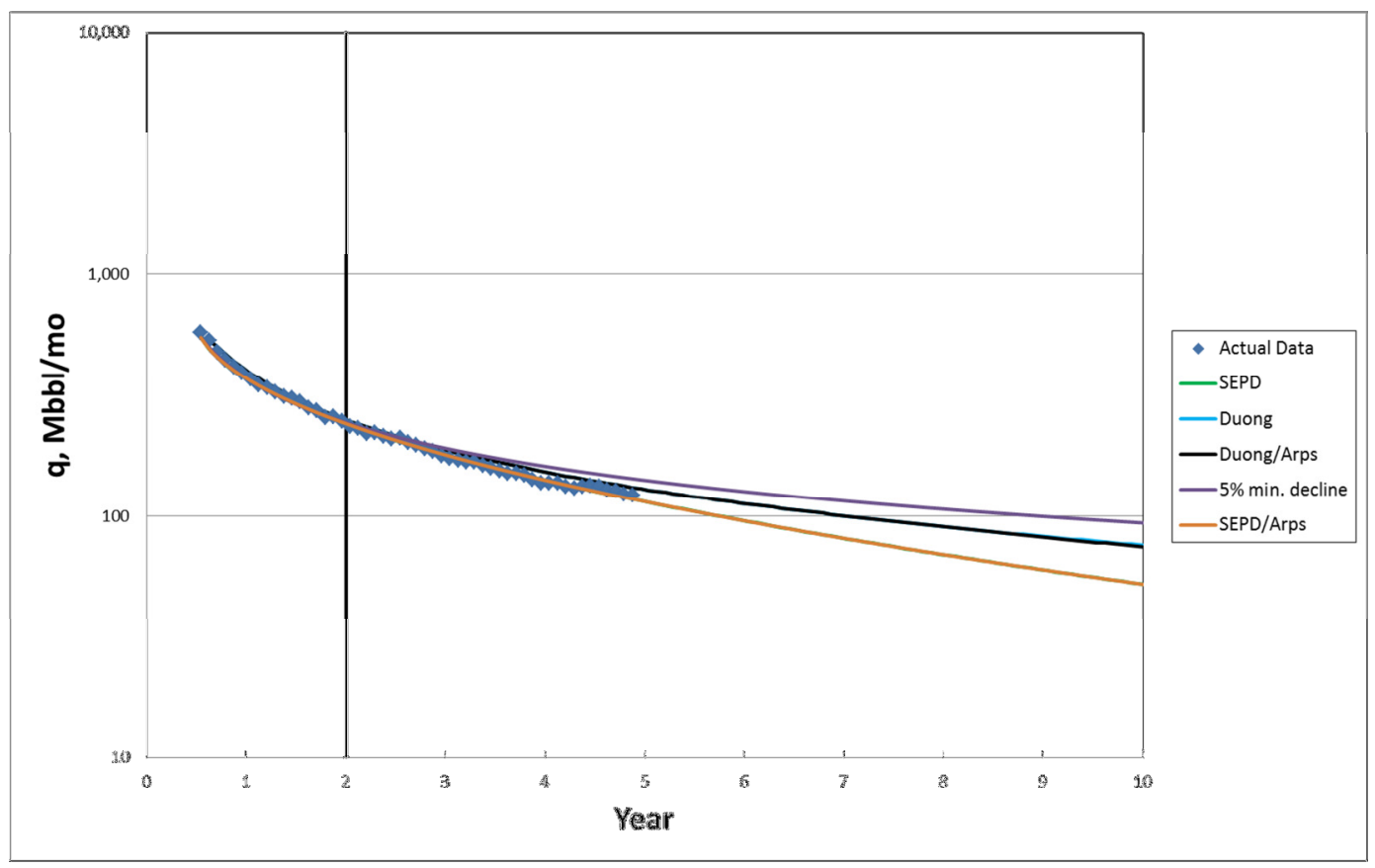

Figure 18: Elm Coulee grouped well hindcast after first two years, ignoring first six months of history 


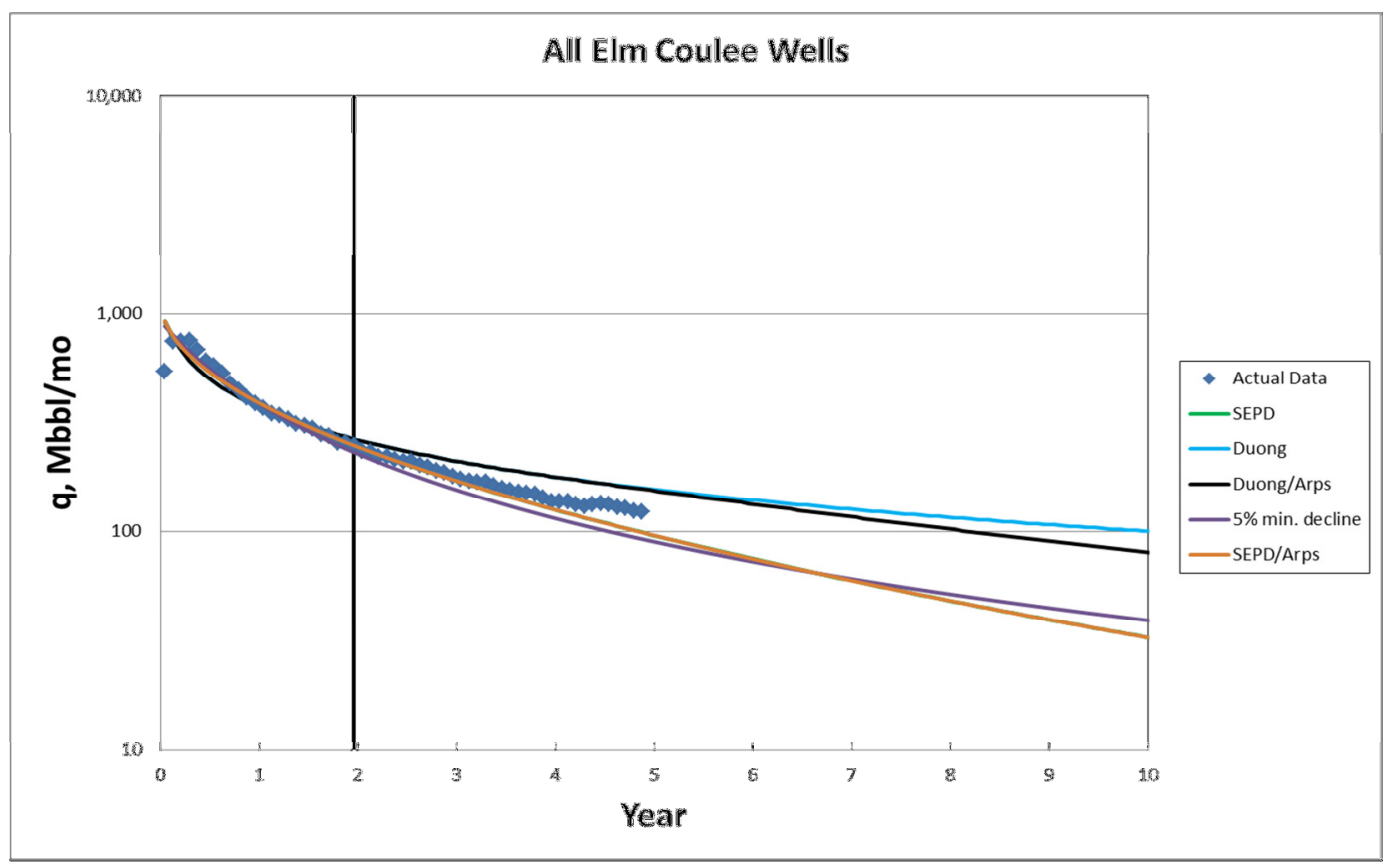

Figure 19: EIm Coulee grouped well hindcast after first two years 


\section{BOUNDARY-DOMINATED FLOW ANALYSIS}

While the previous hindcast study indicated how the decline curve methods may be applied to wells in transient flow, a study of wells in boundary-dominated flow is necessary in order to determine how well the SEPD/Arps and Duong/Arps methods work. Figure 20 shows production from lease Toni 2-17H, in the Elm Coulee field which I will use as an example.

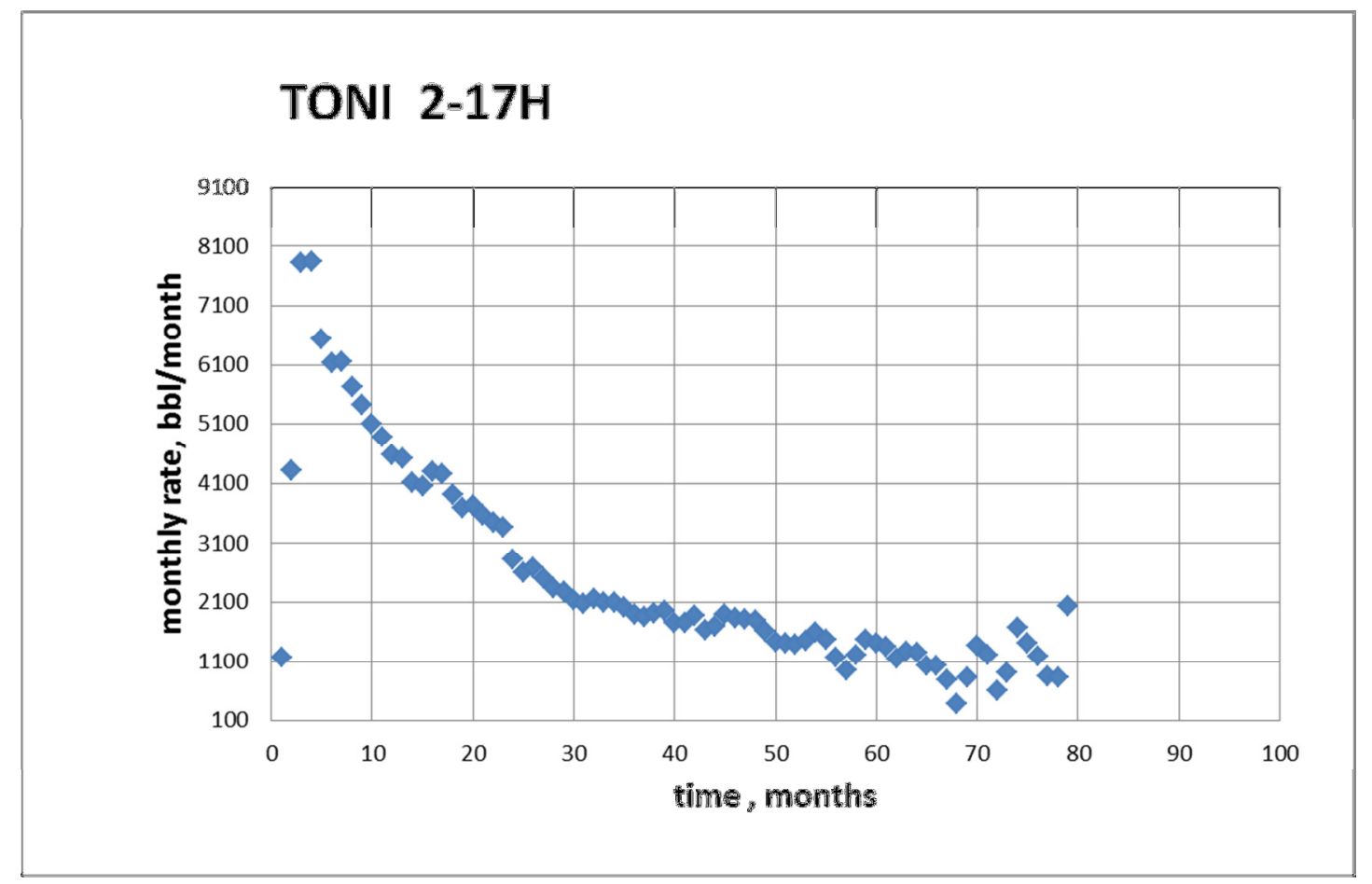

Figure 20: TONI 2-17H, Rate versus time 


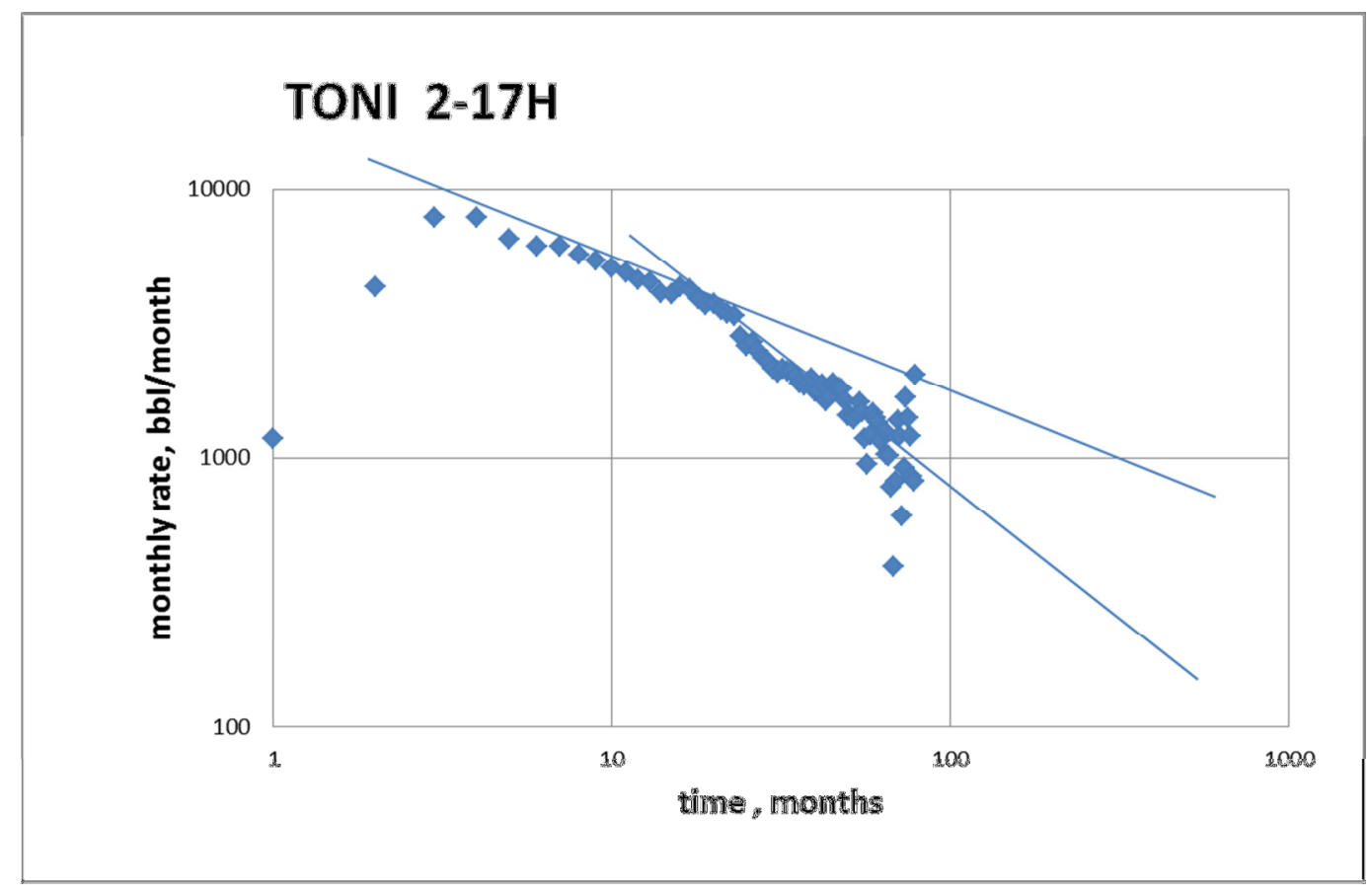

Figure 21: TONI 2-17H, Production rate versus time plot

Figure 21 shows log-oil flow-rate versus log-time. The change is evident from negative half-slope, indicating linear flow, to a negative unit slope of log-rate versus logtime, indicating boundary-dominated flow. It is unclear from this graph the exact time at which the change occurs. There is a significant amount of scatter at the end of the production history, above and below the expected trend. This obscures the trend somewhat. Since the production occurs both above and below the expected BDF trend, I have assumed that boundary flow has occurred despite possible well interventions at the end. 


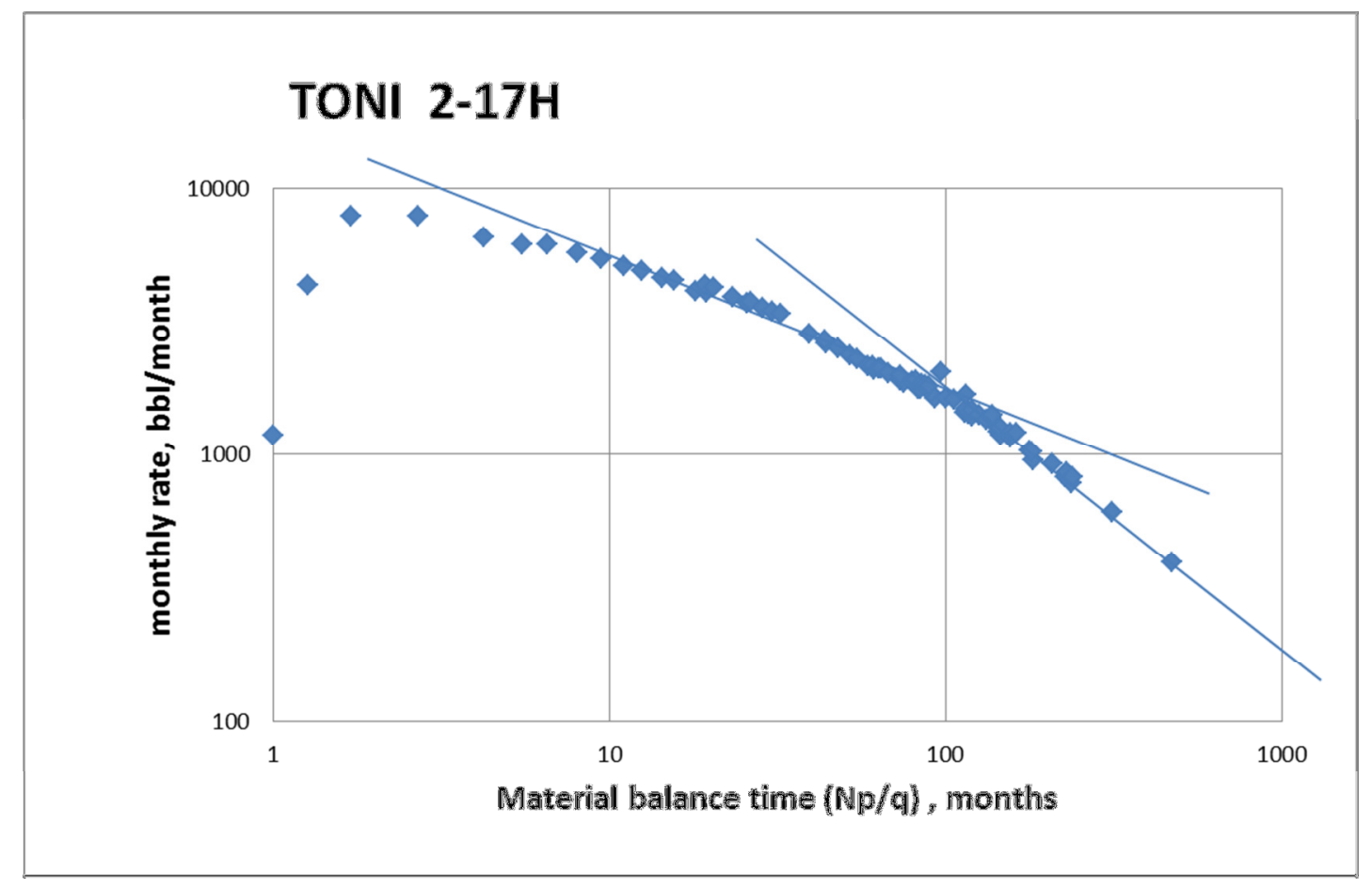

Figure 22: TONI 2-17H, Production rate versus material balance time diagnostic plot

The log-oil production rate versus material balance time plot in Figure 22 shows the onset of boundary-dominated flow occurring around $132 \mathrm{~Np} / \mathrm{q}$ months. This correlates to 61 months in actual time. This graph would be more accurate if bottomhole pressure data were available to change rate into pressure-normalized rate.

Another example well, FOGHORN-ERVIN 20-3-HLID3 (Figure 23, Figure 24, and Figure 25), a switch to boundary-dominated flow is seen. Boundary-dominated flow is seen after 136 material balance time months, or about 55 actual months. 


\section{FOGHORN-ERVIN 20-3-HLID3}

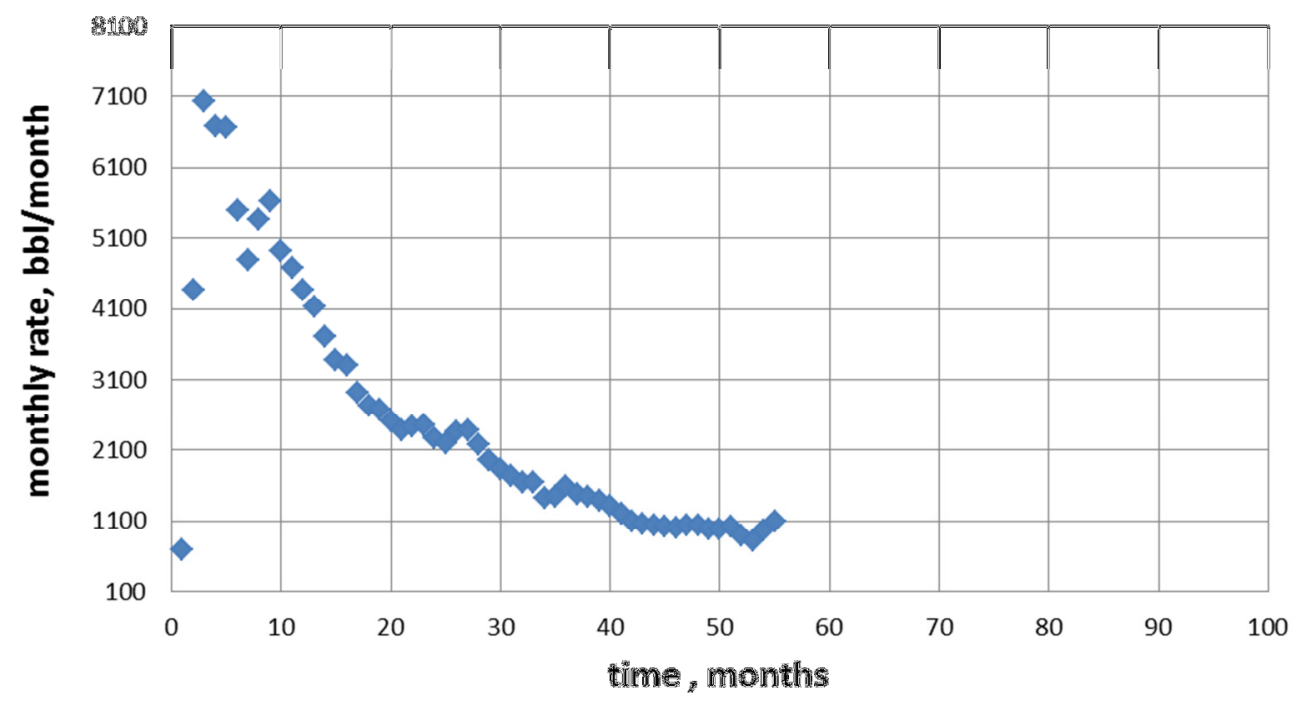

Figure 23: FOGHORN-ERVIN 20-3-HLID3, Rate versus time

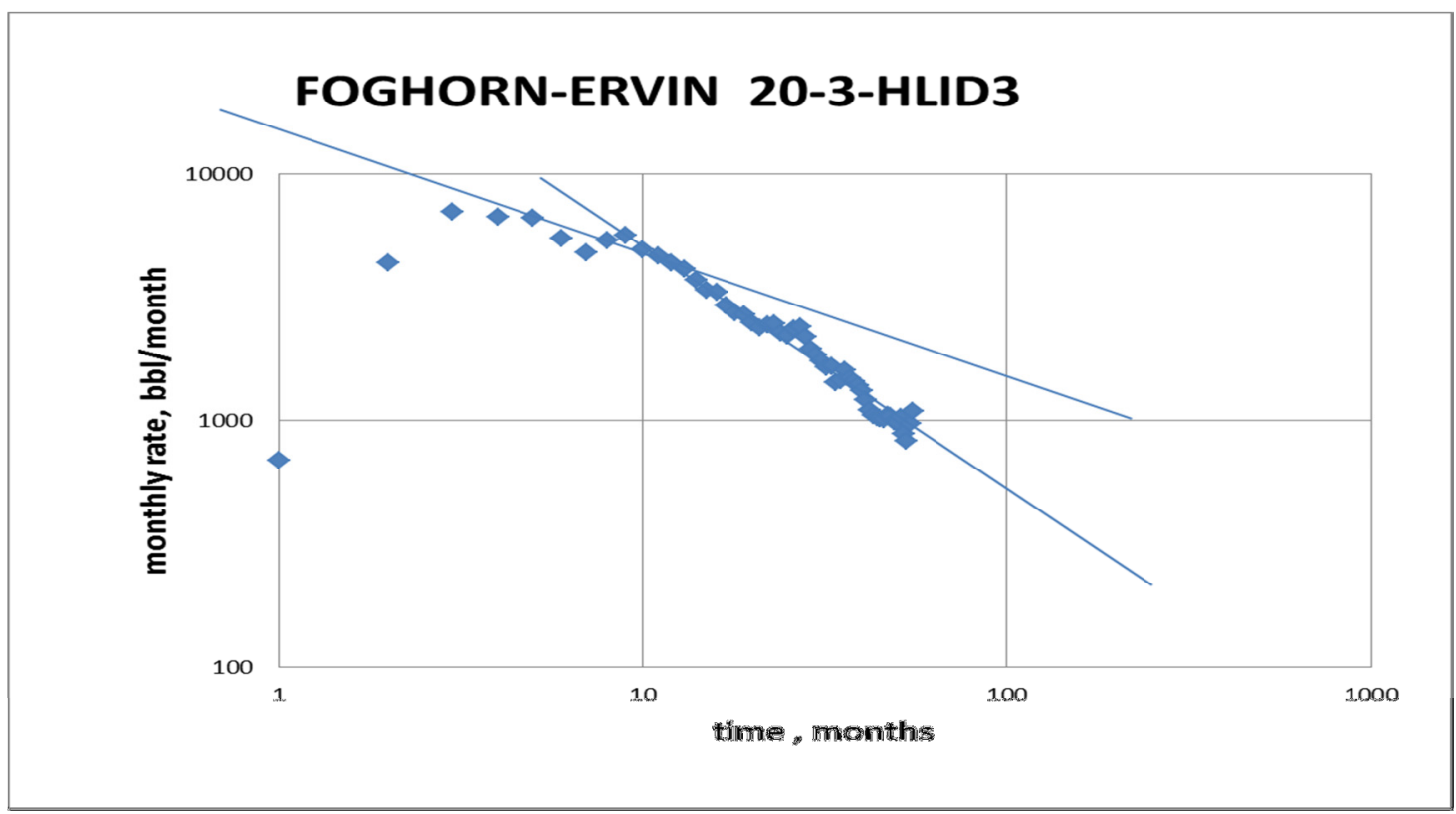

Figure 24: FOGHORN-ERVIN 20-3-HLID3, Production rate versus time plot 


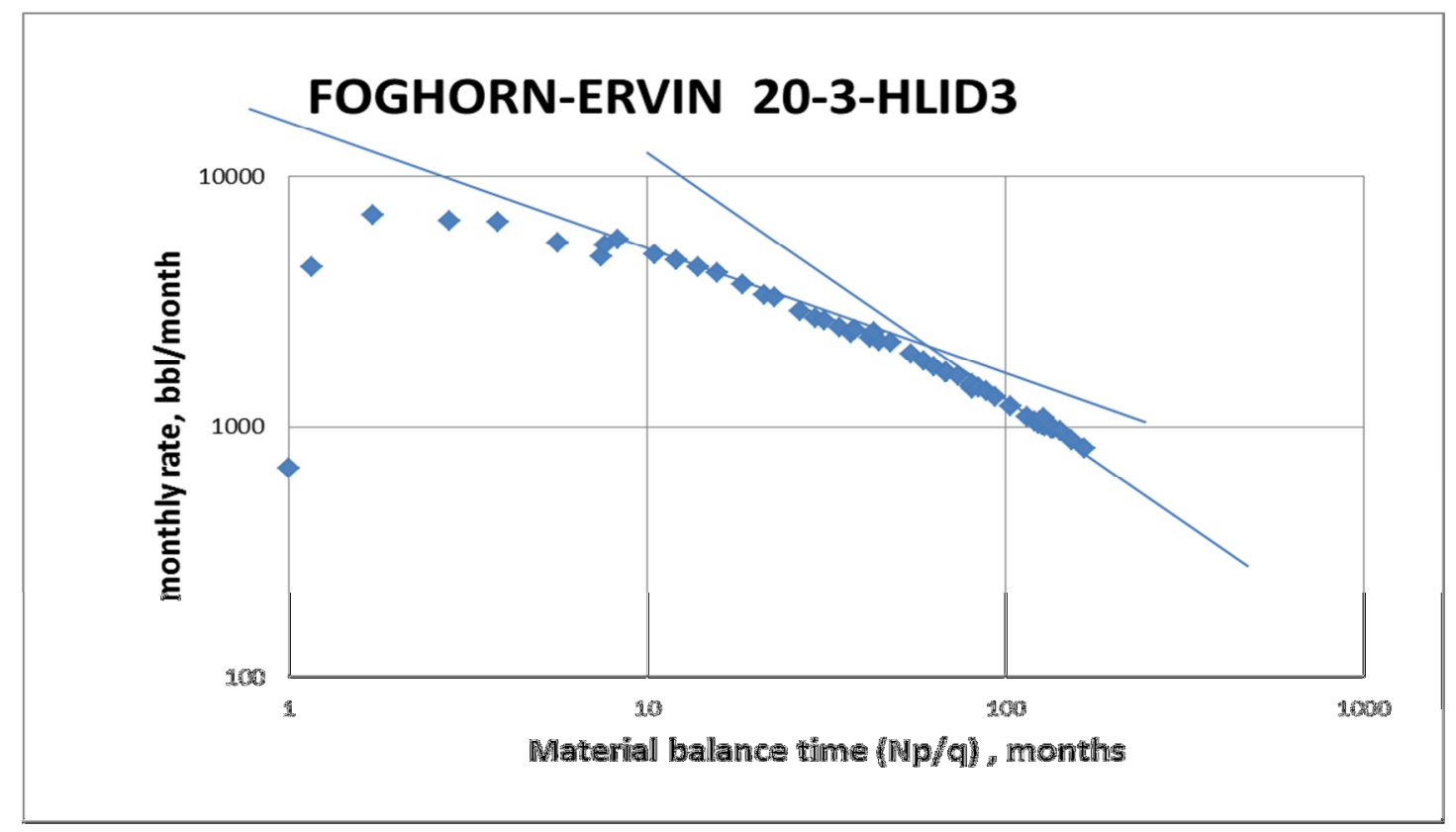

Figure 25: FOGHORN-ERVIN 20-3-HLID3, Production rate versus material balance time diagnostic plot

Hindcasting with two years of data, the Duong method overestimates production while the terminal decline method underestimates it. The SEPD method gives the closest hindcast. This is true whether the first six months are included or not. Ignoring the first six months slightly increases the accuracy of the Duong method and slightly increases the error in the terminal decline model as shown in Figure 26 and Figure 27. 


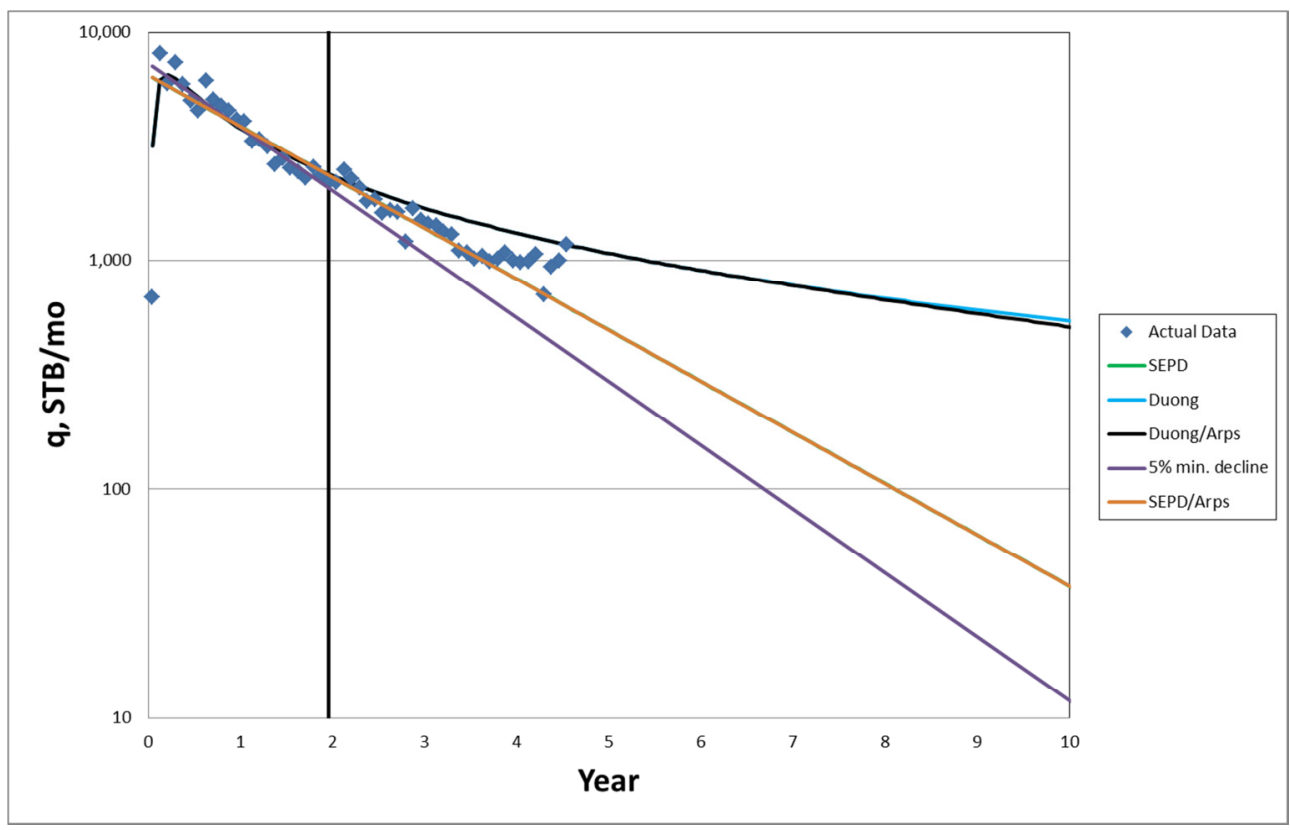

Figure 26: Elm Coulee well example hindcast after two years of history

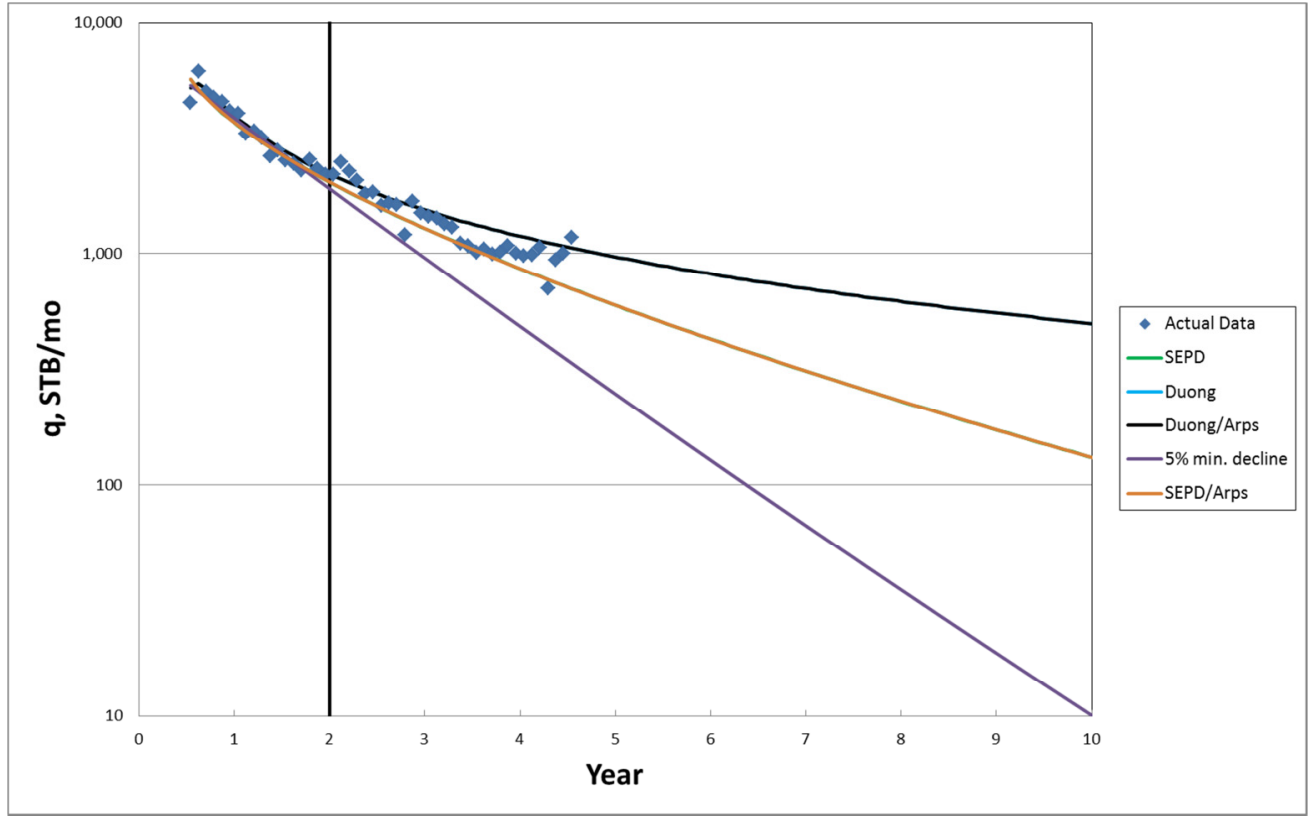

Figure 27: Elm Coulee well example hindcast after two years, ignoring first six months of history 
The lack of erratically changing flow rates make the first six months of data less crucial to the forecast than many other wells in the Elm Coulee. From these graphs we see that the correction in the 10 year production rate forecast is very minor.

Using a 10\% decline rate to predict boundary-dominated flow, as discussed earlier, predicts boundary-dominated flow very late in the life of the well. In Figure 28 I changed this assumption to base BDF onset on the log-rate versus material balance time diagnostic plot, setting BDF at around 55 months. This moves up the transition in the modified Duong and SEPD methods, again with b-value of 0.3 for SEPD/Arps and Duong/Arps after two years. This appears to increase the accuracy of the Duong method, with little change to the SEPD method.

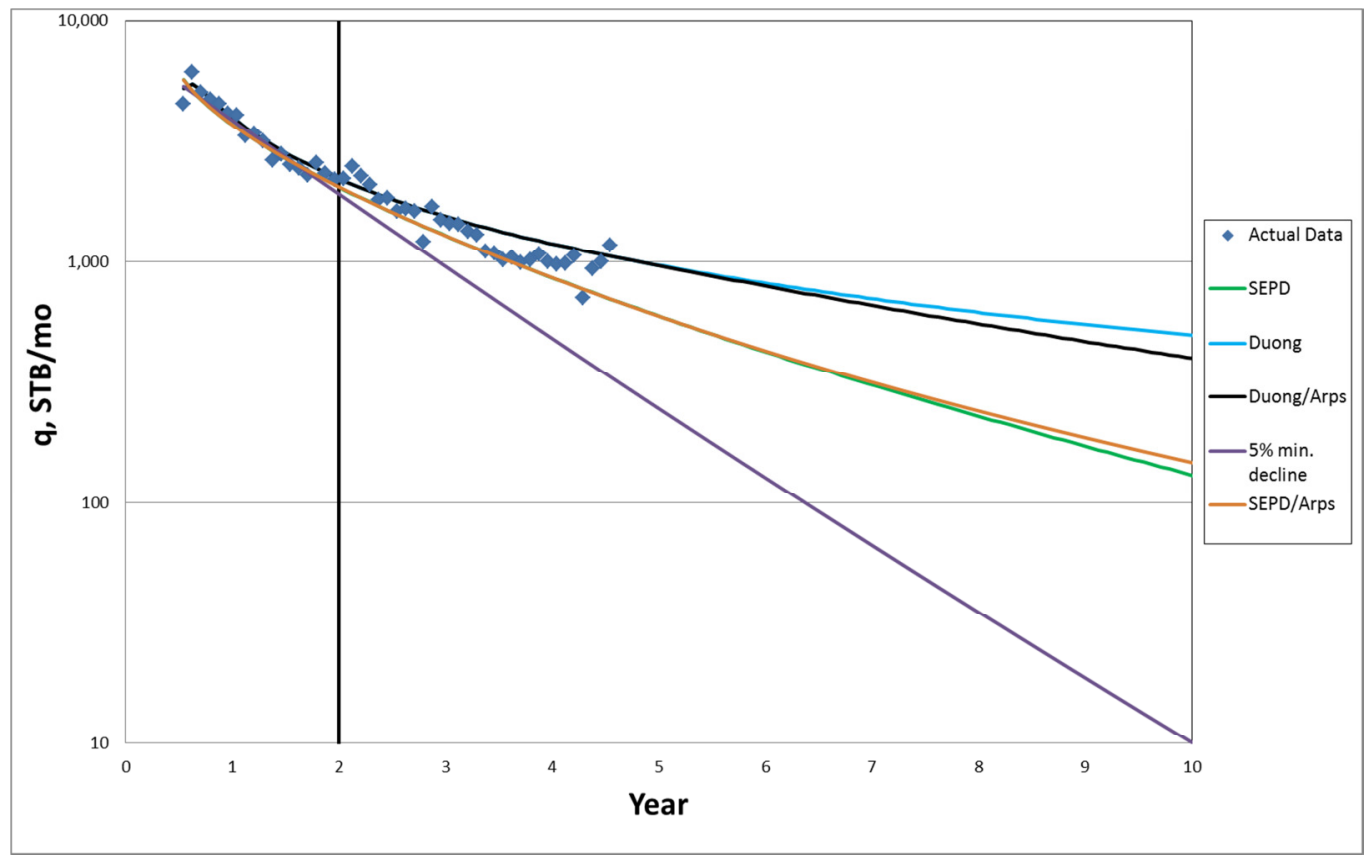

Figure 28: Elm Coulee well example hindcast after two years, ignoring first six months of history, BDF onset at 55 months 


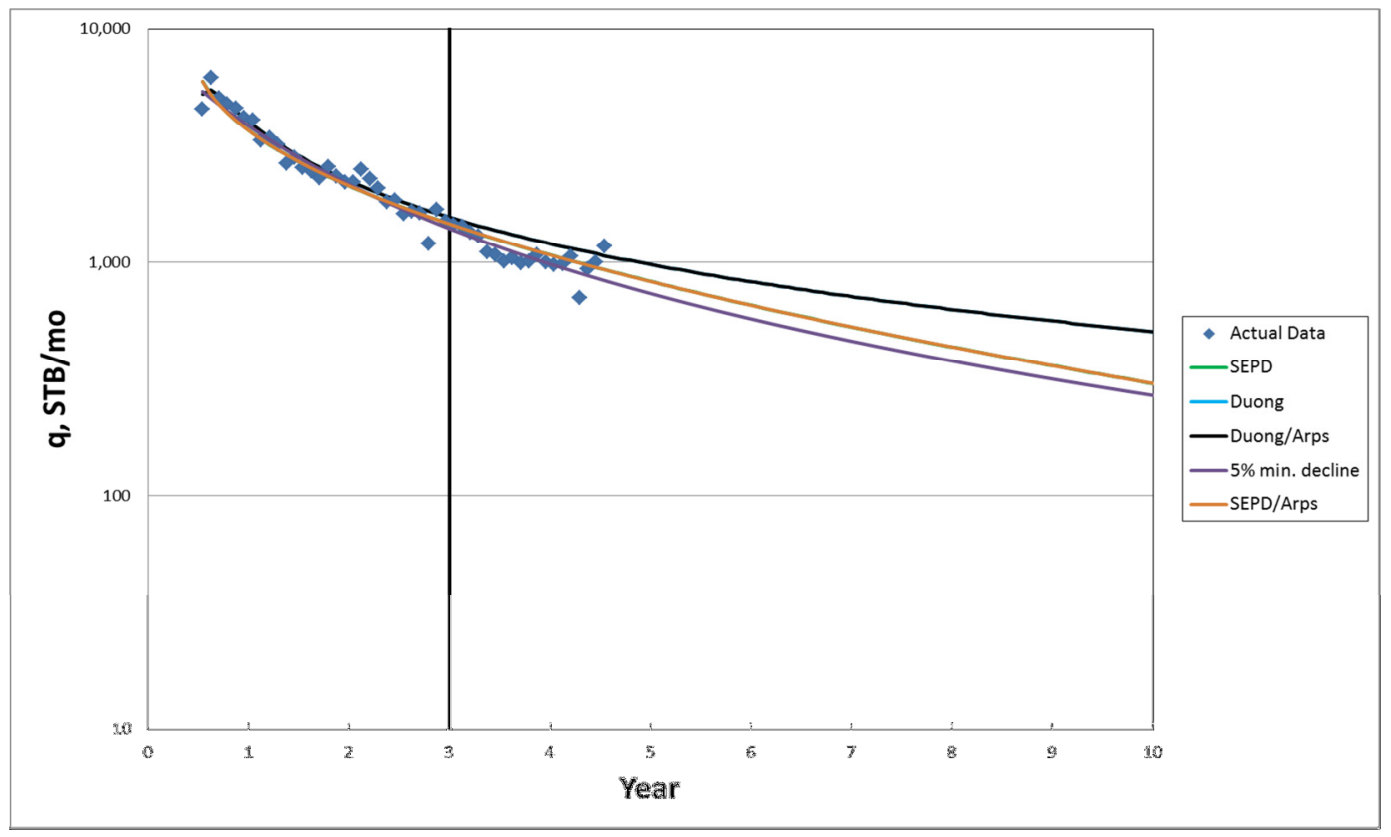

Figure 29: Elm Coulee well example hindcast after three years, ignoring first six months of history

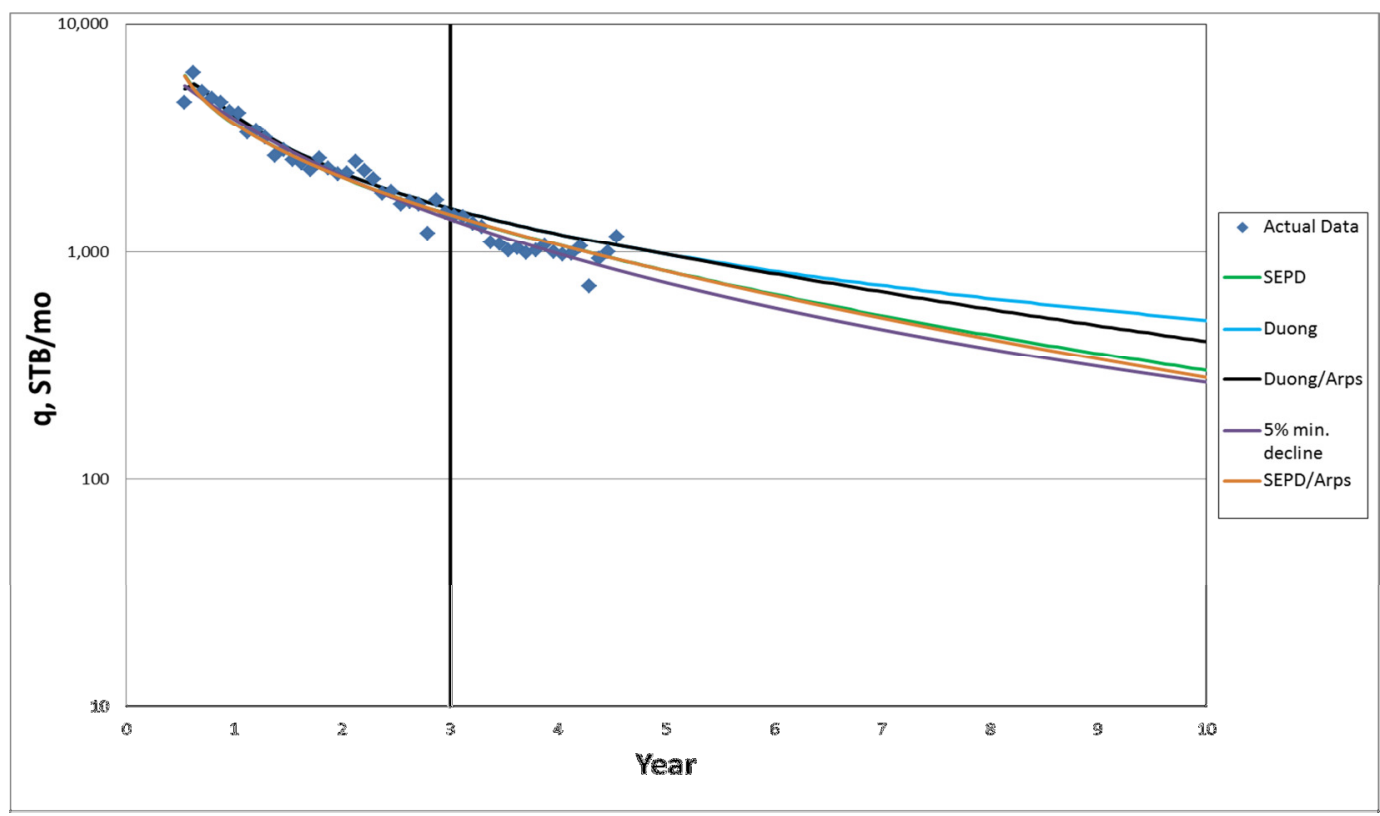

Figure 30: Elm Coulee well example hindcast after three years, ignoring first six months, BDF onset at 55 months 
Figure 27 shows the forecast without the predetermined BDF onset and Figure 28 shows BDF assumed to start at 55 months. Both the SEPD/Arps and the Duong/Arps create hindcasts that improve on the accuracy of the SEPD or the Duong methods. Figure 29 and Figure 30 similarly show BDF onset 10\% decline and 55 months respectively, but begin the hindcast after 3 years.

We can postulate that rather than setting a decline rate at which to set the beginning of boundary-dominated flow, it would be better to have an estimate of when boundary-dominated flow should occur based on reservoir and well properties, as explained by Nobakht, et al, (2010). While these properties were not available for most wells in this study, operating companies should have access to this data for their own wells and be able to use it rather than relying on decline rates to predict the start of boundary-dominated flow.

\subsection{Study of Boundary-Dominated Flow Onset in Elm Coulee Field}

I performed a further analysis on all of the wells used in the previous study of the Elm Coulee field. While there was little difference between the hindcasts that accounted for the switch to boundary-dominated flow (BDF) and those that did not, we should expect this difference to increase later in the life of the wells.

I found that 65 of the 154 wells appear to have reached BDF by the end of known production history. In order to diagnose BDF I used a log-production versus log-material balance time plot for each well. Material balance time is calculated as cumulative 
production divided by production rate $\left(\mathrm{N}_{\mathrm{p}} / \mathrm{q}\right)$. A negative half slope is indicative of linear flow, while a negative unit slope is indicative of BDF, as shown in Figure 31.

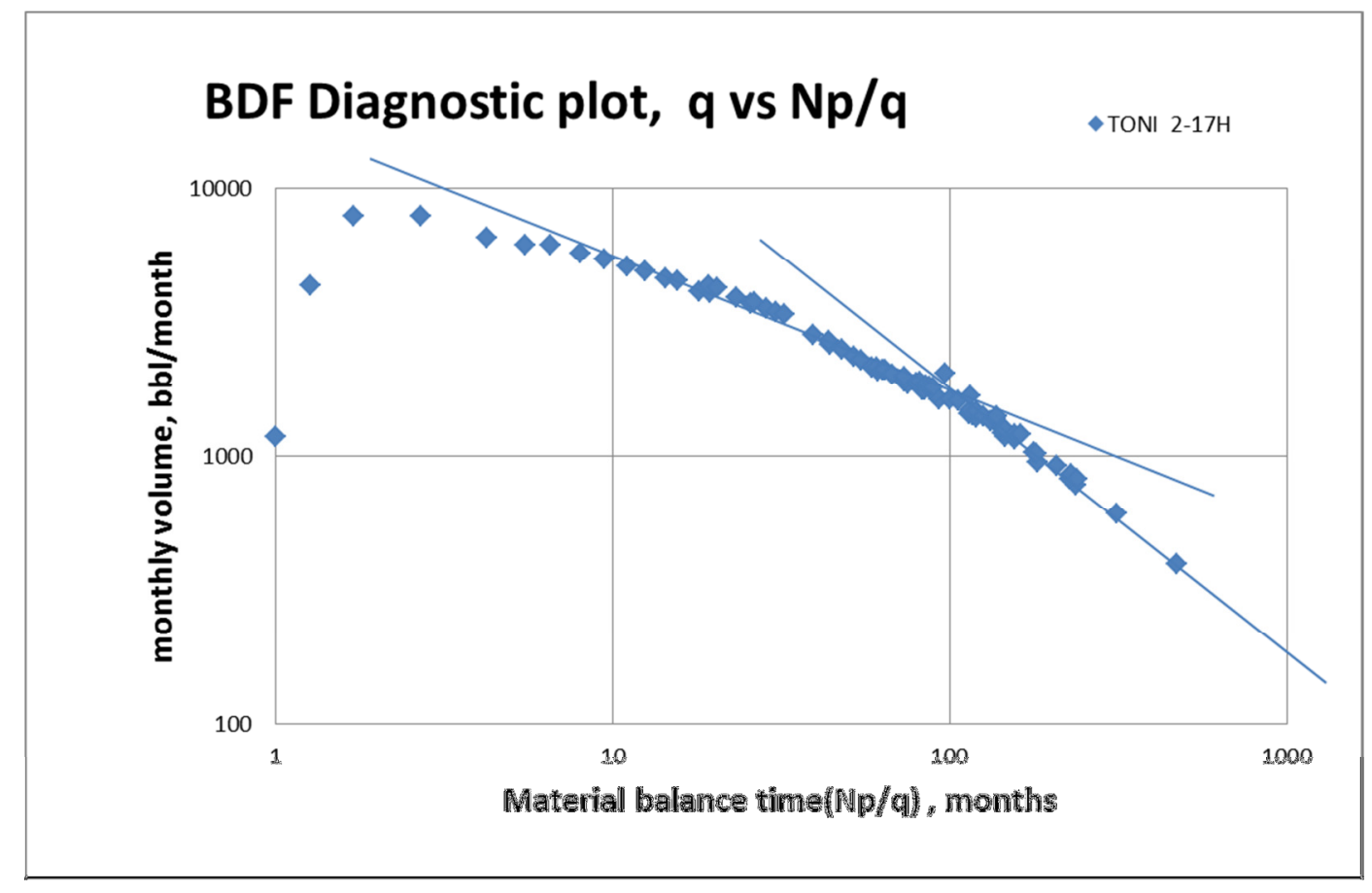

Figure 31: Production rate versus material balance time diagnostic plot

In order to smooth the production data for my assessment I fit an Arps curve to the production data using an Excel Solver. I omitted the first six months of production data, as I had found that this increased the accuracy of hindcasts. For this exercise it is not important for the decline curve to model BDF, but should give a more accurate fit since the trend will mostly be in linear flow until the time BDF begins. Not surprisingly, the Arps decline model in the Figure 32 does not fit the very early or late data properly. The fit has a b-value of about 0.6 . 


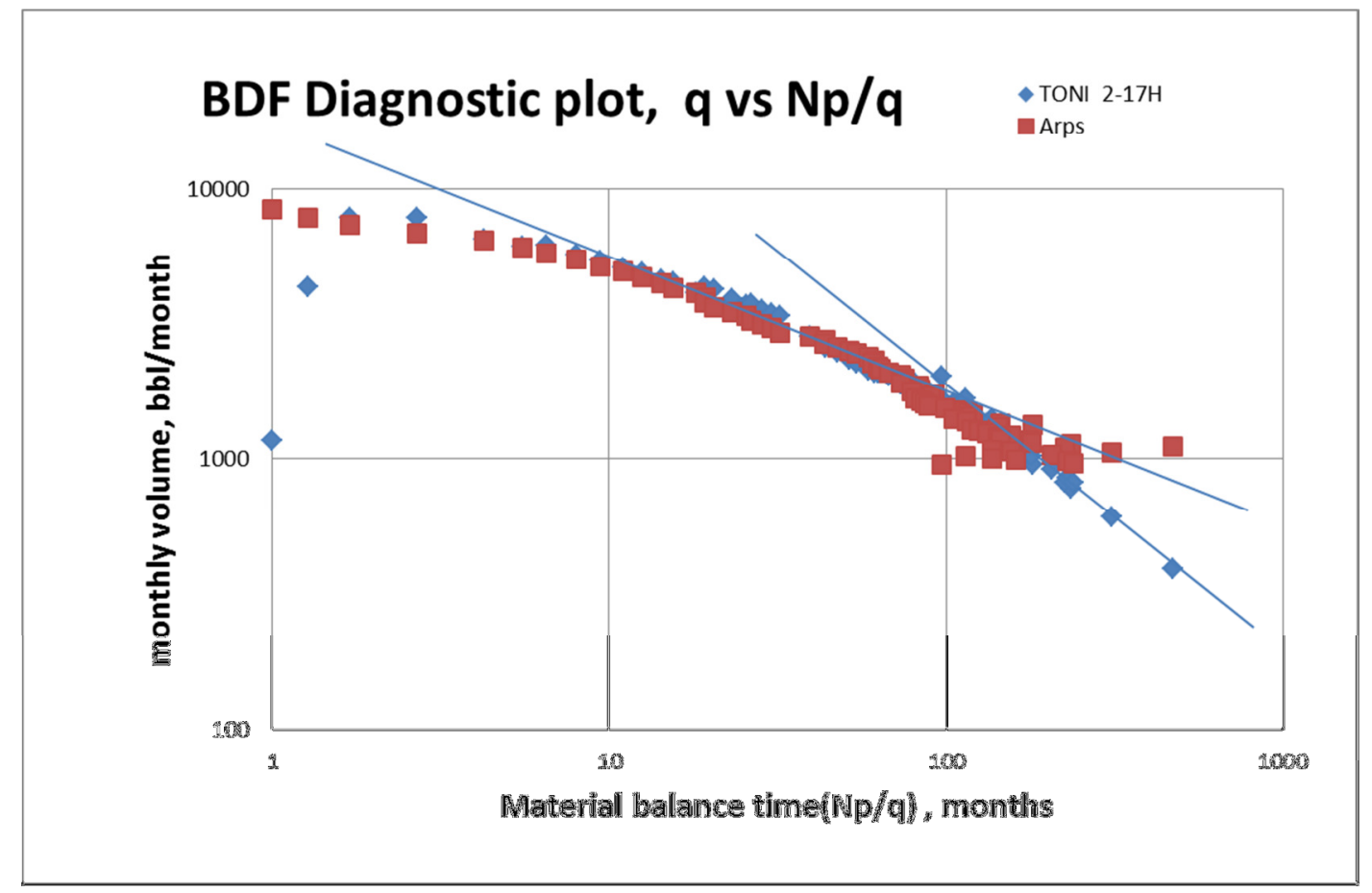

Figure 32: Production rate versus material balance time diagnostic plot, fitted with Arps decline model

In many cases the onset of BDF may be seen clearly by visual inspection with a unit slope line. To create a more consistent analysis I fit an Arps curve to the production data, ignoring the first six months; I calculated the slope of the log-production versus log-material balance time at each time, from that point until the end of the production history, including all points in between. At the onset of BDF the log-log slope of all the following production data points should be approximately equal to -1. Using this criteria, I picked the point at which the calculated slope to the end of production was began to be consistently near -1 as the onset of boundary-dominated flow. In addition, boundarydominated flow onset was assumed only if $1 / 3$ of a log-cycle of the well history showed 
a slope near -1 . For this study I considered slopes of between -0.9 and -1.1 to be "near" boundary-dominated flow. Since there is constant fluctuation in the production rate it is necessary to establish an interval during which boundary-dominated flow is likely.

The results of this study, shown in Table 7, showed 65 wells in boundarydominated flow. The wells produced for an average of 71.2 months and boundarydominated flow occurred at about 57.2 months, approximately a year before the end of production. The time at which $10 \%$ decline was predicted to occur, according to the decline curve fit, was after an average of 146.6 months, significantly later than shown by these wells. The actual decline rate at BDF onset averaged $22 \%$.

Table 7: Summary of diagnostic plots

\begin{tabular}{|l|r|}
\hline & Averages \\
\hline Number of wells in BDF & 65 \\
\hline Total Well History, months & 71.2 \\
\hline BDF Onset, months & 57.2 \\
\hline BDF Onset, MBT months & 169.8 \\
\hline $10 \%$ Decline Time, months & 146.6 \\
\hline Decline Rate @ BDF, \% & $22 \%$ \\
\hline
\end{tabular}

The $22 \%$ decline rate at BDF onset is much higher than the $10 \%$ that was assumed for the hindcast study. The histogram below, Figure 33, shows that the most common decline rate for BDF onset was between $15 \%$ and $20 \%$. There are several outliers that entered BDF at continuous decline rates of up to $46 \%$ per year. 


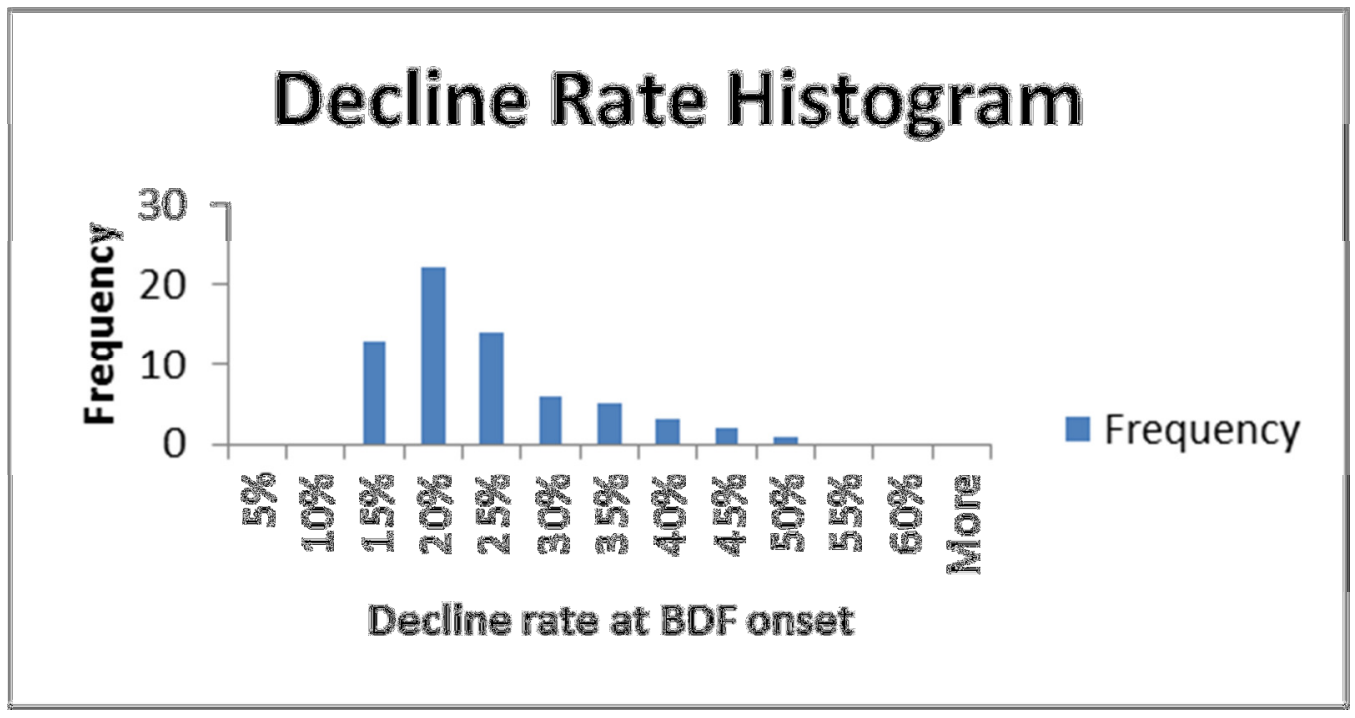

Figure 33: Histogram of decline rates at boundary-dominated flow onset

While this study should give an estimate of what might be expected in this field, there are a few things that should be kept in mind. As discussed earlier, the diagnostic plots would be more accurate if pressure normalized rate was used instead of rate. Since pressure values were not available in the public data I have used the assumption that pressure will be relatively stable after six months and certainly by the time that the wells enter boundary-dominated flow.

Another thing that should be kept in mind there are 89 wells that were not included in the study because there was insufficient evidence for the well being in boundary-dominated flow. Since these wells do not yet exhibit boundary-dominated flow and on average will show boundary-dominated flow after a longer period of transient than the other wells, they will likely have a lower decline rate once in BDF than 
those reported above. In other words, I have studied wells that have anomalously early transitions to BDF have been reported on, while those with late transitions to $\mathrm{BDF}$ cannot be averaged in BDF yet.

The other 89 wells may be included in this study tentatively by assuming that the last known month of production is the earliest that BDF may begin, since it has not been demonstrated to exist prior to this period. I included these wells in the study by assuming that BDF began at the last month of production, though this is likely earlier than the actual onset of BDF. The result of including these wells was surprising. Summarized in Table 8 , the new average amended-BDF onset was calculated to be 65.2 months, 8 months later than the earlier estimate. The average decline rate at amended-BDF onset is $17 \%$, significantly lower than what was previously reported. Another interesting change was that the $10 \%$ decline rate was achieved by the wells at an average of 130.9 months, compared to 146.6 months for wells confirmed to be in boundary-dominated flow.

Table 8: Summary of diagnostic plots, BDF assumed at end of history if not present in data

\begin{tabular}{|l|r|}
\hline & Averages \\
\hline Number of Wells & 154 \\
\hline Total Well History, months & 71.1 \\
\hline BDF Onset, months & 65.2 \\
\hline BDF Onset, MBT months & 169.3 \\
\hline 10\% Decline Time, months & 130.9 \\
\hline Decline Rate @ BDF, \% & $17 \%$ \\
\hline
\end{tabular}




\section{Decline Rate Histogram}

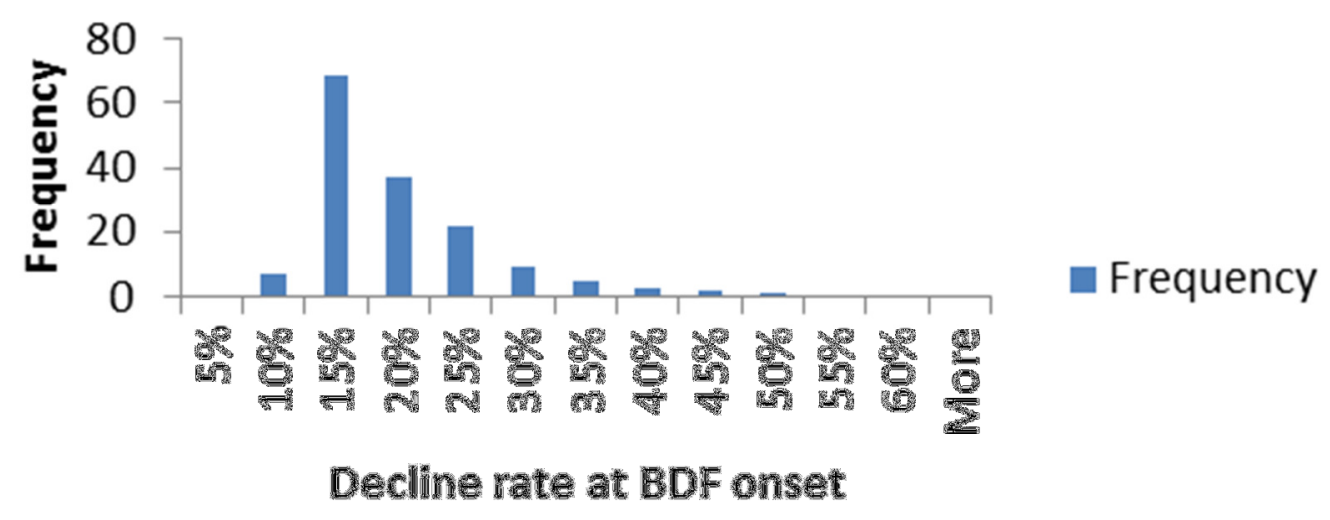

Figure 34: Histogram of decline rates at boundary-dominated flow onset, amended study

While it is preferable to estimate the time when boundary-dominated flow begins from reservoir data, using a switch at a certain decline rate can give an estimate of when this might occur. This will be important for economic considerations early in the development of a field. When there is high uncertainty in ultimate recovery it may be adequate to ask what is reasonable rather than what is expected. Figure 34 shows that assuming decline rate at BDF will has a very wide range. It may be helpful to quantify uncertainty for BDF onset to deal with the wide range of possible outcomes. 


\subsection{Unexpected Deviations from Linear Flow}

This study has assumed that the linear flow trend ends at the time that fracture interference begins. Another cause of boundary-dominated flow onset could occur in wells drilled near a fault or pinchout. In this case the radius of investigation from the

fracture may reach the boundary before the flow from different fractures interfere with each other. These cases should be rare, but may skew assumptions of when fracture interference will occur.

Another cause for a unit slope to appear on the material balance time plot is a malfunction of the production equipment. This will cause a sharp deviation from the assumed linear flow trend. This lowered rate will appear to be boundary-dominated flow, creating a false assumption of fracture interference or a nearby boundary.

\subsection{Elm Coulee Geology}

The Elm Coulee field is considered a "sweet spot" of the Bakken formation. The formation is very productive in spite of the Middle Bakken being thinner in this region. The productivity is due to increased permeability (an order of magnitude higher than the rest of the Middle Bakken). There is also a greater frequency of natural fracturing than most other parts of the Bakken formation.

The most production comes from the slightly overpressured Middle Bakken, which is $15-20$ feet thick. Depth ranges from around 8,500 feet in the northwest to 10,500 feet in the southwest (Walker, et al). Average porosity is about $9 \%$ and permeability averages about 0.05 to 0.1 millidarcies. Reserves are estimated to be on the 
order of 500,000 barrels per horizontal well, or about 270 million barrels in the field (Walker et al. 2006).

The reservoir has undergone many diagenetic changes that enhanced porosity and permeability. Early dolomitization was followed by de-dolomitization and later burial related dolomitization. These changes led a dolomite rich rock with the creation of secondary porosity in the form of slot pores due to dolomite dissolution. Dolomite dissolution was caused by the organic acids expelled by the upper and lower shale layers.

Vertical fractures are related to salt dissolution followed by sediment collapse, reactivated basement faults, or sediment dewatering. Horizontal faults were created by expulsion of hydrocarbons into the Middle Bakken (Alexandre et al. 2012).

Vertical wells in this area are not very productive. Horizontal wells gather from the thin productive zone with the help of fracture stimulation and localized natural fractures. Some production comes from the upper and lower Bakken formations, but due to the very low permeability of these shales production is dominated by the Middle Bakken.

The Elm Coulee field occurs at the southwest edge where the Bakken pinches out. The Lower Bakken thins out first (northernmost), followed by the Middle Bakken and then Upper Bakken. There is evidence that this area on the southwest of the Bakken was created by shoaling in a higher energy depositional environment (Borglum and Todd 2012). 
The Brockton-Froid NE/SW left lateral strike system is present in the northern portion of the Elm Coulee field. There are also NW/SE aligned faults that appear to have occurred earlier than the strike slip system (Honsberger, 2013). These faults may result in baffles that compartmentalize production.

Wells near the fault zone or the pinchout may experience boundary-dominated flow earlier than otherwise predicted by well or fracture spacing.

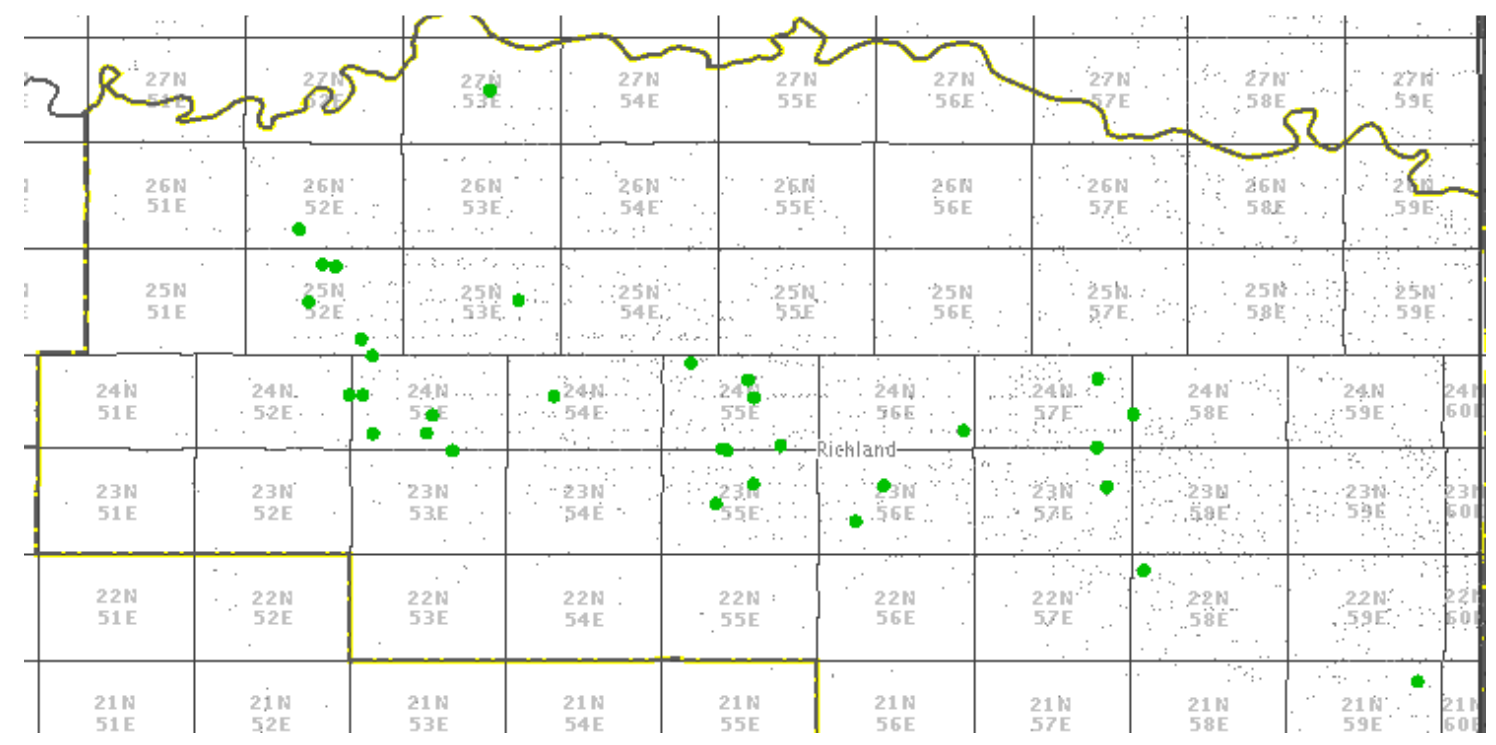

Figure 35: Map of Elm Coulee wells studied with high decline rate at BDF onset

Figure 35 shows wells with greater than $20 \%$ decline rate at boundary-dominated flow shows that early decline is spread throughout the system, though perhaps more concentrated in the northwest corner of Richland county near the Brockton-Froid left lateral strike system. Figure 36, a map of all the wells examined in this study. 


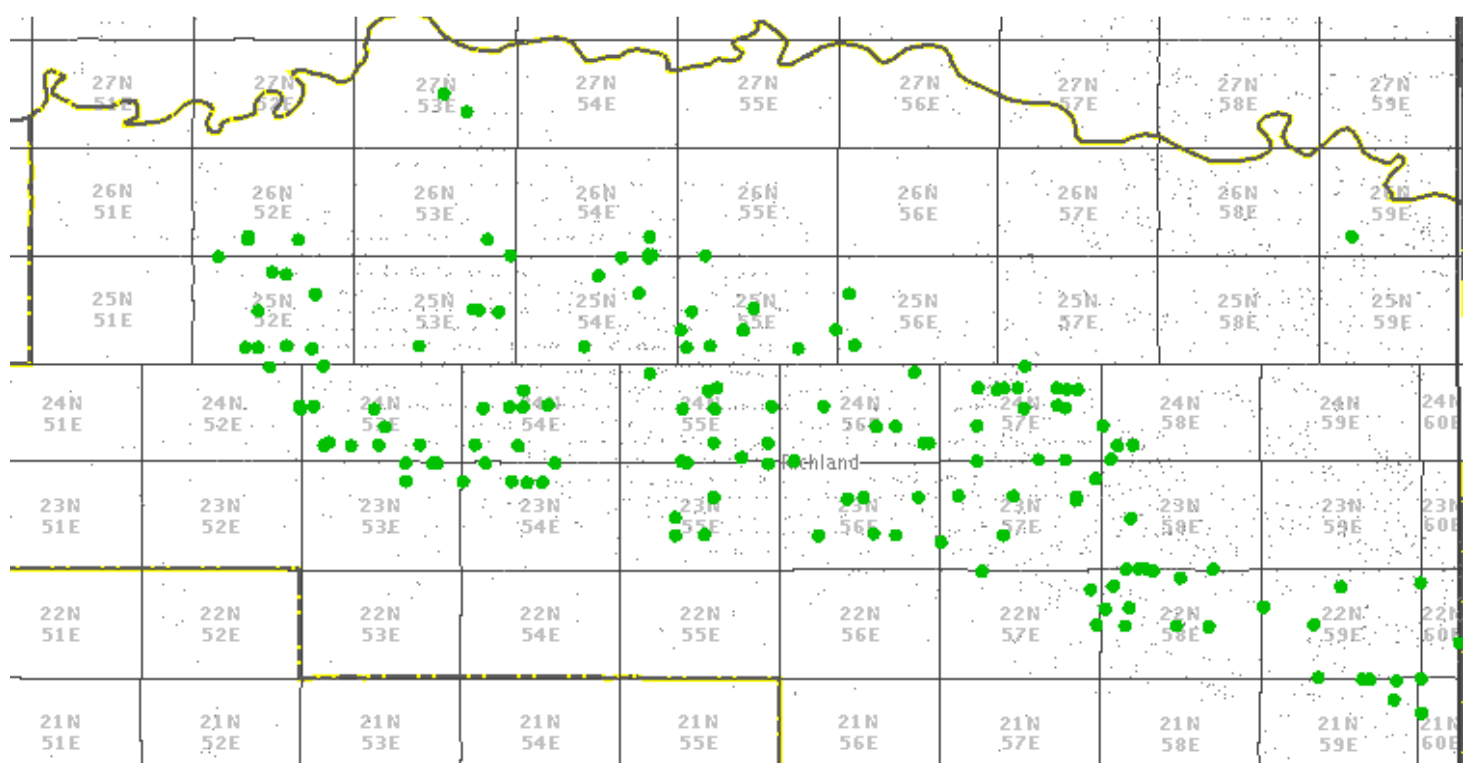

Figure 36: Map of Elm Coulee wells studied 


\section{TYPICAL WET GAS SHALE WELLS}

Graphs of wet gas production forecasts in a shale formation show the Duong, SEPD, and Arps with 5\% minimum decline with much less variation than that shown by Elm Coulee wells. Daily production data are available for these wells.

Figure 37 shows a well forecast in the wet gas shale formation using both daily data and a pressure correction. The projected forecasts are much closer together than that observed in the wells in the Elm Coulee or Eagle Ford. Of the 12 wells that I studied in this field, the Arps with 5\% minimum decline, SEPD, and Duong forecasts were all quite similar compared to the other forecasts in this study. This helps validate these methods since the well forecasts are consistent. 


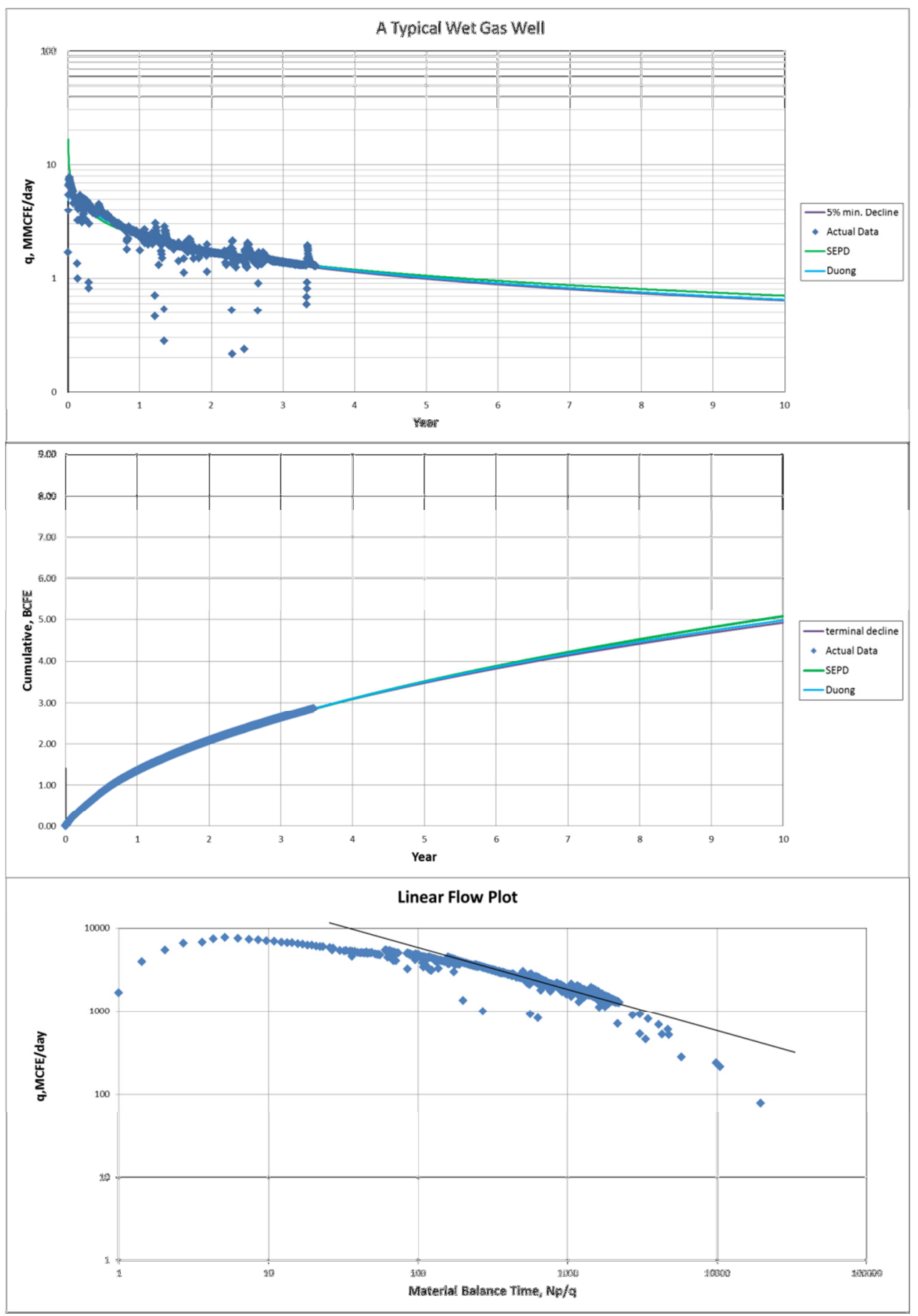

Figure 37: Wet gas well forecast with daily production data 


\section{SHALE OIL WELL WITH PRESSURE}

Using a correction for changes in bottomhole pressure, I was able to smooth the production data from a shale oil well. This helps create a more accurate forecast since a trend with less erratic variations (due to pressure changes) will likely have a better fit than otherwise.

$q_{\text {corrected }}=q_{\text {observed }} *\left(p_{i}-p_{w f, \text { stable }}\right) /\left(p_{i}-p_{w f, \text { observed }}\right)$ bbl/day

This equation will correct the production rate to what it should be if the

bottomhole pressure were stable. The value of $p_{w f, s t a b l e}$ is the average pressure of the last month of production. This is not a perfect correction. Ideally $p_{w f, s t a b l e}$ should be the same as sandface pressure before abandonment, but this will not be observed until the end of the well's production life. It is assumed that pressure will stabilize over time. After fitting decline curves to the corrected rate, calculating the ultimate recovery will be more accurate since the stable pressure the rate is based on will be much closer to the abandonment pressure than the initial pressures. 


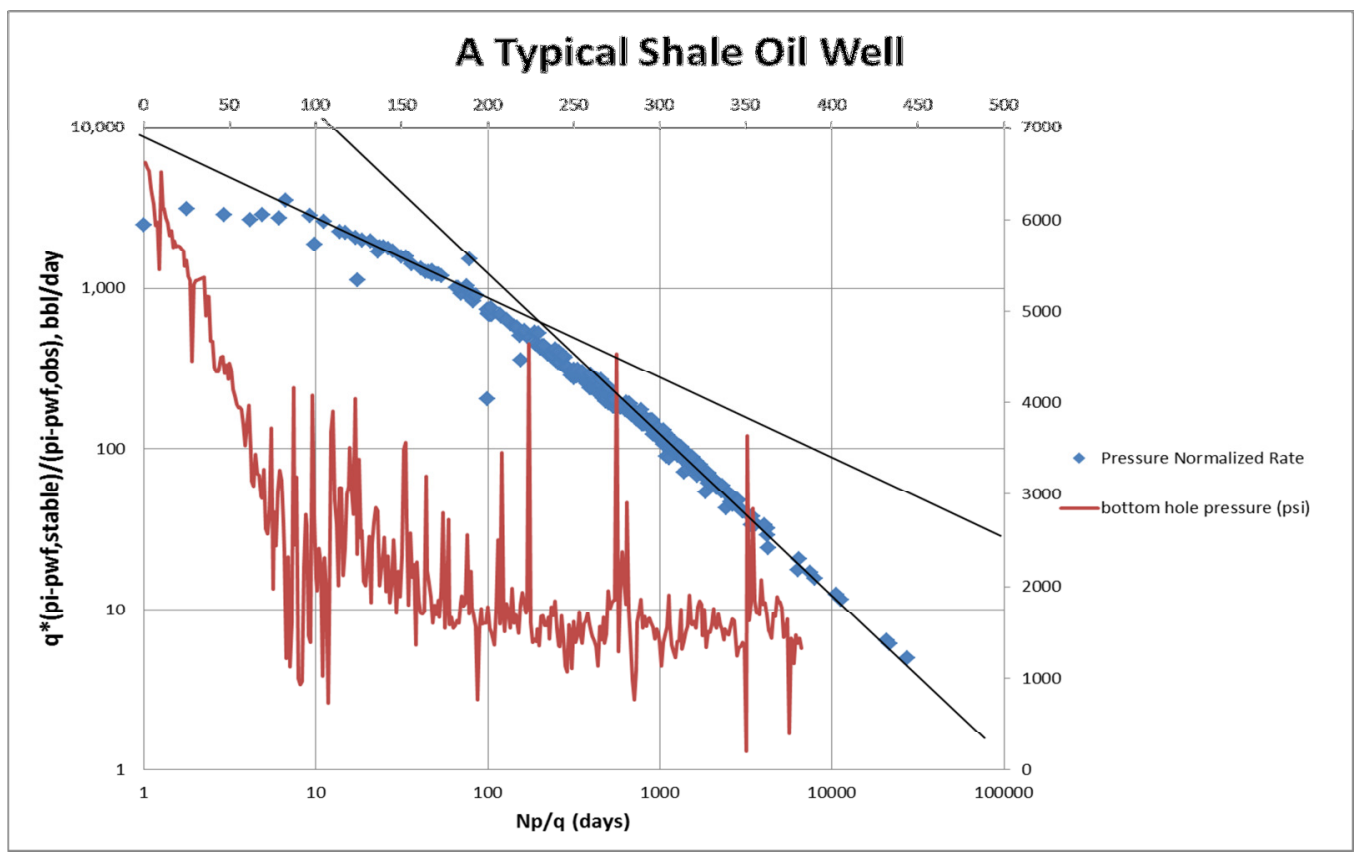

Figure 38: Rate and pressure versus material balance time, Shale oil well, with daily data

Figure 38 shows a diagnostic plot showing bottom-hole pressure as well as the pressure normalized rate. There is significantly less scatter in the production history and it is easier to identify the different flow regimes from this graph. 


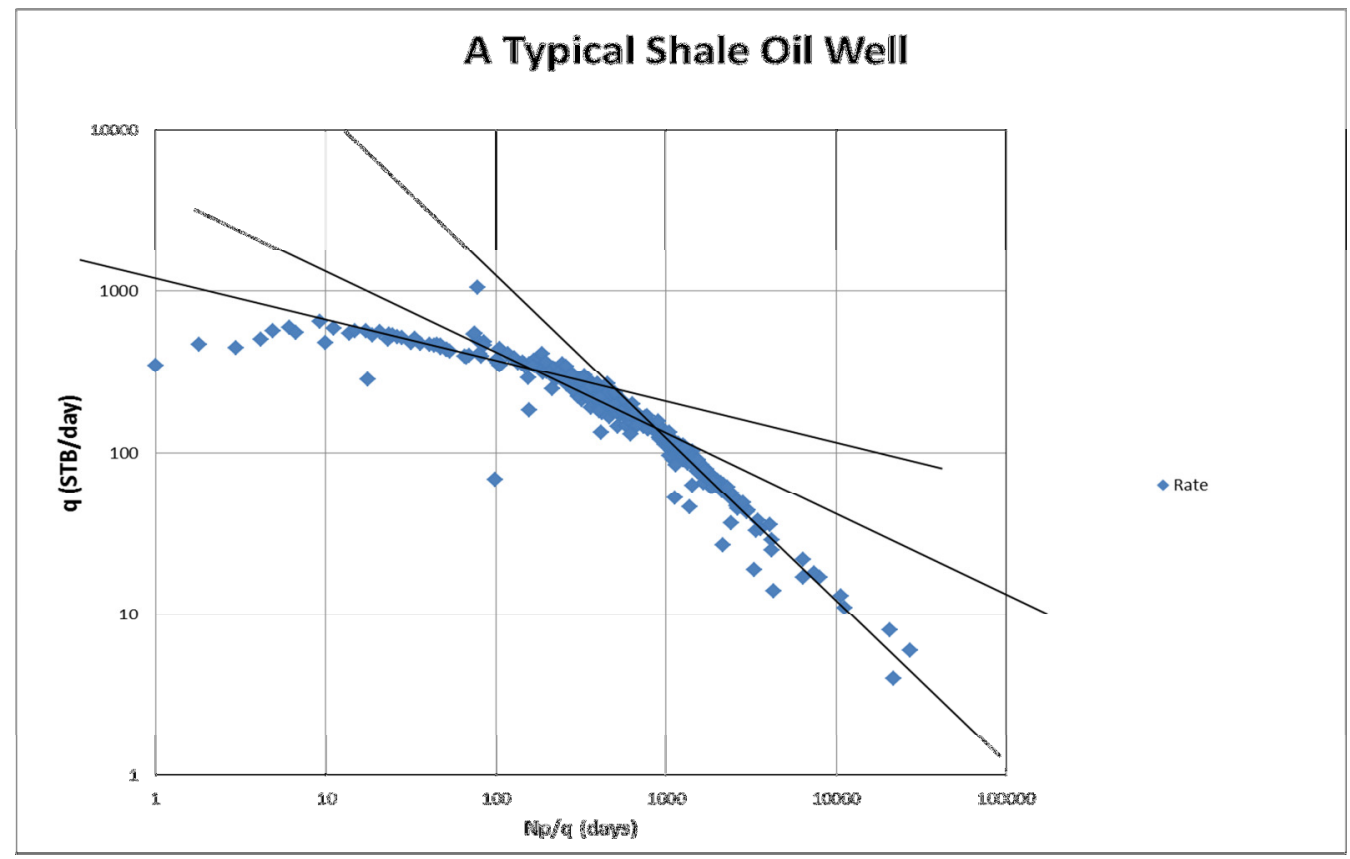

Figure 39: Rate versus material balance time, Shale oil well, daily data

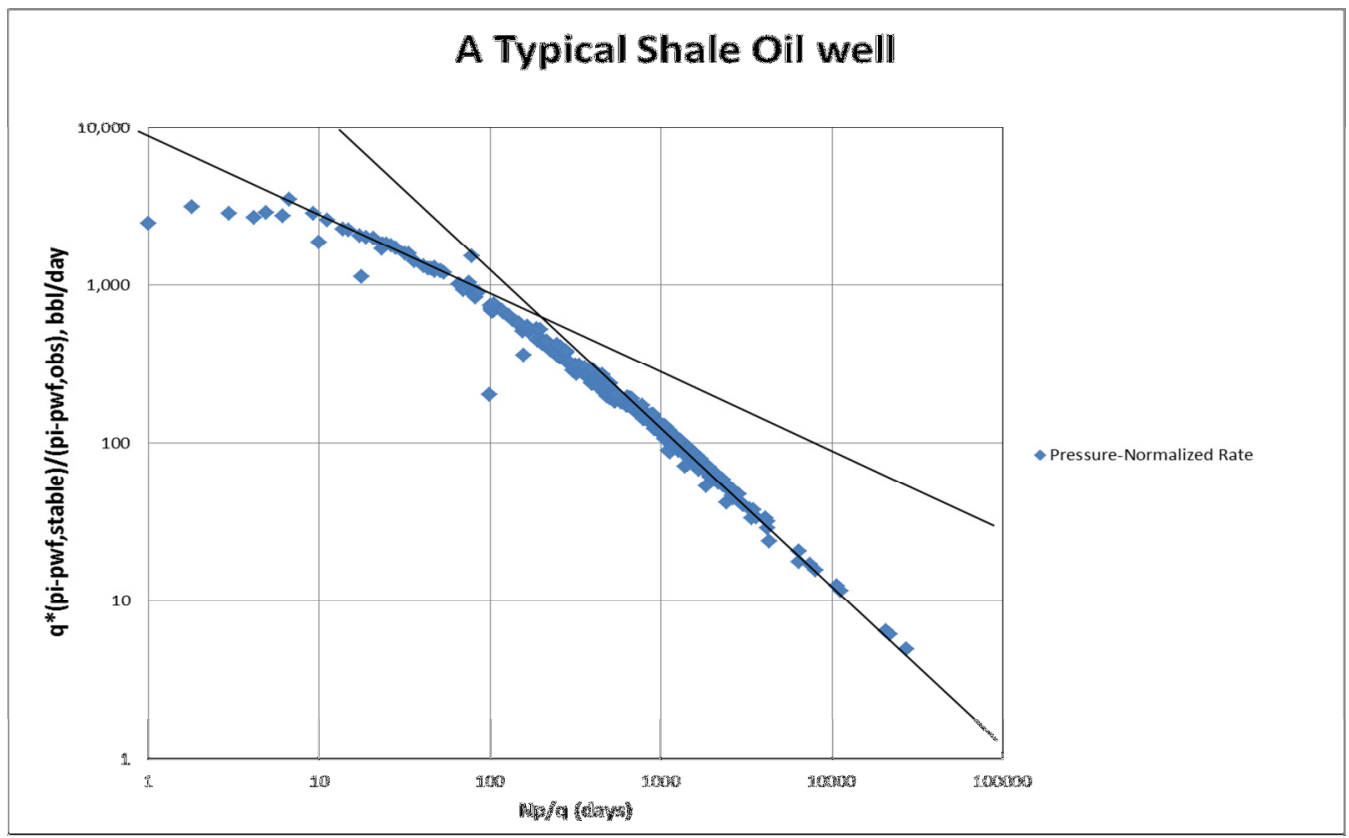

Figure 40: Pressure-normalized rate versus material balance time, shale oil well, daily data 
After 100 days or so the production rates are roughly the same with or without the pressure correction since there is little pressure change. The early production rates however are dramatically different. With the pressure correction, linear flow appears at about $11^{\text {th }}$ day in Figure 40. Without the pressure correction, apparent bi-linear flow appears at about this time, and apparent linear flow doesn't start until about day 100 in Figure 39.

Boundary-dominated flow appears in the pressure corrected diagnostic plot after about 160 days. The same is true for the plot without the pressure correction, but in Figure 39 it is more ambiguous since the end of linear flow appears to converge with the beginning of boundary-dominated flow in a larger cluster of points. This is likely due to the increase in scatter of the data in the material balance time plot without the pressure correction. Figure 41 and Figure 42 show the pressure corrected rate forecast for this well. 


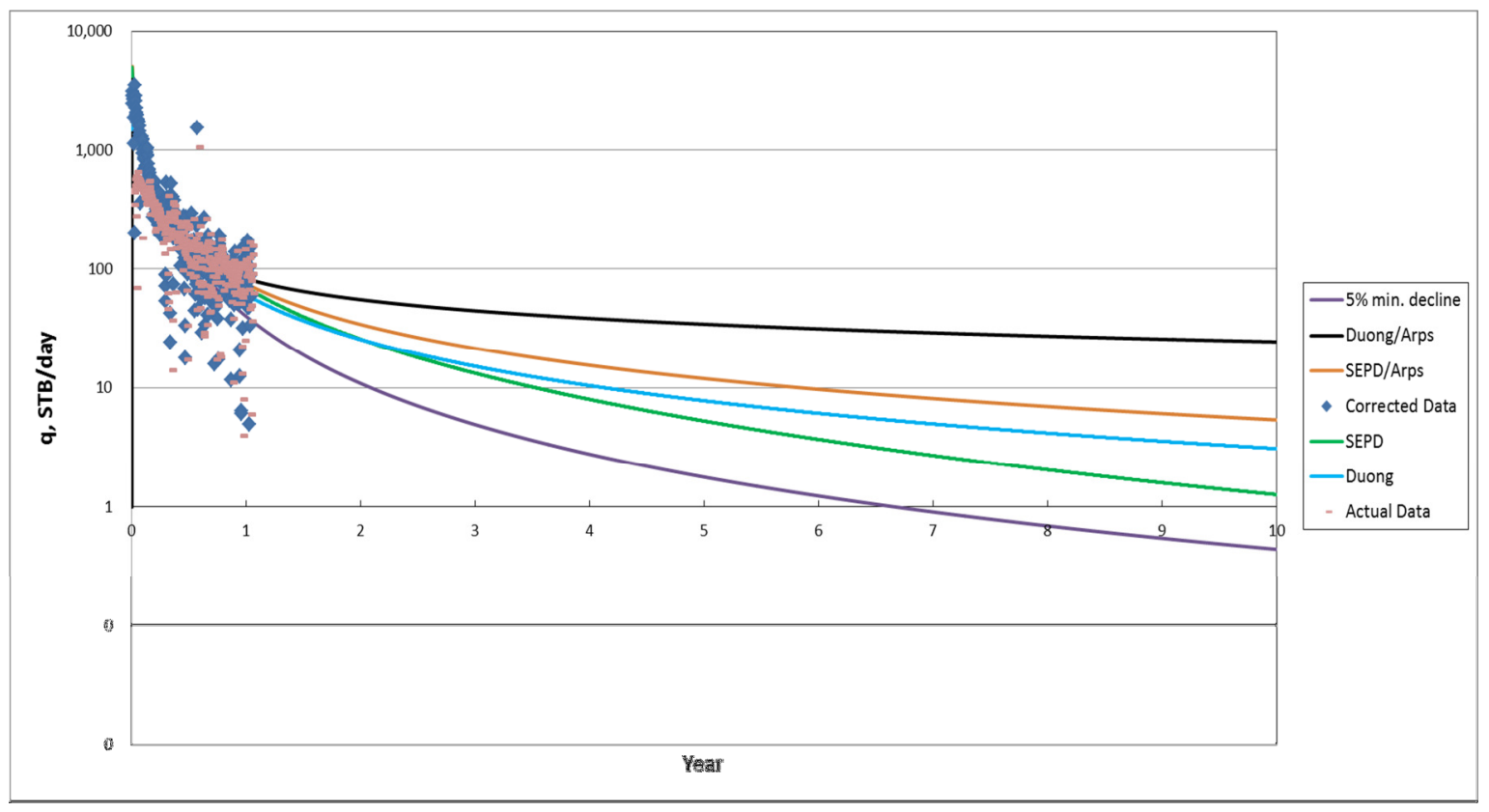

Figure 41: Production rate forecast, shale oil well

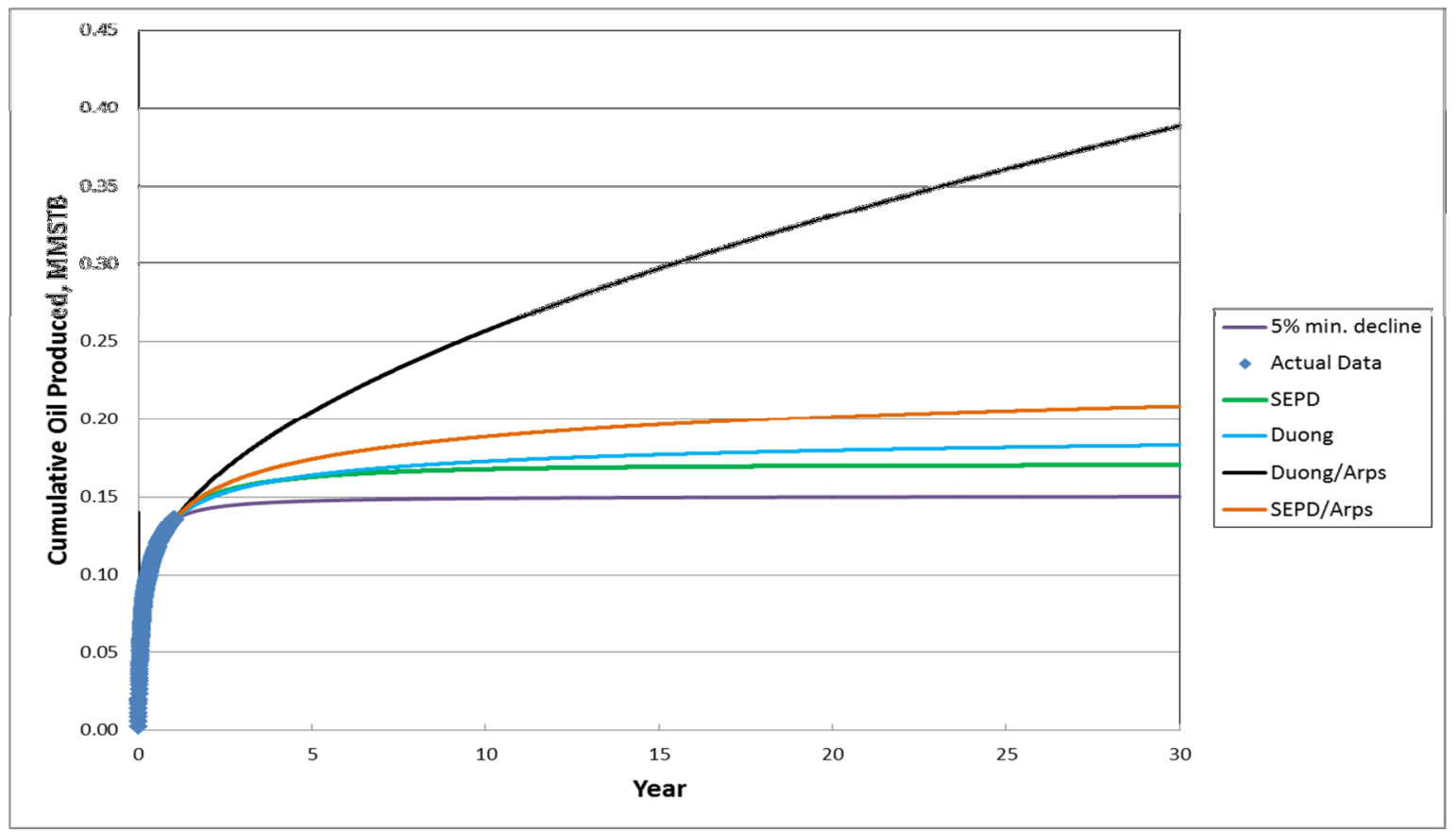

Figure 42: Cumulative production forecast, shale oil well 


\section{30 YEAR FORECAST FOR WELLS SHOWING BDF}

Returning to the Elm Coulee field data, I performed forecasts on all of the wells that showed evidence of boundary-dominated flow in order to learn how the models behave after BDF onset. I implemented the switch to boundary-dominated flow at a fixed time using the BDF onset found with the rate versus material-balance time plots, seen in Figure 43 and Figure 44.

Overall, the Duong method produced the most optimistic forecasts, followed by Arps with 5\% minimum decline. For both the Duong and SEPD models, adding an Arps tail for BDF decreased the forecast estimate. Without the early production history, the forecasts tended to be more optimistic than otherwise.

Unfortunately, in nearly all the wells there was not sufficient data after BDF onset to reliably fit an Arps curve to this data. It remains to be confirmed whether the assumption of a b-value of 0.3 is accurate for a shale oil well in boundary-dominated flow (or a b-value of 0.4 for a shale gas well).

I forecasted the wells again, this time using a $15 \%$ decline rate for BDF onset in the modified SEPD and modified Duong, seen in Figure 45 and Figure 46. For the modified SEPD case, the $15 \%$ decline rate was fairly close to the average of setting BDF with the diagnostic plot. For the modified Duong case, it was more optimistic. From the forecast results, it appears that omitting the first six months created more optimistic forecasts for the Arps model with 5\% minimum decline, SEPD, and the 
Duong model. The first six months of data had a smaller effect on the Modified SEPD and Modified Duong models. The comparison is shown in Table 9 and Figure 47.

Table 9: EIm Coulee average forecasted 30 year EUR

\begin{tabular}{|l|r|r|r|r|}
\hline \multicolumn{5}{|c|}{ Forecasted 30 year EUR, STB } \\
\hline $\begin{array}{l}\text { Forecast } \\
\text { Methods }\end{array}$ & $\begin{array}{l}\text { BDF from MBT plot, } \\
\text { omit early history }\end{array}$ & $\begin{array}{l}\text { BDF from MBT plot, } \\
\text { include early history }\end{array}$ & $\begin{array}{l}\text { BDF at 15\% decline, } \\
\text { omit early history }\end{array}$ & $\begin{array}{l}\text { BDF at 15\% decline, } \\
\text { include early history }\end{array}$ \\
\hline $\begin{array}{l}5 \% \text { min. } \\
\text { decline }\end{array}$ & 184,657 & 177,120 & 184,657 & 177,120 \\
\hline SEPD & 171,320 & 165,680 & 171,320 & 165,680 \\
\hline SEPD/Arps & 162,227 & 158,971 & 160,143 & 160,463 \\
\hline Duong & 189,935 & 186,586 & 189,935 & 186,618 \\
\hline Duong/Arps & 166,723 & 165,068 & 172,122 & 170,560 \\
\hline
\end{tabular}

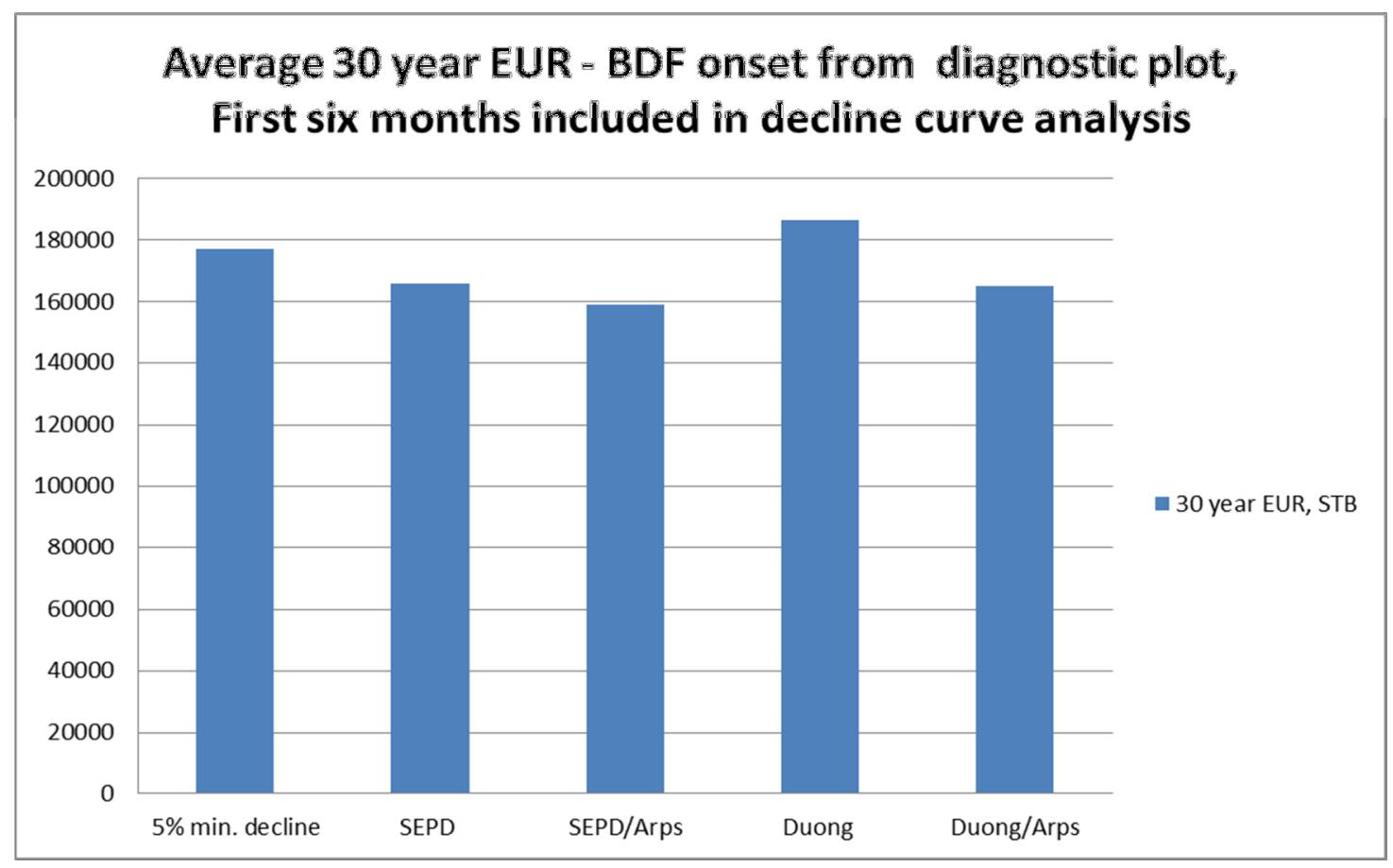

Figure 43: EIm Coulee average forecasted 30 year EUR 


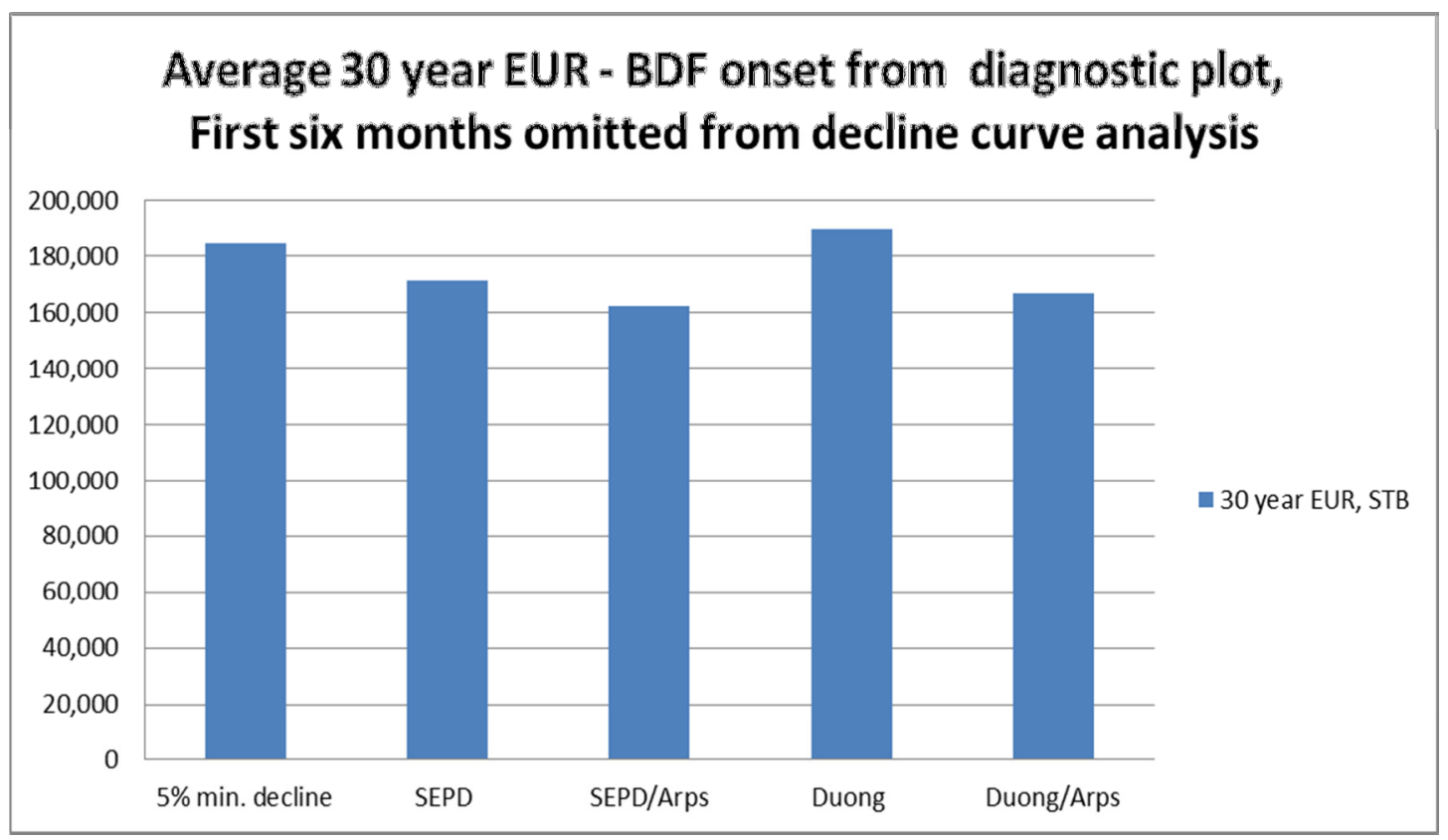

Figure 44: EIm Coulee average forecasted 30 year EUR, first six months ignored

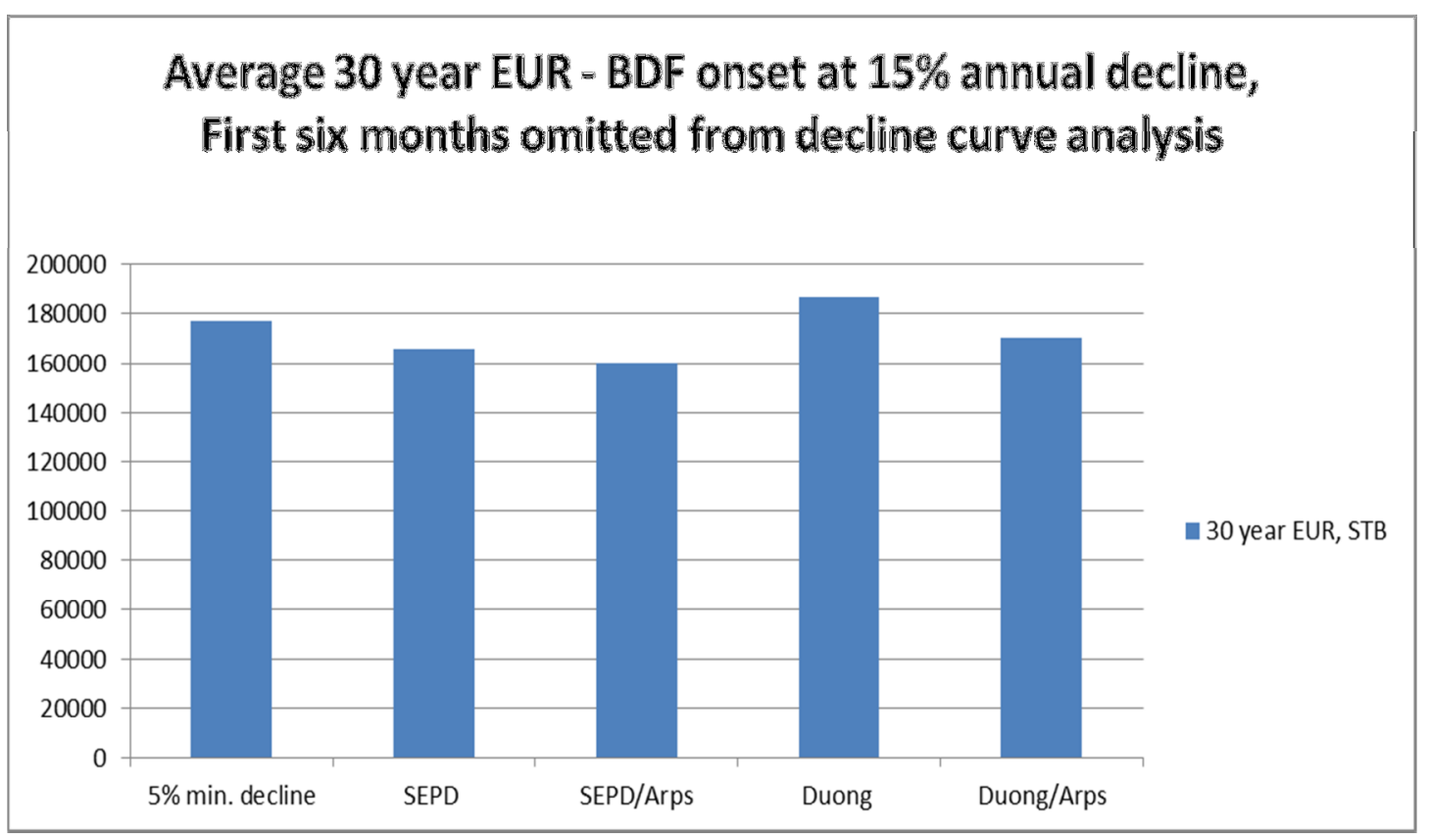

Figure 45: Elm Coulee average forecasted 30 year EUR, BDF onset at $15 \%$ decline 


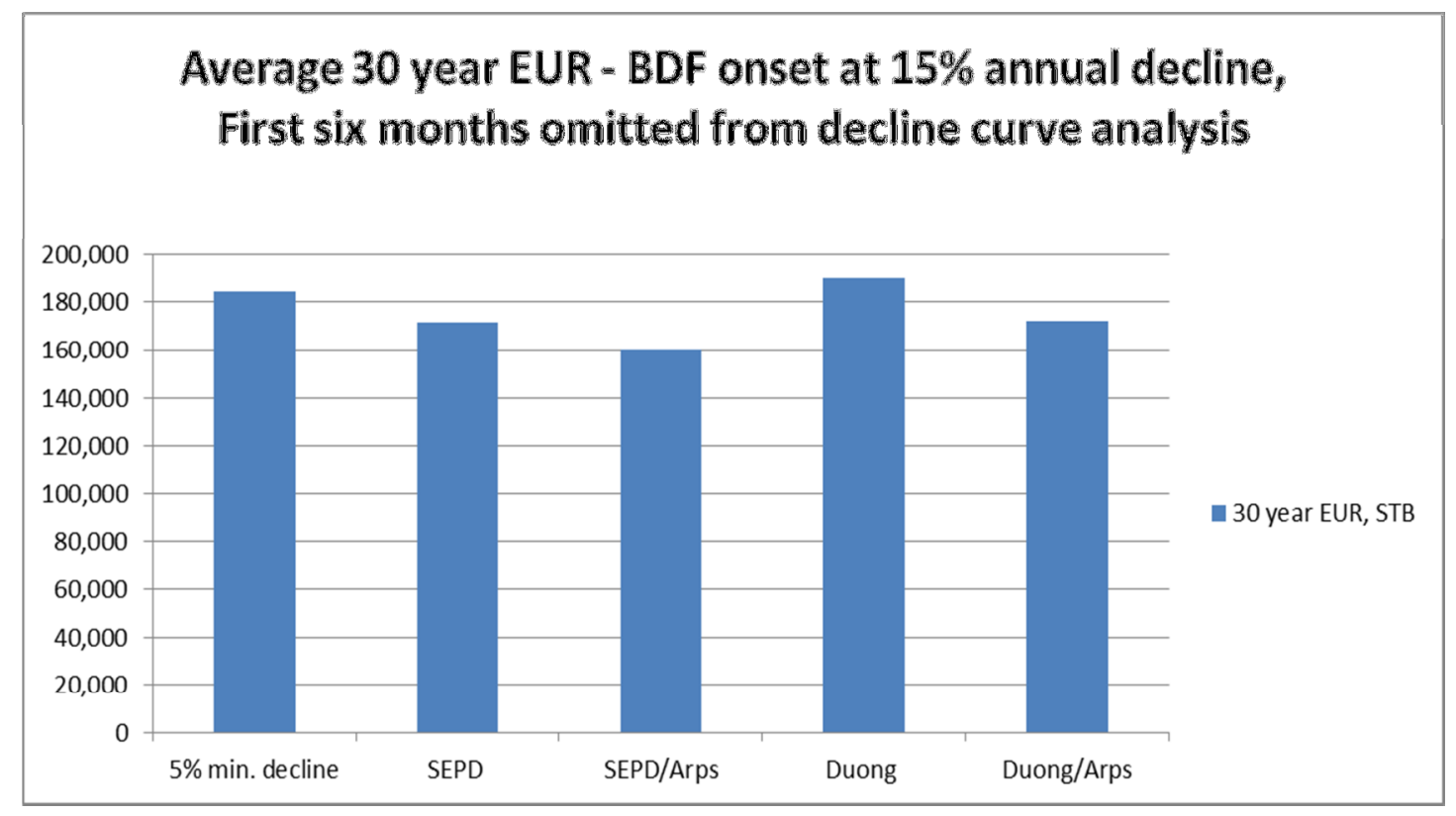

Figure 46: Elm Coulee average forecasted 30 year EUR, first six months ignored, BDF onset at $15 \%$ decline

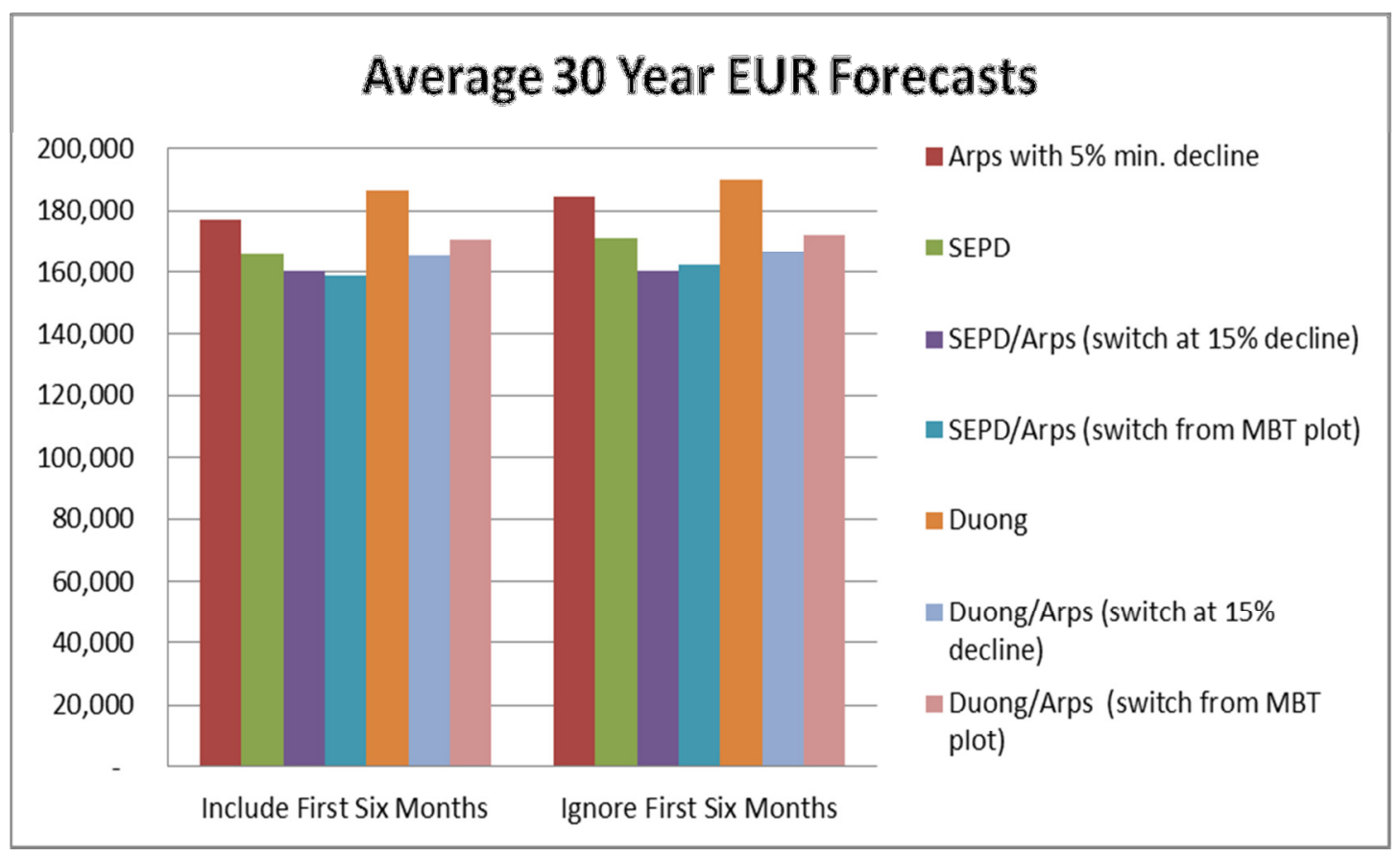

Figure 47: Average 30 Year EUR Forecasts, Cumulative STB 


\section{GROUPED WELL FORECASTS FOR WELLS SHOWING BDF}

Similar to the Grouped well hindcast, I forecasted the grouped Elm Coulee well set to have a more complete analysis of the field. I examined the wells that showed BDF at the end of the history in order to visualize the difference in EUR when the SEPD and Duong methods were modified to account for boundary-dominated flow. When the group forecast is divided by the number of wells, the group forecast EUR is higher than the average individual well forecast for each type of decline. Figure 48 shows decline curves found from forecasting all wells that have entered BDF. Figure 49 gives a comparison of 30 year EUR using different decline curves using, the group forecast, adding up individual forecasts, with or without the first six months in the fit.

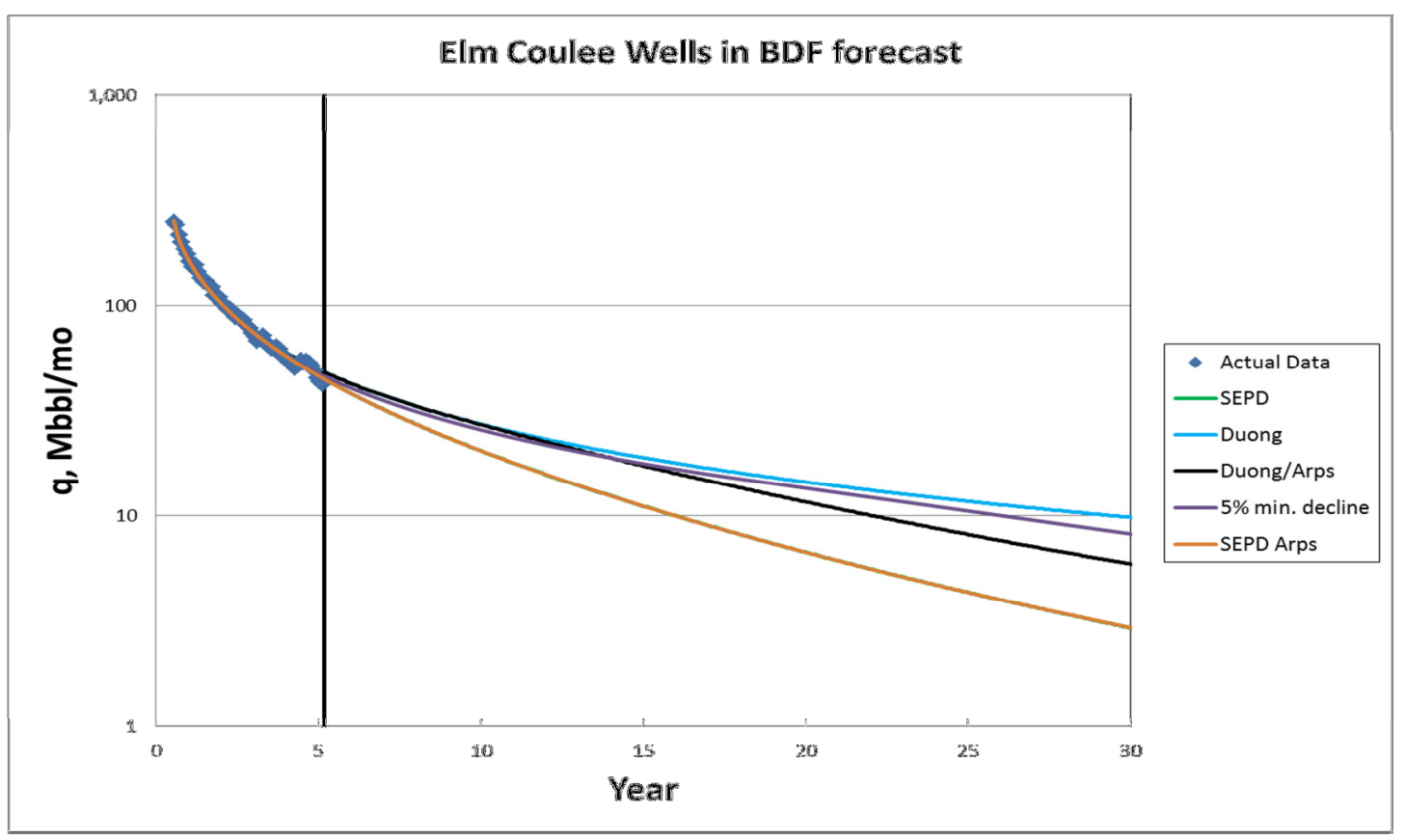

Figure 48: Grouped Elm Coulee wells in BDF 


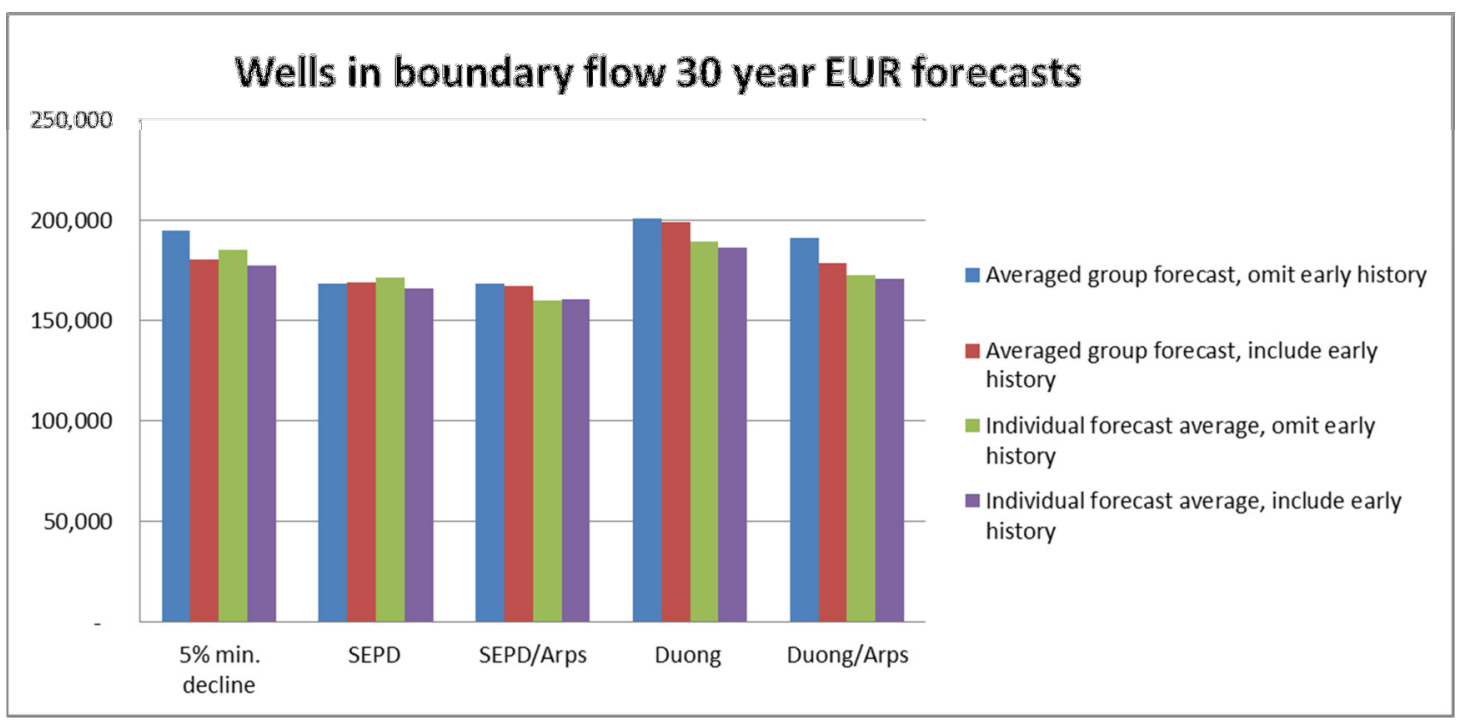

Figure 49: Grouped well average forecast, BDF at $15 \%$ decline rate, STB

I analyzed the grouped production on a material balance time diagnostic plot and curiously the BDF well group did not appear to have entered BDF yet. I show the sum of all the Elm Coulee wells studied as wells that appear to be in BDF in Figure 50 and Figure 51. The slope in Figure 51 approached -0.9 , which is close to a unit slope, but not as close as expected. 


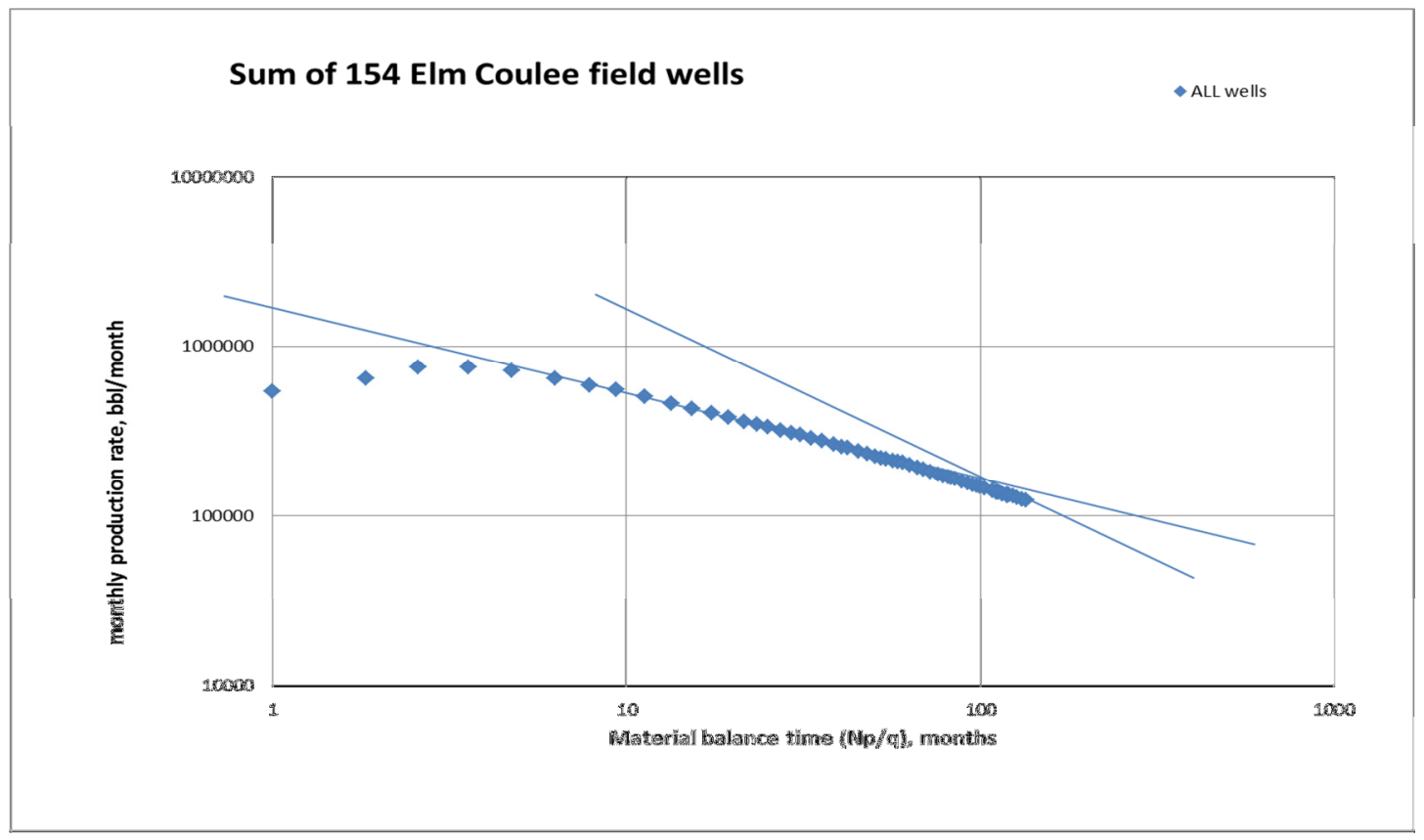

Figure 50: Rate versus material balance time diagnostic plot, sum of all Elm Coulee wells

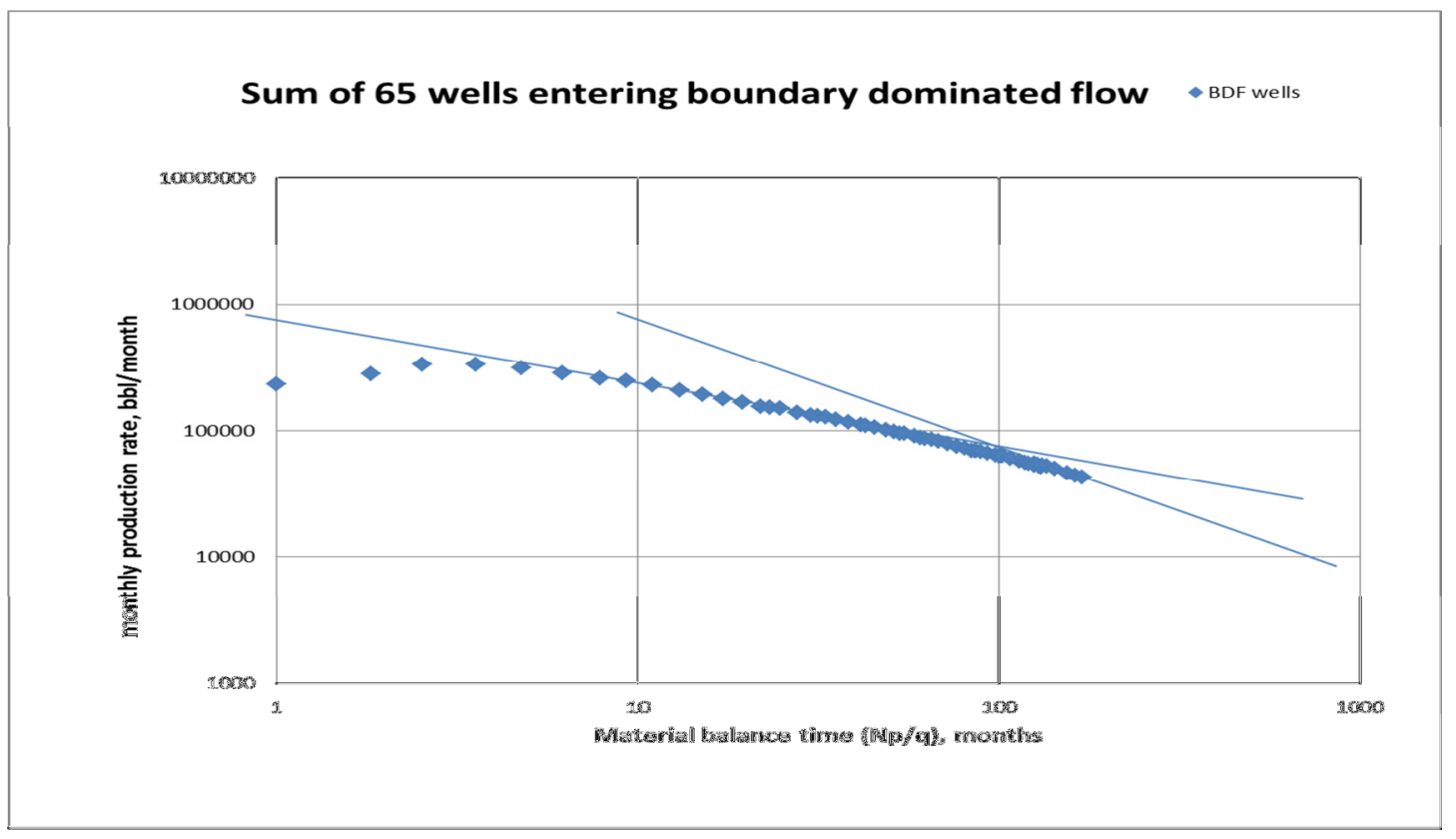

Figure 51: Rate versus material balance time diagnostic plot, sum of wells entering BDF 


\section{ARPS PARAMETERS}

An interesting trend in the forecasts was that b-values for the Arps fit tended to be much smaller if the full history of the forecast was used than when the first six months were omitted. This can be seen in Table 10 This difference was greatest in forecasts where the least amount of history was used. As seen in the high standard deviations between b-values, it is difficult to pinpoint what a reasonable b-value in this formation should be. It is not surprising that there is a large amount of variation, but that the average b-value over the whole field may be twice as high when ignoring the earliest data points. This reinforces the understanding that it is difficult to detect linear flow early on in the well history.

Since a b-value of 2 is what is expected of a well in linear flow, we would expect that this to be representative of a large portion of the data. If we look at the b-values from the hindcasts that omit the first six months of production included, they are often close to those expected from linear flow.

Table 10: Average b-values for hindcasts and forecasts

\begin{tabular}{|c|c|c|c|c|}
\hline \multicolumn{5}{|c|}{ Arps b-values } \\
\hline & $\begin{array}{c}\text { With first six months } \\
\text { of production history }\end{array}$ & $\begin{array}{c}\text { Without first six months } \\
\text { of production history }\end{array}$ \\
\hline & & Standard & & Standard \\
Time of Forecast & Average & Deviation & Average & Deviation \\
\hline 1.5 years & 0.764 & 1.016 & 1.718 & 1.852 \\
\hline 2 years & 0.780 & 0.860 & 1.673 & 1.535 \\
\hline 2.5 years & 0.886 & 0.814 & 1.523 & 1.127 \\
\hline 3 years & 0.918 & 0.744 & 1.606 & 1.916 \\
\hline
\end{tabular}




\section{CONCLUSIONS}

- On average, the most accurate method found of fitting known production history in the Elm Coulee field is implementing the Arps hyperbolic equation while ignoring the first six months of production.

- The Duong method was the second most accurate method in fitting known data if the first six months are ignored. The Duong method was also the most reliable method. Using the Duong method with an Arps modification for BDF may be the best method for predicting production in these formations.

- Methods used for shale gas forecasting have been shown to be applicable to shale oil or tight oil formations as well: Arps method with 5\% minimum decline, the stretched exponential method (SEPD), and the Duong method were found to be useful in predicting transient flow production in shale oil wells as shown from hindcasts in the Elm Coulee field. The Arps and Duong methods required that the early production history be removed from the fit in order to accurately model linear flow.

- Boundary-dominated flow was observed in diagnostic plots of wells in the Elm Coulee field in 65 wells out of the 154 wells studied. This was determined by finding at least $1 / 3$ of a log cycle of data with negative unit slope on a rate versus material balance time diagnostic plot. 
- Adding a hyperbolic tail to the Duong and SEPD methods tends to lower the 30 year forecast estimate regardless of whether the switch to BDF is set at a specific point in time or at a certain decline rate.

- The average decline rate at BDF onset of wells shown to be in boundarydominated flow was about $22 \%$. However, since these were the early BDF onset cases, the actual average for all the wells in this field will likely be less than $17 \%$.

- Some occurrences of boundary-dominated flow may be due to production problems or wells near faults rather than fracture interference.

- Forecasts may be improved by using daily production data or pressure correction.

- In general, the Duong method will produce the most optimistic forecasts in the Elm Coulee field, followed by the Arps model with 5\% minimum decline, and then the SEPD model. 


\section{REFERENCES}

Alexandre, C.S., Sonnenberg, S., and Sarg, J.F. 2012. Diagenesis of the Bakken Formation, Elm Coulee Field, Richland County, Montana. In AAPG Annual Convention and Exhibition. Long Beach, California, USA: AAPG.

Ambrose, R.J., Clarkson, C.R., Youngblood, J.E. et al. 2011. Life-Cycle Decline Curve Estimation for Tight/Shale Reservoirs. Paper presented at the SPE Hydraulic Fracturing Technology Conference, The Woodlands, Texas, USA. Society of Petroleum Engineers SPE-140519-MS. DOI: 10.2118/140519-ms.

Arps, J.J. 1945. Analysis of Decline Curves. AIME 160: 228-247.

Borglum, S.J. and Todd, B.J. 2012. An Investigation of Ancient Geological Events and Localized Fracturing on Current Bakken Production Trends. Paper presented at the SPE Eastern Regional Meeting, Lexington, Kentucky, USA. Society of Petroleum Engineers SPE-161331-MS. DOI: 10.2118/161331-ms.

Chu, L., Ye, P., Harmawan, I.S. et al. 2012. Characterizing and Simulating the Nonstationariness and Nonlinearity in Unconventional Oil Reservoirs: Bakken Application. Paper presented at the SPE Canadian Unconventional Resources Conference, Calgary, Alberta, Canada. Society of Petroleum Engineers SPE161137-MS. DOI: 10.2118/161137-ms.

Duong, A.N. 2010. An Unconventional Rate Decline Approach for Tight and FractureDominated Gas Wells. Paper presented at the Canadian Unconventional Resources and International Petroleum Conference, Calgary, Alberta, Canada. Society of Petroleum Engineers 137748-MS.

Ilk, D., Currie, S.M., Symmons, D. et al. 2010. Hybrid Rate-Decline Models for the Analysis of Production Performance in Unconventional Reservoirs. Paper presented at the SPE Annual Technical Conference and Exhibition, Florence, Italy. Society of Petroleum Engineers 135616-MS.

Joshi, K. and Lee, W.J. 2013. Comparison of Various Deterministic Forecasting Techniques in Shale Gas Reservoirs. Paper presented at the 2013 SPE Hydraulic Fracturing Technology Conference, The Woodlands, Texas, USA. Society of Petroleum Engineers SPE-163870-MS. DOI: 10.2118/163870-ms. 
Kurtoglu, B., Cox, S.A., and Kazemi, H. 2011. Evaluation of Long-Term Performance of Oil Wells in Elm Coulee Field. Paper presented at the Canadian Unconventional Resources Conference, Alberta, Canada. Society of Petroleum Engineers SPE-149273-MS. DOI: 10.2118/149273-ms.

Luo, S., Neal, L., Arulampalam, P. et al. 2010. Flow Regime Analysis of Multi-Stage Hydraulically-Fractured Horizontal Wells with Reciprocal Rate Derivative Function: Bakken Case Study. Paper presented at the Canadian Unconventional Resources and International Petroleum Conference, Calgary, Alberta, Canada. Society of Petroleum Engineers 137514-MS.

Mangha, V.O., Ilk, D., Blasingame, T.A. et al. 2012. Practical Considerations for Decline Curve Analysis in Unconventional Reservoirs --- Application of Recently Developed Rate-Time Relations. Paper presented at the SPE Hydrocarbon Economics and Evaluation Symposium, Calgary, Alberta, Canada. Society of Petroleum Engineers SPE-162910-MS. DOI: 10.2118/162910-ms.

Nobakht, M., Mattar, L., Moghadam, S. et al. 2010. Simplified yet Rigorous Forecasting of Tight/Shale Gas Production in Linear Flow. Paper presented at the SPE Western Regional Meeting, Anaheim, California, USA. Society of Petroleum Engineers 133615-MS.

Tran, T., Sinurat, P.D., and Wattenbarger, B.A. 2011. Production Characteristics of the Bakken Shale Oil. Paper presented at the SPE Annual Technical Conference and Exhibition, Denver, Colorado, USA. Society of Petroleum Engineers SPE145684-MS. DOI: 10.2118/145684-ms.

V. Hough, E. and McClurg, T. 2011. Impact of Geological Variation and Completion Type in the U.S. Bakken Oil Shale Play Using Decline Curve Analysis and Transient Flow Character. In AAPG International Conference and Exhibit. Milan, Italy.

Valko, P.P. and Lee, W.J. 2010. A Better Way to Forecast Production from Unconventional Gas Wells. Paper presented at the SPE Annual Technical Conference and Exhibition, Florence, Italy. Society of Petroleum Engineers 134231-MS.

Walker, B., Powell, A., Rollins, D. et al. 2006. Elm Coulee Field Middle Bakken Member (Lower Mississippian/Upper Devonian) Richland County, Montana. In AAPG Rocky Mountain Section meeting. Billings, Montana: AAPG. 